UNITED NATIONS CONFERENCE ON TRADE AND DEVELOPMENT Geneva

\title{
TRADE AND ENVIRONMENT REVIEW
}

\author{
2006
}

CHAPTER 3: PART I - Organic agriculture: a trade and sustainable development opportunity for developing countries

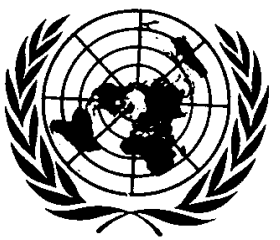

UNITED NATIONS

New York and Geneva, 2006 


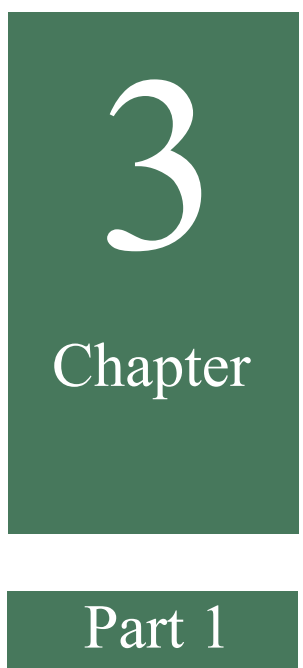

Organic Agriculture:

A Trade and Sustainable Development Opportunity for Developing Countries

Sophia Twarog (UNCTAD) 


\section{A. Introduction}

Increasing environmental and health concerns in developed countries, as manifested in the growing number of environmental and health-related Government regulations and private sector standards, can pose new burdens on developing countries wishing to export to these markets. Yet these concerns may also lead to some opportunities for developing-country exporters. The organic agriculture sector $(\mathrm{OA})$ is one such example.

Developed-country markets for certified OA products have been growing much faster than overall food markets over the past two decades. This presents some promising export opportunities for producers and exporters of organic products in developing countries. In addition to income generation, OA can offer an array of positive effects at home, related to the environment and to sustainable natural resource use (improved soil fertility, reduced soil erosion, enhanced biodiversity), and in the social sphere in terms of rural employment generation, lower urban migration, improved household nutrition, local food security and greater self-reliance. This multidimensional potential has been recognized in a number of forums, including the World Summit on Sustainable Development in 2002.

The objective of this paper is to analyse OA as a trade and sustainable development opportunity for developing countries. It attempts to capture the current state of production and markets, highlight a range of possible benefits, as well as challenges in reaping those benefits, and make recommendations for future action at national and international levels. It builds on the considerable work that UNCTAD has carried out on this subject over the past five years, including intergovernmental consensus building, research and policy analysis, and technical cooperation. ${ }^{1}$

The paper is organized as follows. Section B provides some definitions of OA and gives an indication of organic production worldwide. Section C highlights OA as a potential opportunity for local and national sustainable development. Section D presents an overview of the major organic markets worldwide and discusses OA as a potential export opportunity. Section E outlines a number of challenges related to production and trade that producers and exporters of organic agricultural products from developing countries must successfully meet in order to reap potential benefits. Section F highlights areas for further work and makes a number of recommendations.

Part II of this chapter, by Vossenaar and Angel, examines the experiences of Central American countries, Cuba and the Dominican Republic, drawing upon the results of work carried out under the UNCTAD/FIELD project, Building Capacity for Improved Policy- Making and Negotiation on Key Trade and Environment Issues.

\section{B. Organic agriculture: definitions and scope}

\section{What is organic agriculture?}

There are a number of definitions and also misconceptions as to what constitutes organic agriculture. Definitions vary slightly across national and regional regulations and private voluntary standards. At the international level, there are two main points of reference: the Codex Alimentarius Commission, a joint intergovernmental initiative of the Food and Agriculture Organization of the United Nations (FAO) and the World Health Organization (WHO) dealing with food safety and labelling matters, and the International Federation of Organic Agriculture Movements (IFOAM), an international umbrella organization for the organic movement with some 700 members worldwide. Both have developed organic standards that are intended to serve as "standards for standards" (i.e. not intended to be standards themselves, but to assist countries and institutions in developing their own standards). 
IFOAM defines OA as including

"...all agricultural systems that promote environmentally, socially and economically sound production of food and fibers. Recycling nutrients and strengthening natural processes helps to maintain soil fertility and ensure successful production. By respecting the natural capacity of plants, animals and the landscape, it aims to optimize quality in all aspects of agriculture and the environment. Organic agriculture dramatically reduces external inputs by refraining from the use of synthetic fertilizers and pesticides, genetically modified organisms and pharmaceuticals. Pests and diseases are controlled with naturally occurring means and substances according to both traditional as well as modern scientific knowledge, increasing both agricultural yields and disease resistance. Organic agriculture adheres to globally accepted principles, which are implemented within local socio-economic, climatic and cultural settings." (IFOAM, 2004)

The Codex Alimentarius Commission further specifies that

"organic agriculture is one among the broad spectrum of methodologies which are supportive of the environment. Organic production systems are based on specific and precise standards of production which aim at achieving optimal agroecosystems which are socially, ecologically and economically sustainable..... 'Organic' is a labelling term that denotes products that have been produced in accordance with organic production standards and certified by a duly constituted certification body or authority." (Codex Alimentarius Commission, 2001)

Thus, organic agriculture (OA) is a part of the larger category of sustainable agriculture. Sustainable agriculture has been defined in a number of ways, including as

"environmentally friendly methods of farming that allow the production of crops or livestock without damage to the farm as an ecosystem, including effects on soil, water supplies, biodiversity, or other surrounding natural resources. The concept of sustainable agriculture is an 'intergenerational' one in which we pass on a conserved or improved natural resource base instead of one which has been depleted or polluted." (National Safety Council, 2005).

Another definition is "farming that provides a secure living for farm families; maintains the natural environment and resources; supports the rural community; and offers respect and fair treatment to all involved, from farm workers to consumers to the animals raised for food." (GRACE, 2005). Sustainable agriculture includes a number of systems, such as integrated pest management (IPM) and low external input and sustainable agriculture (LEISA), which allow only limited use of synthetic external inputs.

Within the category of sustainable agriculture, $\mathrm{OA}$ is distinguishable in several ways: it takes a holistic approach to farm management, does not permit use of genetically modified organisms (GMOs) or synthetic agro-chemicals, and involves production in accordance with precise production standards. Within the category of $\mathrm{OA}$, uncertified $O A$ products are produced according to organic methods but are not certified as organic by a third party. Certified $O A$ products, on the other hand, are produced and processed in accordance with organic standards and this is checked and certified by a third party (i.e. a certification body). The certification body generally indicates this positive assessment by allowing its seal to be affixed to the product. Once certified as organic, the product may be marketed as such. Certified OA products generally fetch higher prices than those produced using conventional agricultural techniques (i.e. products not produced according to organic standards and often involving the use of synthetic agro-chemicals.). Only OA products certified according to the standards in the target markets can be exported to and sold as organic in those markets.

Simply ending the application of agro-chemicals does not qualify the production as OA, as doing so without implementing improved farm management and organic practices to rebuild the 
natural resource base will likely lead to declining soil fertility and low yields and productivity. A further misconception of OA equates it with "going back" to traditional agriculture. Some forms of traditional agriculture would meet organic production standards and could thus be considered as uncertified OA. In general, however, the two are not identical. Moreover, using modern OA techniques can build on traditional agricultural practices to improve soil and plant health and increase agricultural productivity, particularly on farms where agro-chemicals have not previously been used (FAO, 2002). Not all traditional agricultural practices are sustainable in the long term, although many are. Figure 1 below attempts to graphically present the different categories of terms used in this paper. The overlap between categories illustrates the fact that, in practice, the different terms exist within a spectrum of approaches that sometimes have no clear divisions.

In general, this paper focuses on the certified $O A$ category, as this is where benefits from the market may be obtained. However, uncertified OA generally can offer the same agricultural output, environmental, social and cultural benefits as certified OA.

When talking about certified OA products, most people think of organic food and beverages. But the scope of OA products has been rapidly expanding into other categories. Consumers today can purchase organic pet food, cosmetics, cleaning products, textiles and even mattresses. For processed certified OA products, each stage of production, processing, storage and transportation must be certified as organic in order for the final product to be certified. The objective is to maintain the organic integrity of the final product and includes requirements such as no commingling of organic and conventional products.

Figure 1. Categories of agricultural practices prevalent in developing countries

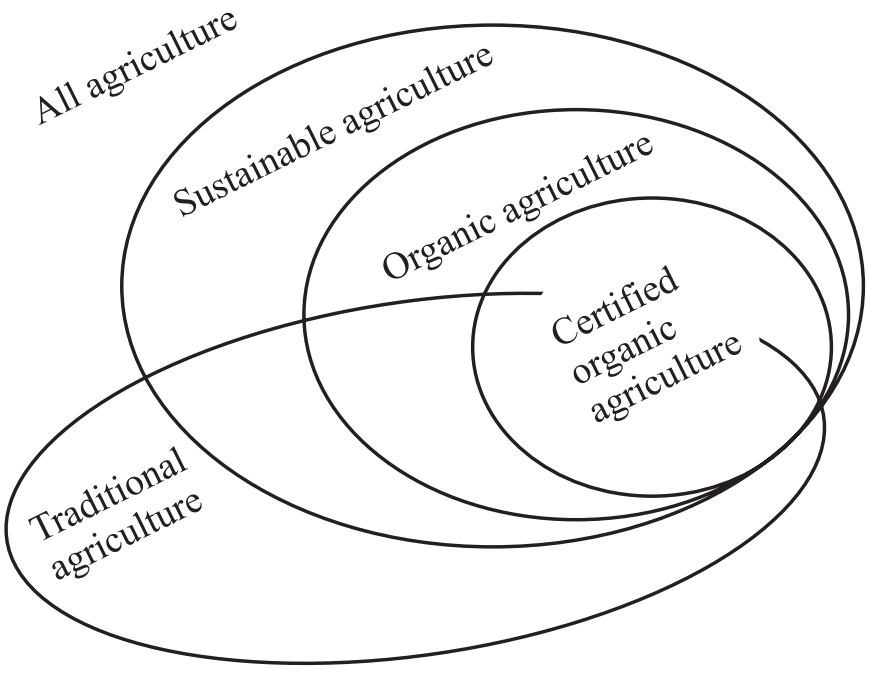

\section{Organic production worldwide}

It is not easy to find accurate statistics on OA. Even in Europe, data on production and markets are often unreliable, contradictory or based upon rough estimates. ${ }^{2}$ Official government statistics rarely, if ever, exist. Researchers trying to make estimates of organic production and sales must therefore resort to other methods. For example, Willer and Yussefi (2005) asked experts from IFOAM, certification bodies and other institutions to contribute OA statistics at their disposal and also carried out an Internet and literature search to arrive at their estimates on world production.

The results of their survey ${ }^{3}$ indicate that over 110 countries produce certified OA products and over 26 million hectares are under organic management in over 550,000 farms in all regions of the 
world, and this is growing continuously. Nearly half of this total acreage is located in Argentina and Australia and is used primarily as pastureland for extensive grazing. The percentage of arable land managed organically is highest in Europe. In Austria, Liechtenstein and Switzerland, over 10 per cent of agricultural land is managed organically. In addition to the above, it is estimated that there are at least 14.5 million hectares of organically certified "wild harvested plants" worldwide. Figure 2 offers a graphic representation of regional certified OA output and annex 1 provides indicative country-level data. Due to the lack of reliable statistics, however, annex I data probably considerably underestimates the true scope of certified organic production. Other leading experts have estimated, for example, that in 2002 more than 140 countries produced certified organic food and beverages, including some 100 developing countries, of which around 20 are least developed countries (LDCs) (Kortbech-Olesen, 2002, personal communication). Several experts believe that today nearly all countries produce at least some certified organic products (Rundgren, 2005, personal communication; Kortbech-Olesen, 2005, personal communication). Moreover, it should be borne in mind that certified organic production represents only a portion of total production carried out using organic methods in accordance with organic standards.

\section{Figure 2. Certified organic production by region}

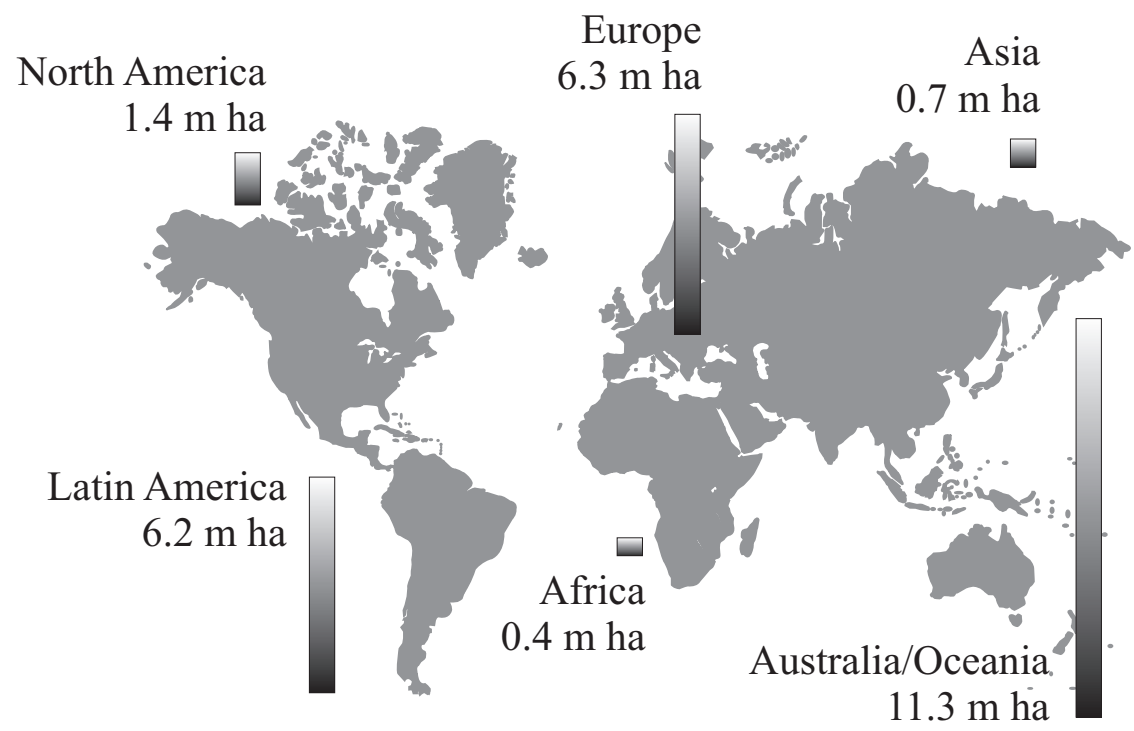

Source: Willer and Yussefi, 2005.

\section{Organic production in developing countries}

In the developing world, Latin America is the leading region for certified OA production. Its ancient, sophisticated agricultural traditions and fertile land provide a good foundation for this type of agriculture. Production has been increasing rapidly in recent years in most countries of the region (see table 1).

The main certified OA products produced in the region are fresh fruit and vegetables (e.g. apples, grapes, bananas, pineapples) grains and cereals, coffee, ${ }^{4}$ cocoa, sugar and meats. ${ }^{5}$ Most OA products - with the exception of fruit juices and wine - are exported to Europe and the United States with little value added processing. There are a large number of domestic certifiers of organic products. To enter European markets, however, recertification by a European certifier is often required, except for products from Argentina and Costa Rica which are on the EU thirdcountry list (signifying that their standards and conformity assessment systems for organic agri- 
Table 1. Changes in area of land under certified organic production in selected Latin American countries (2000-2004)

Estimated area of certified OA land (ha)

\begin{tabular}{|c|c|c|c|c|c|}
\hline & 2000 & 2001 & 2002 & 2003 & 2004 \\
\hline Argentina & 3192000 & & & & $2800000^{\mathrm{a}}$ \\
\hline Bolivia & 31025 & & 364100 & & \\
\hline Brazil & 275576 & & & 803180 & \\
\hline Chile & & & 285268 & 646150 & \\
\hline Costa Rica & 8974 & & & 13987 & \\
\hline Mexico & 85675 & & 215843 & & \\
\hline Peru & & 84908 & & 150000 & \\
\hline Uruguay & 1200 & & & & 760000 \\
\hline
\end{tabular}

Source: Compiled from Lernoud, 2005.

a The decrease reflects the decertification of livestock certified areas due to changes in the market for organic meat (Lernoud, 2005). The economic crisis in Argentina during this period probably also played a role.

culture are recognized by the EU as being equivalent to its own). Domestic markets are developing in many Latin American countries including Argentina, Brazil, Bolivia, Costa Rica, Ecuador, Mexico, Peru and Uruguay.

The Asian region has experienced steady expansion in OA production, the fastest growth occurring in countries with relatively more developed agricultural sectors and stronger economies. The development of Asian OA gets its momentum from two divergent groups: NGOs working on sustainable development that are interested in $\mathrm{OA}$ as a development tool for poverty reduction and increased self-reliance; and agribusiness companies that have converted to organic to take advantage of market opportunities. Production is mainly fresh produce, field crops and aquaculture. However, little value added processing is done in the region. Organic livestock production is constrained by limited availability of organic feed. Much OA is practiced by grower groups, either self-organized groups of farmers or those under contract with export companies. Some export companies have their own large-scale OA farms. Exports are the main driver of OA production growth in Asia since domestic markets there remain very limited, with the exception of Japan (the main market in the region) and a handful of relatively well-off developing economies such as China, Hong Kong (China), Malaysia, the Republic of Korea, Singapore and Thailand (Panyakul and Kung Wai, 2005; IFAD, 2005).

In Africa, much agriculture has, by default, low external inputs, but is not necessarily organic. Certified organic farming is relatively underdeveloped, but growing. Uncertified OA and "ecoagriculture" are, however, much more widespread and on the rise. The adoption of organic production methods has often been motivated by concerns such as enhancing soil fertility, combating desertification, increasing the agricultural productivity of smallholders, reducing costs of purchasing external inputs and promoting the use of local plant varieties. Recently, interest in certified OA for export has also been increasing. Virtually all certified OA produced in Africa is exported, mainly to Europe. Only Egypt and South Africa have significant domestic markets. In other countries, there is evidence of growth in demand for "naturally" grown products, which are generally not certified. Organic urban farming is being explored in some places, and this accounts for a large proportion of the fresh produce and protein consumed in many African cities. Certified OA products grown include fruit and vegetables, tropical beverages, oils, herbs and spices. Few African governments have been actively promoting their organic sectors (Parrott and Kalibwani, 2005), the notable exception being the Government of Tunisia. ${ }^{6}$ 
Most organic farmers in developing countries are smallholders. In Brazil, for example, 90 per cent of organic farms are smallholdings (Lernoud and Piovano, 2004). In Mexico, over 98 per cent of the country's 53,000 certified organic farms were smallholdings, ${ }^{7}$ accounting for 84 per cent of organic land and generating 69 per cent of foreign currency revenues from organic exports (Gomez Tovar and Gomez Cruz, 2004; Lernoud, 2005). In Uganda and the Republic of Tanzania, most organic farming is carried out by small-holder farmers organized largely by export companies in Uganda or in strong cooperative unions in Tanzania. (Taylor et al, 2005). However, large-scale organic farms are an important feature of organic production in some developing countries. In Argentina, for example, 74 per cent of organic acreage is in Patagonia (sheep production) and this is owned by only 5 per cent of organic farmers, while smallholders farm the remaining 26 per cent of the land under organic management. In some countries, multinational companies are purchasing land to produce organic products for export. For example, in Argentina, the Italian Benetton family owns over 20 per cent of the total land under certified organic management.

While certified organic products are produced in all regions of the world, sales of these products are highly concentrated in North America and Europe. Therefore, many developing countries are interested in OA as an export opportunity, as discussed in section D below. However, OA may also offer a range of local and national sustainable development benefits. These benefits are explored in the next section.

\section{Potential contribution of organic agriculture to national sustainable development}

In developing countries, a shift towards sustainable agricultural practices, such as OA, can deliver long-term food security as well as economic, environmental, social and cultural benefits.

\section{Economic benefits}

Organic agriculture can procure higher incomes for farmers. This can be due to higher prices received for certified OA products, larger quantities produced and sold, and/or lower input costs. ${ }^{8}$ The interaction of these three variables can be expressed in terms of the following equation:

$$
\text { Net income or profits }=(\text { price }) \times(\text { quantity sold })-\text { total costs }\left(\Pi=\mathrm{P}^{*} \mathrm{Q}-\mathrm{TC}\right)
$$

To properly analyse the impact on livelihoods of organic farming, it is necessary to examine its profitability over a period of several years. Each of these variables is examined separately below. In addition, many argue that OA markets offer not only higher, but also more sustainable income for farmers due to better and more stable farm-gate prices, stable markets and long- term relationships between producers and traders (Musiime, Keizire and Muwanga, 2005).

Price: Certified organic products almost always fetch higher prices than conventional products. This is true both at the retail and farm level, and is one of the main attractions in "going organic" for many farmers. The exact amount of the price premium" received by farmers varies according to product, season and the short-term supply-demand balance in the target market. The issue of bargaining power may also play a role (i.e. whether there is only one buyer of organic products in a region or several).

While global systematic data on farm-gate organic price premiums are not available, anecdotal evidence exists. In Uganda, for example, organic cotton farmers received a price premium of around 25 per cent. The out-growers of the company African Organics received price premiums in the range of 40 to 80 per cent for products such as pineapples, ginger and bananas (Waniala, 2004). In April 2004, Ugandan growers of organic apple bananas and passion fruit earned 212 per cent and 100 per cent more, respectively, than their conventional counterparts (Musiime, Keizire and Muwanga, 2005). In May 2005, the export price of Ugandan robusta coffee beans was \$0.97/ 
$\mathrm{kg}$, whereas organic robusta sold at $\$ 1.35 / \mathrm{kg}$, implying a price premium of at least 39 per cent (The Standard, 2005). Tunisian organic olive farmers received price premiums in the range of 10-20 per cent in 2005 (see commentary by Maamer Belkhiria and Ben Kheder, in this TER). A study carried out by the International Fund for Agricultural Development (IFAD, 2003) of small farmers in Latin America and the Caribbean revealed that price premiums received by farmers ranged from a minimum of 22.2 per cent for bananas in the Dominican Republic to 150 per cent for cacao in Costa Rica.

However, in some cases, certified organic products end up being sold as conventional products, as happened with organic cotton produced in one region of Uganda (Waniala, 2004). Thus, from the farmers' perspective, the expected price premium may be lower than the observable price premium, ${ }^{10}$ and it is the expected price that influences the farmer's planting decisions. Uncertified organic products, on the other hand, do not generally fetch price premiums.

Quantity: OA can lead to higher overall farm output and productivity (i.e. increased yields/ output per hectare). When comparing agricultural yields of organic farming with those of conventional or traditional farming, two factors must be borne in mind. First, organic farming is based on the principle of crop rotation, with different crops being planted each year. Thus a full rotation cycle of several years must be used to obtain results that can be accurately compared with systems based on monocropping. Second, organic farming often involves multi- or intercropping practices. To compare yields of only one crop may therefore be misleading; a more accurate measure would take into account total production of crops per land area.

Third, whether yields increase or decrease depends very much on the starting point. Perceptions on this subject have been much influenced by the earliest studies, which were almost exclusively carried out in developed, particularly European, countries that had a long history of intensive, high external input farming and depleted soils. When these conventional farms converted to organic, yields dropped initially, but as the soil fertility was gradually built up, yields increased. In Europe, organic yields after the transition period are often lower than conventional crop yields. In the United States, on the other hand, post-transition period organic yields are comparable to conventional yields. ${ }^{11}$ A recent review of a 22 -year farming trial in the United States concluded, for example, that "organic farming produces the same yields of corn and soybeans as does conventional farming, but uses 30 percent less energy, less water and no pesticides." Under drought conditions, the organic systems produced higher yields (Lang, 2005, referring to Pimental, 2005).

Moreover, the European scenario does not accurately reflect the situation in developing countries. In some developing countries, agriculture is dominated by large-scale, high external input farming. But the vast majority of farmers in developing countries are small- scale farmers, many or even most of whom do not use large amounts of external inputs such as synthetic fertilizers and pesticides, often because they cannot afford to purchase them. Many rely on traditional agricultural techniques instead. In these cases, application of OA techniques nearly always increases agricultural productivity by optimizing the use of local resources; indeed, agricultural yields can double or even triple (FAO, 2002; IFAD, 2005).

The following table presents data on changes in agricultural productivity for 17 certified and non-certified organic projects and initiatives in selected developing countries (for details, see FAO, 2002). In 15 of these projects yields increased significantly, while in two cotton projects yields remained constant. This is perhaps not surprising given that cotton is among the most pesticideintensive crops grown. For example, in 1994 cotton accounted for about 24 per cent ( $\$ 1.8$ billion) of the global insecticides market, even though the crop occupied only 2.4 per cent of the world's total arable land ${ }^{12}$ (Myers, 2000). In Tunisia, application of organic techniques increased yields of olive farms by 14 to 40 per cent (see the commentary by Maamer Belkhiria and Ben Kheder in this TER).

Total costs: Total costs include the direct costs of production - land, labour and capital (in this case, for example, seeds, planting materials and fertilizers) - as well as costs related to such 
aspects as transportation, storage and certification. Total costs for organic products may be higher or lower than for conventional products.

OA can be more labour-intensive than conventional farming. On small farms, particularly in conditions of rural unemployment or underemployment, family members often provide the additional labour. In remote areas, opportunity costs for such labour may be fairly low. On larger farms, it may be necessary to hire additional labour, which would then increase actual expenditures. In addition, workers may need to be trained in OA techniques, which involves costs in terms

\begin{tabular}{|c|c|c|c|c|}
\hline \multirow[b]{2}{*}{ Country } & \multicolumn{4}{|c|}{$\begin{array}{l}\text { Table 2. Impact on agricultural productivity of a shift to } \\
\text { organic agriculture (certified and non-certified) in selected developing countries }\end{array}$} \\
\hline & Project & $\begin{array}{l}\text { Number of } \\
\text { farm } \\
\text { households }\end{array}$ & $\begin{array}{c}\text { Area under } \\
\text { organic }^{\mathrm{a}} \\
\text { agriculture } \\
\text { in the project (ha) }\end{array}$ & $\begin{array}{l}\text { Changes in agricultural } \\
\text { productivity observed } \\
\text { during the project }\end{array}$ \\
\hline Bolivia & $\begin{array}{l}\text { PRODINPO integrated } \\
\text { development programme }\end{array}$ & 2000 & 1000 & $\begin{array}{l}\text { Potato yields up from } 4 \mathrm{t} / \mathrm{ha} \\
\text { to } 10-15 \mathrm{t} / \mathrm{ha}\end{array}$ \\
\hline Brazil & $\begin{array}{l}\text { AS-PTA alternative } \\
\text { agriculture }\end{array}$ & 15000 & 60000 & $\begin{array}{l}\text { Bean yields up by } \\
50-100 \text { per cent }\end{array}$ \\
\hline Cuba & Organic urban gardens & 26000 & 8000 & $\begin{array}{l}\text { Total production up from } \\
4000 \mathrm{t} / \mathrm{yr} \text { to } 700000 \mathrm{t} / \mathrm{yr}\end{array}$ \\
\hline Egypt & SEKEM biodynamic cotton & 150 & 2000 & $\begin{array}{l}\text { Cotton yields up from } 2.25 \mathrm{t} / \mathrm{ha} \\
\text { to } 3.0 \mathrm{t} / \mathrm{ha}\end{array}$ \\
\hline Ethiopia & FAO Freedom from Hunger & 2300 & 2150 & $\begin{array}{l}\text { Sweet potato yields up } \\
\text { from } 6 \mathrm{t} / \mathrm{ha} \text { to } 30 \mathrm{t} / \mathrm{ha}\end{array}$ \\
\hline Ethiopia & $\begin{array}{l}\text { Cheha integrated } \\
\text { rural development }\end{array}$ & 12500 & 5000 & Cereals yields up by 60 per cent \\
\hline Kenya & Manor House Agriculture & 70000 & 7000 & $\begin{array}{l}\text { Maize yields up from } 2.25 \mathrm{t} / \mathrm{ha} \\
\text { to } 9 \mathrm{t} / \mathrm{ha} \text {; new vegetable crops }\end{array}$ \\
\hline Kenya & C-MAD Programme & 500 & 1000 & $\begin{array}{l}\text { Maize yields up from } 2 \\
\text { t/ha to } 4 \mathrm{t} / \mathrm{ha}\end{array}$ \\
\hline Kenya & $\begin{array}{l}\text { Mumias Education for } \\
\text { Empowerment project }\end{array}$ & 2069 & 217 & $\begin{array}{l}\text { Beans } / \text { groundnut yields up } \\
\text { from } 300 \mathrm{~kg} / \mathrm{ha} \text { to } 600 \mathrm{~kg} / \mathrm{ha}\end{array}$ \\
\hline Kenya & Push-pull pest management & 300 & 150 & Maize yields up by 60 per cent \\
\hline Mexico & $\begin{array}{l}\text { UCIRI Fair trade and } \\
\text { organic coffee }\end{array}$ & 4800 & 5000 & $\begin{array}{l}\text { Coffee yields up from } 300-600 \\
\mathrm{~kg} / \mathrm{ha} \text { to } 600-1200 \mathrm{~kg} / \mathrm{ha}\end{array}$ \\
\hline Nepal & $\begin{array}{l}\text { Jajarkot Permaculture } \\
\text { Programme }\end{array}$ & 580 & 350 & $\begin{array}{l}\text { Rice yields up from } 1.8 \text { to } \\
2.4 \mathrm{t} / \mathrm{ha} \text {; maize yields up } \\
\text { from } 1.2 \text { to } 1.6 \mathrm{t} / \mathrm{ha}\end{array}$ \\
\hline Pakistan & $\begin{array}{l}\text { Sindh Rural Women's } \\
\text { Uplift Group }\end{array}$ & 5000 & 2500 & $\begin{array}{l}\text { Mango yields up from } 7.5 \mathrm{t} / \mathrm{ha} \\
\text { to } 22.5 \mathrm{t} / \mathrm{ha} \text {; citrus yields up } \\
\text { from } 12 \mathrm{t} / \mathrm{h} \text { to } 30 \mathrm{t} / \mathrm{ha}\end{array}$ \\
\hline Senegal & $\begin{array}{l}\text { Rodale Regenerative } \\
\text { Agriculture Research Centre }\end{array}$ & 2000 & 2000 & $\begin{array}{l}\text { Millet/sorghum yields up from } \\
0.34 \mathrm{t} / \mathrm{ha} \text { to } 0.6-1.0 \mathrm{t} / \mathrm{ha}\end{array}$ \\
\hline Senegal & ENDA organic cotton & 523 & 233 & $\begin{array}{l}\text { Cotton yields: no change at } \\
300 \mathrm{~kg} / \mathrm{ha}\end{array}$ \\
\hline $\begin{array}{l}\text { United Rep. } \\
\text { of Tanzania }\end{array}$ & GTZ organic cotton & 134 & 778 & $\begin{array}{l}\text { Cotton yields: no change at } \\
660 \mathrm{~kg} / \mathrm{ha}\end{array}$ \\
\hline Zimbabwe & Chivi Food Security Project & 500 & 600 & $\begin{array}{l}\text { Sorghum/millet yields doubled; } \\
\text { new vegetable crops produced }\end{array}$ \\
\hline
\end{tabular}


of time and in some cases fees. This is an additional labour-related cost. On the other hand, organic farmers spend much less than conventional farmers on external inputs, particularly agro-chemicals. In many developing countries, costs of these inputs are a major expense for farmers and are mainly financed by high interest loans. (Musiime, Keizire and Muwanga, 2005). Thus the savings generated by reducing purchases of external inputs usually outweigh the additional labour-related costs.

For certified organic products, transportation and storage costs may be higher, as organic products must be segregated from conventional ones. In addition, organic certification by third-party certification bodies recognized in target markets can be relatively expensive, particularly for smallholders (discussed in more detail in Section E below).

Subsidies: Agricultural subsidies provided by governments to farmers increase farm profitability. Most developed-country governments subsidize their farmers - both conventional and organic. However, very few developing-country governments are in a position to offer their farmers direct price support; some subsidize agricultural inputs, particularly synthetic fertilizers and pesticides. This in fact acts as a tax on the organic sector and reduces its profitability vis-à-vis conventional farming. Only a small handful of developing-country governments target $\mathrm{OA}$ with direct subsidies or other financial incentives. The main exception is Tunisia, where the Government covers 70 per cent of the certification costs during the first five years of organic operation - up to a maximum of 5,000 Tunisian dinars (approximately \$3,700) - as well as 30 per cent of the investment costs of equipment and tools specific to organic projects. In addition, supplies necessary for organic production for export are exempt from customs duties and value added tax (Republic of Tunisia 2005).

In some developing countries, NGOs or donor agencies cover part or all of OA certification costs, particularly in the first few years of OA production. While not a subsidy per se, the positive effect on farmers' incomes is similar.

Profitability: Farm profitability will depend on the relative magnitude and directions of these variables. Most studies have shown that profitability of organic farming is greater than or equal to that of conventional farming. In Europe, for example, profitability of organic farms was comparable to that of conventional farms, despite the fact that conventional farms received proportionately greater subsidies than did their organic counterparts ${ }^{13}$ (Offermann \& Nieberg, 1999). In Latin America, in the above-mentioned survey by IFAD, "in all cases organic producers obtained higher net revenues relative to their previous situation" (IFAD, 2003). An IFAD survey in Asia concluded that "organic systems, primarily because of price premiums, are generally more profitable than conventional ones" (IFAD, 2005).

\section{Food security}

Food security is a critical and complex subject, with important links to the economic factors discussed above. It is not simply a question of agricultural yields. Much of the world's food insecurity is based upon difficulty - or lack - of access to food due to poverty. Helping to increase the productivity of smallholders through OA improves their livelihoods and overall well-being (FAO, 2002). In addition to improving yields of crops that farmers may produce for their own consumption, organic farming can also provide higher incomes, which contribute to greater food security.

Diversified production. Food security also implies having a reliable and stable food supply. OA is based on multicropping, polycultures and crop rotation, as opposed to monocropping. This is less risky for farmers for several reasons. First, the planting of a variety of crops leads to much higher resilience (resistance to adverse conditions) and regulates pests and weeds in a natural way. Second, while monocropping ties the farmer's livelihood to the success of one crop, OA practices tend to spread risk: even if one crop out of ten were to fail, the farmer will still be able to harvest nine crops. It can thus enhance local food security. 
Improved nutrition. The increase in incomes as well as the larger quantity and variety of food produced by organic farms lead to improved nutrition for rural families. Introducing, for example, animals on the farm to supply organic fertilizer has the positive side-effect of providing eggs, milk or meat that augment protein content in local diets.

\section{Environmental benefits}

OA provides a wide range of environmental benefits as compared to conventional agriculture. It is for this reason that it is included in UNCTAD's general analysis of environmentally preferable products (EPPs). ${ }^{14}$ These benefits include the following:

Less pollution. As it does not employ synthetic agro-chemical inputs, OA causes much less environmental pollution, particularly of groundwater supplies. Moreover, nitrate leaching rates per hectare in OA systems are roughly half of those in conventional agriculture systems. (Stolze et $\mathrm{al}, 2000$ in $\mathrm{FAO}, 2002$ ).

Improved soil and less erosion. OA techniques improve soil structure and increase soil organic matter, thereby improving the soil's water retention capacity. It has the additional social benefit of augmenting supplies of drinking water (FAO, 2002). The improved soil structure also reduces soil erosion, which is a leading cause of soil degradation worldwide with a negative impact on agricultural yields (FAO, 2002).

This improvement may be especially important for countries regularly faced with droughts or floods. For example, the Rodale Institute Farming Systems Trial, which investigated how managed and natural systems respond to climate-related stress, found that organic systems recorded higher productivity than their conventional counterparts over a five-year drought period. This was found to be due to the higher water-holding capacity of the soils under organic treatments, as the soils in the organic plots captured more water and retained more of it in the crop root zone than in the conventional plots (Lotter, Seidel and Liebhardt, 2003). A study undertaken in Nicaragua after Hurricane Mitch indicated that agro-ecologically managed farms proved to be much more resistant to this extreme ecological disturbance than conventionally managed farms: the agro-ecological plots had 40 per cent more topsoil, a 49 per cent lower incidence of landslides and more than 20 per cent more vegetative cover (Holt-Giménez, 2002 in FAO, 2002).

Enhanced biodiversity. OA leads to a greater abundance and variety of the whole range of agricultural and wild flora and fauna in and around the farm - from microbes and earthworms in the soil, to more diverse crops in the fields, to wild vegetation around the fields and to birds in the air (FAO, 2002). For example, a long-term trial study in Switzerland revealed 50 to 80 per cent more earthworms on organically managed farms as compared to conventionally managed ones (Pfiffner and Mäder, 1997 in FAO, 2002). A separate study found that organic soils in Switzerland had up to 90 per cent higher total mass of micro-organisms than conventionally managed soils (Fliessbah et al, 2001). A study carried out in the United Kingdom by the British Trust for Ornithology found that bird densities of all species studied were higher on organic farms than on conventional farms (Chamberlain et al, 1996).

$\mathrm{OA}$ is an important means of developing and preserving in situ local varieties of plants and animals that have been developed by farmers over long periods of time. This must be seen against the backdrop of an alarming global loss of agro-biodiversity due largely to mechanization and increasing scales of agriculture often based on monocropping, as well as to agro-chemicals (FAO, 1996). It is estimated that more than 90 per cent of crop varieties have disappeared from farmers' fields in the past century (ITDG, 2002).

No genetic contamination. As OA strictly excludes the use of GMOs, there is no risk of these having unexpected interactions with surrounding flora and fauna. 
Mitigating climate change. According to the FAO and others, OA offers the potential to mitigate climate change. It does this by reducing emissions of agricultural greenhouse gases, which in conventional agriculture are primarily generated by the production and use of synthetic fertilizers. Moreover, by restoring the organic matter content of soils, OA may even counteract climate change. Its carbon-sequestration efficiency is double that of conventional agriculture. OA systems are also better able to adjust to climatic changes (FAO, 2002; Haas and Köpke, 1994).).

Reduced energy consumption. OA consumes less energy than conventional agriculture, both directly (oil and other fuels) and indirectly (synthetic pesticides and fertilizers that have been manufactured using energy). This conclusion was reached by a number of scientific studies that revealed that the total energy consumption of organic farms is between 30 and 64 per cent of that of conventional farms (Haas and Köpke, 1994, Zarea et al, 2000, and Fliessbach et al, 2001 in FAO, 2002). Organic systems also outperform conventional systems in terms of energy efficiency (i.e. the ratio of energy input and output). A study in Iran, for example, found the energy efficiency of OA to be 81 per cent better than high-input conventional agriculture. (Zarea et al, 2000 in FAO, 2002).

Landscape services. OA provides diversified landscapes and semi-natural habitats, enhancing the functional and aesthetic value of agricultural land.

\section{Social and cultural benefits}

A number of social and cultural benefits have been observed in developing-country communities that shift to OA.

Benefits for smallholders. Smallholders in particular could gain considerably from OA. In developing countries, smallholders often constitute up to 70 per cent of the rural population. Owing to the nature of their production systems (i.e. low agro-chemical inputs), many smallholders can quite easily convert their farms to organic. They may, however, face serious problems in coping with the costs and requirements of certification, which is a necessity for capturing benefits from the organic market. In contrast, larger enterprises are in a better financial and managerial position to undergo the certification process. However, the production systems of such enterprises are also often heavily dependent on external inputs of agro-chemicals. As a result, they face the problem, initially, of reduced yields and difficulties in converting to OA.

Women's empowerment. Similarly, OA may have positive effects on the incomes of women, who make up a large share of smallholding farmers, particularly in sub-Saharan Africa and Asia (ESCAP, 2003). In some cases the need for more labour inputs could also prove onerous (IFAD, 2005).

Traditional knowledge. OA can build on and enhance the traditional knowledge (TK) and practices of local and indigenous communities. Much TK is about the land and how to work with it, as well as about harvesting and storage techniques. In addition, TK has long been used by farmers to selectively breed cultivars or varieties well suited to local conditions. These local farmer varieties are also called landraces. The interface between modern OA techniques and farmers' traditional agricultural knowledge and landraces offers fertile ground for innovations and improvements in local agricultural productivity. This is in line with the general UNCTAD finding that the interface between "modern" scientific knowledge and TK systems has the potential to generate important innovations and other benefits such as increased project effectiveness (UNCTAD, 2004a). Farmers' TK can enhance the successful implementation of OA techniques, while OA techniques can enhance the productivity of traditional farming systems.

Health and safety. OA can bring a number of local health benefits. In developing countries, up to 14 per cent of all occupational injuries in the agricultural sector and 10 per cent of all fatal 
injuries are attributable to pesticides (Myers, 2000). With OA, farm workers and their families living on or near the farms are no longer exposed to hazardous chemical inputs, resulting in improved health. As mentioned above, OA can also lead to improved local nutrition and cleaner, more reliable, local drinking water supplies.

Community revitalization. Some other social benefits are readily observable and very important, but difficult to quantify. For example, shifting to OA can lead to a stronger sense of community identity, self-reliance and empowerment. Building on local TK also revitalizes pride in a community's history and identity. Successful conversion to OA can lead to greater self-confidence, making organic farmers more likely to experiment and innovate. This in turn generates increased income flows in the long term.

Reduced rural-urban migration. Because of the stronger sense of community identity, improved livelihoods and possible increased demand for labour, OA has the potential to reduce rates of rural-urban migration, thus taking pressure off overcrowded cities (FAO, 2002).

\section{Organic agriculture as an export opportunity for developing countries}

This section examines OA as an export opportunity for developing countries, including areas of possible comparative advantage. It gives an overview of global sales of certified organic products, with a focus on the major organic markets (i.e. the United States, Europe, Canada and Japan) and developing country markets. This includes information as available on types of products, points of sale, imports and price premiums. The section then discusses OA market access and entry conditions, including an overview of the regulations governing imports of organic products in the European Union, the United States, Japan and Switzerland.

During the past decade, the major markets for OA products have been growing rapidly. This growth has been driven by increasing consumer awareness and concerns about environmental and food safety issues, including a number of food scares. More recently, concerns about genetically modified (GM) foods have also helped boost growth of the organic market. In countries where mandatory labelling of GM-containing foods is not required, for example in the United States, choosing certified organic products may be the only way for consumers to ensure that their food is GM-free.

OA production is expanding in developed countries, but domestic supply is expected to remain below domestic demand for most organic products for some years to come, creating export opportunities for developing countries. Furthermore, the long-standing interest of developed-country consumers in tropical products and the emerging appetite for so-called "ethnic" foods create demand for organic products that cannot be easily supplied by domestic producers. In many developed countries, "organic" applies not only to apples, granola and muesli, but also to chocolate bars, mango juice, Sumatran coffee and frozen Thai curry preparations.

Systematic data on international trade in organic products is virtually non-existent. The Harmonized Commodity Description and Coding System does not differentiate between products produced conventionally and those produced organically. However, there is evidence that many developing countries are taking advantage of organic export opportunities. In Mexico, for example, $80-85$ per cent of organic produce is exported. Foreign currency revenues generated by OA exports from Mexico have been rising rapidly, from \$34 million in 1996 to $\$ 280$ million in 2002, accounting for 8.5 per cent of the total export revenues in the agricultural sector (Gomez Tovar and Gomez Cruz, 2004). Similarly, in Uganda, the value of organic exports rose from \$4.6 million in 2002/2003 to $\$ 7.7$ million in 2003/2004 (Musiime and Naluwairo 2004).

Developing countries may have some inherent comparative advantage in organic production. This is due to their relatively abundant labour supply as compared to developed countries, and 
their relatively lower use of agro-chemicals in agriculture. Among the best export opportunities for developing countries could be for products such as:

- Fresh and processed tropical organic products (e.g. bananas, pineapples, coffee, cocoa and mangoes);

- Counter-seasonal fresh produce; and

- Other products with large, short-term demand-supply gaps.

The organic food market can roughly be divided into three segments:

- Ingredients for the food processing industry;

- Products for direct consumption; and

- Products for the catering and institutional sector.

According to the Centre for the Promotion of Imports from Developing Countries (CBI), the first segment is the most important for developing-country exporters (to Europe), as they often do not have good market information and cannot compete with major brands in the retail market. Moreover, the demand for organic convenience foods is rising rapidly (CBI, 2004).

Some producers in developing countries consider OA as one effective way to respond to increasingly stringent food safety and quality requirements in key export markets, such as the new EU regulations on food safety and the private EurepGAP standard imposed by major European supermarkets on their suppliers of food products ${ }^{15}$. Since OA excludes the use of synthetic agrochemicals, organic products would not be affected by stringent maximum residue levels (MRLs)

Table 3. Overview of world markets for organic food and beverages

\begin{tabular}{|c|c|c|c|c|}
\hline Markets & $\begin{array}{l}\text { Retail sales } \\
\text { estimate } \\
\text { (\$ million) } \\
2000\end{array}$ & $\begin{array}{c}\text { Retail sales } \\
\text { forecast } \\
(\$ \text { million }) \\
2003\end{array}$ & $\begin{array}{l}\text { Approximate } \\
\text { share in total } \\
\text { food sales } \\
\text { (per cent) }\end{array}$ & $\begin{array}{l}\text { Expected annual } \\
\text { growth rates } \\
2003-2005 \\
\text { (per cent) }\end{array}$ \\
\hline Total & $15225-16475$ & $23000-25000$ & - & \\
\hline Europe & $6950-7650$ & $10000-11000$ & - & \\
\hline Germany & $2100-2200$ & $2800-3100$ & $2.0-2.5$ & $5-10$ \\
\hline United Kingdom & $1100-1200$ & $1550-1750$ & $1.8-2.3$ & $10-15$ \\
\hline Italy & $1000-1050$ & $1250-1400$ & $1.0-1.5$ & $5-15$ \\
\hline France & $800-850$ & $1200-1300$ & $1.0-1.5$ & $5-10$ \\
\hline Switzerland & $450-475$ & $725-775$ & $2.5-3.0$ & $5-15$ \\
\hline Denmark & $350-375$ & $350-375$ & $2.5-3.0$ & $0-5$ \\
\hline Austria & $200-225$ & $325-375$ & $2.5-3.0$ & $5-10$ \\
\hline Netherlands & $275-325$ & $425-475$ & $1.0-1.5$ & $5-10$ \\
\hline Sweden & $175-225$ & $350-400$ & $1.5-2.0$ & $10-15$ \\
\hline Belgium & $100-125$ & $200-250$ & $1.0-1.5$ & $5-10$ \\
\hline Other Europe* & $400-600$ & 790-900 & - & - \\
\hline United States & $7500-8000$ & $11000-13000$ & $2.0-2.5$ & $15-20$ \\
\hline Canada & 500 & $850-1,000$ & $1.5-2.0$ & $10-20$ \\
\hline Japan & $275-325$ & $350-450$ & $<0.5$ & - \\
\hline Oceania & & $75-100$ & $<0.5$ & - \\
\hline
\end{tabular}

Source: International Trade Centre, compiled in January 2003 (reproduced in Vossenaar, Jha and Wynen, 2004).

*Finland, Greece, Ireland, Norway, Portugal and Spain. Ireland is included for 2003. 
for these chemicals. ${ }^{16}$ There is considerable common ground between organic and EurepGAP standards. The EurepGAP secretariat is currently working with organic certifiers to provide a onestop shop solution, which would enable producers to receive a single audit to meet both organic and EurepGAP certification requirements (Garbutt, 2005, personal communication).

\section{Market trends}

\section{Global market}

The size of the world certified OA market in 2003 was estimated by the International Trade Centre of UNCTAD/WTO (ITC) to be in the range of $\$ 23$ to $\$ 25$ billion, with annual market growth rates in the range of 5-20 per cent. Over 95 per cent of certified organic food sales in 2003 were in Europe and North America (table 3). For developing countries wishing to produce and sell certified OA products, these are the main target markets, and thus the focus of this section.

The ITC forecasts tally fairly well with more recent estimates (summarized in table 4) by Sahota, Director of the Organic Monitor, who estimates that world sales of organic food and drink reached $\$ 25$ billion in 2003 with overall growth rates of 7 to 9 per cent. He points out that Europe overtook North America as the major market in 2003, but that this was largely due to an appreciation of the euro against the dollar (Sahota, 2005).

\section{The United States of America}

In the United States, sales of organic products have grown at annual rates of between 17 and 21 per cent since 1997, while total food sales have grown at an annual rate of 2 to 4 per cent. Between 1997 and 2003, the percentage of organic foods in total foods increased from 0.8 per cent to 1.9 per cent. ${ }^{17}$ Sales of organic products reached $\$ 10.8$ billion in 2003 - an increase of 20 per cent since 2002. Of these, $\$ 10.4$ billion were from organic food sales and $\$ 440$ million from non-food products such as fibres, flowers, household cleaners and pet foods. Fresh fruit and vegetables remain the largest category, accounting for 42 per cent of organic food sales (figures 3 and 4 below). The average annual growth rate for organic foods is projected to be 18 per cent for 20042008 (Organic Trade Association, 2004). ${ }^{18}$

Table 4. Regional distribution of certified organic food sales in 2003

\begin{tabular}{lcc} 
Region & \$ billion & $\begin{array}{c}\text { Per cent of global } \\
\text { certified organic food sales }\end{array}$ \\
\hline
\end{tabular}

\begin{tabular}{lcc}
\hline Western Europe & 13.0 & 52 \\
North America & 11.4 & 45 \\
Asia (including Japan) & 0.48 & 2 \\
Oceania/Australia & 0.24 & 1 \\
Total & 25.0 &
\end{tabular}

Source: Sahota, 2005.

The variety of products available on the United States market has expanded significantly. Traditionally marketed mainly by natural food shops (e.g. Whole Food Market and Wild Oats), organic food is now more widely available in supermarkets such as Safeway and Kroger. A 2004 consumer survey indicated that 66 per cent of American consumers purchased organic products at least occasionally, up from 55 per cent in 2000. This increase was largely driven by improved access to organic products in mainstream markets, heightened concern about health, including the 
impact of GMOs, and more information sources (Hartman Group, 2004). The introduction of the National Organic Programme (NOP) also seems to have helped raise consumer awareness about organic food, especially since it has provided one widely recognized organic label.

Figure 3. Organic food category share, 2003

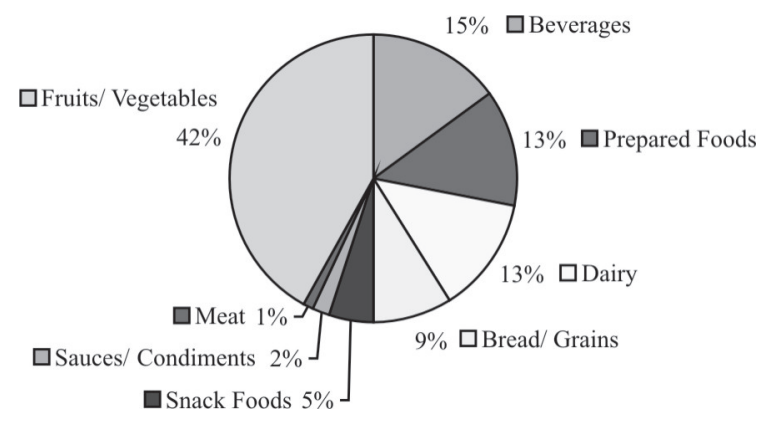

Figure 4. Organic product sales, 1991-2003

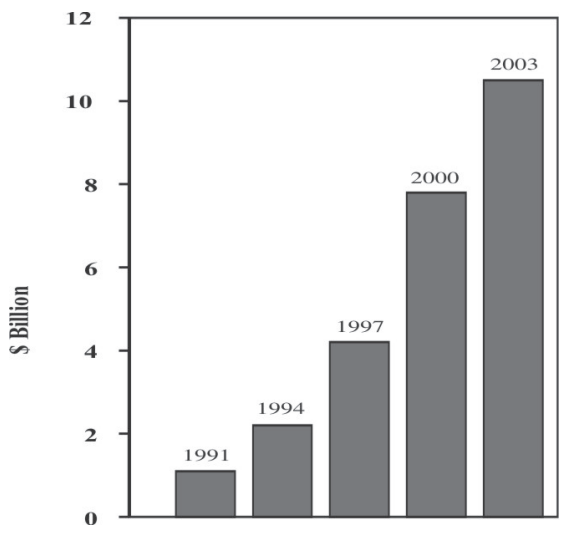

Source: Organic Trade Association, 2004.

Reliable data on organic imports and exports is not available, as United States Customs do not differentiate between organic and conventional products. ${ }^{19}$ Using other sources of information, however, the United States Department of Agriculture (USDA) estimates that in 2002 that country exported between $\$ 125$ million and $\$ 250$ million worth of organic products, of which \$75-\$150 million worth went to neighbouring Canada (largely processed foods) and \$50-\$100 million worth to other countries including those in the EU as well as Australia, Japan and the Republic of Korea. For the same year, the value of organic imports was estimated to be between $\$ 1.0$ billion and $\$ 1.5$ billion. Imported products included fresh fruit and vegetables, tropical products that cannot be grown in the United States, and ingredients for processed products. Imports came from all regions of the world, including Canada, Latin America (e.g. raw ingredients including fats and oils, fruit and vegetables, and cocoa) and Europe (processed foods such as pasta, wine and olive oil) and Asia (soybeans, frozen fruit and vegetables). Whereas the United States used to be a net organic food exporter, due to very strong domestic market growth, the import to export ratio is now approximately 8:1 (USDA, 2005a).

It is commonly believed that organic price premiums are falling around the world. However, in the United States at least they remain high. Table 5 presents comparisons of organic and conventional farm-gate prices for a wide range of products in April 2005. For most of these products, farmers received price premiums of between 30 per cent and 130 per cent (see annex 2 of this chapter for a longer list) (New Farm, 2005).

\section{Europe}

Taken as a whole, Europe is the largest market for organic products. Market growth is strong, but slowing down compared to the exceptionally high growth rates of the 1990s. In 2003, organic sales grew at an average annual rate of approximately 5 per cent to reach 10.5 to 11 billion euros. In 2002, the average growth rate was estimated at 8 per cent. Organic products have managed to hold their own quite well in the face of fierce competition between supermarkets, which has lowered the price of conventional products and thereby made organics relatively more expensive. Sales of organic foods grew at more than double the rate of overall food, which grew by only 2 per cent in 2004 (ACNielsen, 2005). 


\section{Table 5. Farm-gate prices of selected organic and conventional products} in the United States (15 April 2005)

\begin{tabular}{|c|c|c|c|c|}
\hline Product & Unit & $\begin{array}{c}\text { Organic } \\
\text { (price in \$) }\end{array}$ & $\begin{array}{c}\text { Conventional } \\
\text { (price in \$) }\end{array}$ & $\begin{array}{l}\text { Premium } \\
\text { (per cent) }\end{array}$ \\
\hline \multicolumn{5}{|l|}{ Grains } \\
\hline Barley (malting) & Bushel & 3.75 & 2.45 & 53 \\
\hline Corn (\#2 yellow) & Bushel & 6.11 & 2.31 & 165 \\
\hline Soy (feed stock) & Bushel & 14.25 & 5.99 & 138 \\
\hline \multicolumn{5}{|l|}{ Fruit } \\
\hline Apples (Gala) & $88 \mathrm{Ct}$ & 39.36 & 18.75 & 110 \\
\hline Apples (Golden delicious) & $100 \mathrm{Ct}$ & 23.17 & 17.50 & 32 \\
\hline Grapefruit (Ruby) & $48 \mathrm{Ct}$ & 27.98 & 17.00 & 65 \\
\hline Lemons & $140 \mathrm{Ct}$ & 29.00 & 24.50 & 18 \\
\hline Pears (Bartlett) & $90 \mathrm{Ct}$ & 40.98 & 35.00 & 17 \\
\hline Strawberries & $8 / 1 \mathrm{lbs}$ & 28.50 & 12.00 & 138 \\
\hline \multicolumn{5}{|l|}{ Vegetables } \\
\hline Avocados & $48 \mathrm{Ct}$ & 59.50 & 33.33 & 79 \\
\hline Broccoli & $14 \mathrm{Ct}$ & 39.75 & 17.00 & 134 \\
\hline Carrots & $24 \times 2 \mathrm{lbs}$ & 29.42 & 14.67 & 101 \\
\hline Green beans & $25 \mathrm{lbs}$ & 59.95 & 41.00 & 46 \\
\hline Lettuce (Green leaf) & $24 \mathrm{Ct}$ & 38.23 & 26.5 & 44 \\
\hline Mushrooms (Portabella) & $5 \mathrm{lbs}$ & 22.06 & 12.88 & 71 \\
\hline Potatoes (Red A) & $50 \mathrm{lbs}$ & 33.48 & 13.33 & 151 \\
\hline Tomatoes & 2 Layers 4 x 5 & 49.63 & 17.5 & 184 \\
\hline
\end{tabular}

Source: New Farm, 2005.

Surveys indicate that European buyers of OA products are motivated primarily by food safety and health concerns. Nature conservation and environmental protection and taste are among the other major motivating factors (Zanoli et al., 2004 in CBI, 2004).

The biggest European national markets are, in descending order, Germany, the United Kingdom, France, Italy and Switzerland. There is considerable variation in growth rates across countries. Growth rates in France, Germany, Italy and Switzerland were in the 2-5 per cent range, whereas in Spain, the United Kingdom and many Central and Eastern European countries, annual growth rates exceeded 10 per cent (Richter and Padel, 2005).

In recent years, many European governments are more actively promoting the organic sector, including production. Yet demand continues to outstrip supply, necessitating imports. ${ }^{20}$ Among the top five, the United Kingdom is the most import-dependent and France the least. Table 6 below shows the volume (in tons) of organic imports in 2002 for selected products in selected countries. Most of these imports are, however, from other European countries (including re-exports from developing countries). Developing-country supply to the EU is dominated by a number of leading producers, including Argentina, China, Mexico and South Africa. Due to their advantage of geographical proximity to Europe, Egypt and Morocco are leading suppliers of off-season organic 
fruit and vegetables. These countries have a relatively better infrastructure that enables them to meet the EU's regulatory requirements for organic products and general food law requirements (CBI, 2004).

\section{Price premiums in Europe}

Comprehensive, updated price premium data for all of Europe is unavailable. According to CBI, organic products generally fetch retail prices that are 15-25 per cent higher than their conventional counterparts. Premiums have been declining in recent years due to increasing competition in the organic sector as well as economies of scale in shipping, processing and distribution of some products as a result of increased levels of trade.

Table 6. Volume of imports of selected OA products by selected EU countries in 2002 (tons)

Cereals Oil seeds Potatoes Vegetables Fruit Milk Wine

(incl. nuts) (products)

\begin{tabular}{lrrrrrrr}
\hline Denmark & 20000 & & 2000 & 1772 & 3000 & & 3000 \\
France & 112225 & 18,200 & 6000 & 30000 & 25000 & 25000 & 20000 \\
Germany & 100000 & 8,000 & 6000 & 50000 & 30000 & 15000 & 120000 \\
Italy & 200000 & na & & 4280 & 12484 & 120000 & \\
Nertherlands & 40000 & 30,000 & 7500 & 80000 & 2000 & 2500 & \\
United Kingdom & 160000 & Very small & 20000 & 74000 & 30000 & 22000 & 22000
\end{tabular}

Source: Kilcher et al., 2004 (as compiled in CBI, 2004).

According to CBI estimates for Germany, price premiums range from 18 to 142 per cent, with the average price premium in the 60-70 per cent range. In France, price premiums average 20-30 per cent in supermarkets, with specialized health food stores selling at prices 50 per cent higher than these. In Italy, the average retail price premium is 25 per cent in supermarkets and 30 per cent in organic stores. Depending on the season, organic fruit and vegetables can sometimes sell at roughly the same rates as conventional ones (CBI, 2004).

The ZMP ${ }^{21}$ publishes monthly data on conventional and organic products for Germany. Table 7 shows the average retail prices for 12 products and the price premium of organic compared with the conventional product. The premiums range from 39 per cent for organic lettuce to 274 per cent for organic eggs, with most in the 67 to 156 per cent range. The average retail price premium for the 12 products was 111 per cent (ZMP, 2005).

In Switzerland, the average price premium according to the Research Institute of Organic Agriculture (FibL) estimates is 40 to 50 per cent overall, with higher premiums in specialized shops than in supermarkets. In the latter, price premiums are approximately $40-80$ per cent for vegetables, 40-50 per cent for cereals, 50-60 per cent for fruit and nuts, and 10 percent for milk and dairy products (Kilcher et al., 2004). Table 8 shows price premiums in August 2004 in the Migros supermarket chain, one of the country's main retailers of organic products. These premiums are lower than the estimates above. Tables 7 and 8 also reveal wide differences in food prices across countries.

\section{National markets}

In terms of value of retail sales of organic products, the top five European organic national markets are Germany, the United Kingdom, Italy, France and Switzerland (in that order). An overview of each of these five markets is presented below. 


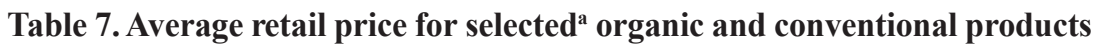
in Germany (March 2005)

\begin{tabular}{lrccc} 
Product & Quantity & $\begin{array}{c}\text { Organic price } \\
\text { (euros) }\end{array}$ & $\begin{array}{c}\text { Conventional } \\
\text { price (euros) }\end{array}$ & $\begin{array}{c}\text { Premium } \\
\text { (\%) }\end{array}$ \\
\hline Ground beef & $1 \mathrm{~kg}$ & 9.71 & 5.15 & 89 \\
Pork chops & $1 \mathrm{~kg}$ & 11.67 & 4.56 & 156 \\
Eggs & 10 & 2.92 & $0.78^{\mathrm{b}}$ & 274 \\
Bananas & $1 \mathrm{~kg}$ & 2.42 & 1.37 & 77 \\
Pears & $1 \mathrm{~kg}$ & 2.64 & 1.51 & 75 \\
Lettuce & 1 & 1.82 & 1.31 & 39 \\
Tomatoes & $1 \mathrm{~kg}$ & 4.38 & 2.14 & 105 \\
Red peppers & $1 \mathrm{~kg}$ & 6.37 & 3.43 & 86 \\
Carrots & $1 \mathrm{~kg}$ & 1.44 & 0.65 & 122 \\
Milk & $1 \mathrm{liter}$ & 0.95 & 0.57 & 67 \\
Butter & $250 \mathrm{~g}$ & 1.59 & 0.81 & 96 \\
Wheat flour & $1 \mathrm{~kg}$ & 1.10 & 0.44 & 150 \\
Average & & & & 111
\end{tabular}

Source: ZMP, 2005.

a The 12 products were selected based on availability of price data for comparable organic and conventional products.

${ }^{\mathrm{b}}$ Eggs from chickens raised in cages; eggs from free-range chickens cost 1.48 euros for 10 eggs.

Germany is the largest national organic market in Europe and the second largest in the world after the United States. It is also the largest importer of organic products in Europe, importing 38 per cent of the value of all organic products sold in its market. Fruit and vegetables top the list, accounting for 30 per cent of the value of German organic imports and half of the organic fruit and vegetables consumed in Germany. These come mainly from France, Italy and Spain. Other imports include coffee, tea, cocoa, nuts, spices and oils, almost all of which come from developing countries (Kilcher et al, 2004). Hamburg is an important port of entry for organic products into the EU (CBI, 2004).

Table 8. Retail prices of selected organic and conventional products in Switzerland (August 2004)

\begin{tabular}{lrccc} 
Product & Quantity & $\begin{array}{c}\text { Organic price } \\
\text { (Swiss Francs) }\end{array}$ & $\begin{array}{c}\text { Conventional price } \\
\text { (Swiss Francs) }\end{array}$ & $\begin{array}{c}\text { Premium } \\
\text { (\%) }\end{array}$ \\
\hline Spätzli (egg noodles) & $500 \mathrm{~g}$ & 3.80 & 3.10 & 22 \\
Bananas & $\mathrm{kg}$ & 3.60 & 3.00 & 20 \\
Milk & 1 litre & 1.70 & 1.45 & 17 \\
Eggs & 4 & 3.20 & 2.60 & 23 \\
Pork chops & $\mathrm{kg}$ & 27.50 & 19.55 & 41 \\
Carrots & $\mathrm{kg}$ & 2.30 to 2.90 & 1.70 to 1.80 & 33 to 61
\end{tabular}

Source: Gruber, 2005 (personal communication).

a The exchange rate in 2004/2005 was roughly 1.50 Swiss francs to 1 euro. 
The main organic product groups consumed are bread and other bakery products, dairy products, tofu, eggs, fruit and vegetables and meat (CBI 2004). Distribution takes place through specialized shops ( 35 per cent) supermarkets ( 35 per cent) and direct sales (18 per cent); the role of supermarkets is on the rise (Kilcher et al., 2004). Since 2001, promoting OA has become an official part of German agricultural policy. The Government's OA programme has an annual budget of 20 million euros, and initiatives such as the State-sponsored Bio-Siegel logo is intended to bring some clarity to the complex and confusing situation of nearly 100 organic labels in Germany, thereby helping to boost the sector (CBI, 2004; Yussefi, Willer and Lünzer, 2004).

In the United Kingdom, 56-65 per cent of organic products were imported in 2002/2003, of which organic fruit and vegetables comprised 76 per cent of the total sales value and cereals accounted for 65-70 per cent. This is despite a food campaign by the Government of the United Kingdom and the Soil Association (the main certifier) urging consumers to buy local organic produce, and efforts by supermarkets (that sell 80 per cent of the organic food in that country) to procure domestically (Richter and Padel, 2005; CBI, 2004).

In France, fresh fruit and vegetables, cereals and beverages accounted for half of organic sales in 2002 and showed the strongest growth (Kilcher et al., 2004). Imports accounted for only ten per cent of the French organic food market, the lowest share in Europe, but are on the rise as domestic production cannot meet rising demand. Some 60 per cent of imports originated in other EU countries (CBI 2004). The main imports from non-EU countries included tropical fruit, coffee, cocoa, tea, spices, sugar, oils and cereals. The best-known organic label (AB for agriculture biologique) is owned by the Government. Kilcher et al. (2004) note that for organic plant products, this label can only be used for products from other EU countries or from those on the EU third-country list, unless the product is included in the "exotic products" list. This could dampen prospects for some developing-country exports.

Italy has the most land under organic production in Europe. Over a third of all Italian organic production is exported, mainly to other European countries, but also to the United States and Japan. Italy relies on imports for processed goods, except for pasta and wine (of which Italy is a net exporter) and fruit and vegetables (Pinton and Zanoli, 2004). Most Italian production is in the south of the country, whereas 65 per cent of the organic consumption is in the north where income levels are relatively higher. In 2003, 60 per cent of organic sales were via specialized food stores and direct sales and 35 per cent via supermarkets. It is expected that by 2005 some 60 per cent will be sold in supermarkets (Kilcher et al., 2004).

In Switzerland, OA products comprise the highest share of overall food sales in Europe. This is largely due to active promotion of such products by the country's two main supermarket chains, Coop and Migros, which together accounted for 75 per cent of organic sales in 2002. Migros currently carries some 850 organic items. The high levels of consumers' income, education and environmental awareness have also contributed to strong demand for organic products. Imports of organic products have been constantly rising and are expected to continue to do so in coming years. Share of imports vary by product group. Virtually all organic coffee, cocoa, tea, tropical fruit and oilseeds are imported, as well as over 90 per cent of organic cereals, sugar and sweeteners, and over 75 per cent of other fresh fruit. On the other hand, only 20 per cent of organic vegetables are imported and almost all organic milk, eggs, wine and potatoes are produced domestically. The private Bio Suisse labelling scheme plays a very important role in the market. Its standards are more restrictive than the Swiss Government's Organic Farming Ordinance. For imported products bearing the Bio Suisse label, transportation by air is prohibited, and fresh products can only be imported if they cannot be grown in Europe for climatic reasons (Kilcher et al., 2004).

Although its domestic organic market is modest, the Netherlands is an important importer of organic products. Rotterdam is the main point of entry into Europe for organic imports, for reexport throughout Europe. 


\section{Canada}

Retail sales of organic products in Canada were estimated at $\$ 750-\$ 1,000$ million in 2003, making it the sixth largest national organic market in the world. Annual growth rates are estimated to be in the 20-25 per cent range. Because of Canada's climatic conditions, many organic products cannot be grown domestically and must therefore be imported. Some 80 per cent of imports are from the United States, although a considerable proportion consists of re-exported products originating in Latin America, particularly Mexico. The main imports from developing countries include tropical and off-season products. In addition, due to Canada's ethnic diversity, there is a strong interest in novel and ethnic products (Kortbech-Olesen, 2004).

The Organic Agriculture Centre of Canada publishes data on average retail food prices for a number of organic and conventional products; their prices can vary substantially across regions. Nevertheless, table 9 gives an indication of average price premiums of organic compared to conventional products in January 2004. The table indicates that average price premiums vary across products, ranging from 11 to 174 per cent.

\section{Japan}

Japan is the largest organic market outside Europe and North America, and is of particular importance for Asian organic producers. Prior to 2001, the Japanese market for organic products was estimated at more than $\$ 3$ billion, which would have made it one of the top three national markets

Table 9. Organic and conventional retail food prices (in Canadian dollars): average for four Canadian cities (Vancouver, Toronto, Montreal and Halifax) (January, 2004)

\begin{tabular}{lrccc} 
Product & Unit & Organic price & $\begin{array}{c}\text { Conventional } \\
\text { price }\end{array}$ & $\begin{array}{c}\text { Premium } \\
\text { (\%) }\end{array}$ \\
\hline Cereals & & & & \\
$\quad$ Oats for cooking & $\mathrm{kg}$ & 3.86 & 2.30 & 68 \\
$\quad$ Wholewheat pasta & $\mathrm{kg}$ & 7.12 & 5.37 & 33 \\
$\quad$ Wholewheat flour & $\mathrm{kg}$ & 2.26 & 1.75 & 29 \\
Dairy and eggs & & & & \\
$\quad$ Cheddar cheese & $\mathrm{kg}$ & 25.69 & 12.64 & 103 \\
Eggs & 1 dozen & 4.98 & 2.58 & 93 \\
$\quad$ Milk (2\%) & litre & 2.59 & 1.79 & 44 \\
Fruit and vegetables & & & & \\
$\quad$ Apples & $\mathrm{kg}$ & 4.35 & 2.89 & 51 \\
$\quad$ Carrots & $\mathrm{kg}$ & 2.69 & 1.37 & 96 \\
Cucumbers & $\mathrm{each}$ & 3.35 & 1.31 & 156 \\
$\quad$ Romaine Lettuce & $\mathrm{each}$ & 2.52 & 1.72 & 47 \\
$\quad$ Green Peppers & $\mathrm{kg}$ & 9.59 & 4.47 & 115 \\
$\quad$ Tomatoes & $\mathrm{kg}$ & 6.40 & 5.79 & 11 \\
Meat & & & & \\
$\quad$ Chicken & $\mathrm{kg}$ & 10.42 & 5.52 & 89 \\
$\quad$ Hamburgers & $\mathrm{kg}$ & 16.14 & 5.90 & 174 \\
Pork chops & $\mathrm{kg}$ & 21.72 & 8.84 & 146
\end{tabular}

Source: Organic Agriculture Centre of Canada, 2004. 
in the world. However, this estimate included specially cultivated agricultural products (using fewer pesticides) in addition to organic products. In 2001, the Government introduced regulations on organic farming, which allow only products certified by a Government accredited organization to be marketed as organic. Thus many products previously marketed as organic lost this status so that estimates of the organic market shrunk to a fraction of its previous $\operatorname{size}^{22}$ (Sahota, 2005).

Consumer demand for organic products is on the rise, fuelled by a number of food scares such as BSE and high dioxin levels. Major food retailers have introduced organic products and a number of specialized shops have opened in major cities. Obstacles to the sector's development include a general lack of awareness by consumers about organic food, a saturated overall food market, and reduced purchasing power of consumers due to economic recession. (IFOAM Japan, 2004). Domestic organic production is increasing, but still remains low (only 0.15 per cent of total domestic agricultural production in 2002). Therefore, imports play an important role. According to IFOAM Japan, "it is likely that the organic market will depend increasingly on imported organic foods" and the ratio of imported to domestically produced organic fresh crops was $2.5: 1$ in 2002. Import dependence is particularly high for fruit: 0.8 billion yen worth were produced domestically compared to 5.9 billion yen worth that were imported, principally bananas and kiwis (largely from the Philippines) and citrus fruit (mainly from the United States) (IFOAM Japan, 2004). Their average price premium has been estimated at 37 per cent. Certification requirements, language and cultural differences have been cited as major barriers to market entry (Organic Monitor, 2003).

\section{Organic markets in developing countries}

As mentioned above, developing countries account for only a very small share of the global sales of certified OA products. This is largely due to lower income levels, consumer unwillingness to pay price premiums, and a lack of consumer awareness of the benefits of organic products. Generally, between 90 and 100 per cent of certified organic products produced in developing countries are exported to developed-country markets. Nevertheless, although developing-country markets for certified OA products are quite small, they are growing. Moreover, there are growing markets for uncertified self-claimed organic and "naturally grown" products in many developing countries. Often sales are made within the local community and are based upon trust between the farmers and consumers, who may know each other personally.

Domestic markets for both certified and uncertified OA products are of great importance to developing-country organic producers. These markets serve as useful outlets for producers just starting out in organic production, in order to gain experience before going for certification. Market entry costs are low, and such markets are accessible to the smallest farmers, even those growing organic vegetables in their backyards in the city. These markets provide the economic foundation that allows production of a broader range of OA products, and can help farmers achieve economies of scale. Even where only one OA product is successfully exported, farmers can sell the other crops produced on the organic farm in domestic markets. Such farms are by their very nature based on inter-cropping and multi-cropping, as opposed to mono-cropping. Domestic markets also provide a fallback option when export opportunities become constrained due to international market fluctuations or changes in import market regulations or procedures.

In Latin America, Argentina and Brazil have the most developed domestic markets for certified OA products. In the 1990s, OA markets in larger Argentinean cities were growing, with sales through home delivery schemes, specialized stores and supermarkets. Yet even in Argentina, 90 per cent are exported, mainly to Europe and the United States. In Brazil, 45 per cent of domestic sales are through supermarkets, 26 per cent through fairs and 16 per cent through specialty shops (Lernoud and Piovano, 2004). The Brazilian Zona Sol supermarket chain has actively promoted organic products. Supermarkets in a number of other Latin American countries, including Costa Rica, Honduras, Nicaragua, Peru and Uruguay, are starting to offer organic products, particularly fruit and vegetables. Most countries of that continent have specialized natural or health food stores. 
These stores play an important role in raising consumer awareness of the health and environmental benefits of organic products, thus helping the organic market to grow. The most popular points of sale for organic products in Latin America are neighbourhood fairs or small informal markets, where local producers sell their goods usually on a weekly basis. Here farmers can get the full price for their products, without resorting to middlemen. Economically, these markets may be small but they are very important for smallholders. Examples include the weekly fairs in villages across Peru organized by the NGO, Red Agroecologica, which builds on the millennium-old tradition of local trade of the indigenous communities; the bi-weekly fair in Porto Alegre, Brazil, which gathers 300 producers; and the FAMA ecological market in Santo Domingo, the Dominican Republic (Lernoud, 2005).

In Asia, significant domestic markets are developing in China, Hong Kong (China), Malaysia, the Philippines, the Republic of South Korea, Singapore and Thailand. These generally offer a mixture of certified organic products alongside self-claimed organic, and are sold through a variety of channels such as supermarkets, organic bazaars, specialty shops, direct sales and Internet marketing. In China, the domestic market is growing rapidly; in 1999, virtually no certified organic products were sold, and today organic vegetables are available in supermarkets in Beijing and Shanghai, dozens of tea shops sell organic tea, and organic rice, fruit and honey are also available, all of which are certified by the Organic Food Development Center and other domestic certifiers. Prices of organic vegetables are generally one to three times higher than those of their conventional equivalents, and sales are good (Xiao, 2005, personal communication). ${ }^{23}$ Trade of organic products within the region is growing, although most are exported to the EU and Japan (Kung Wai, 2004). Some governments promote sales of food produced using fewer agro-chemicals, such as "green food" in China and "safety vegetables" in Viet Nam. While in general this is a positive development, some consumer confusion may result.

In Africa, domestic markets for certified OA products are developing in Egypt and South Africa. The pioneer of the organic movement in Egypt, Sekem, sells most of its certified OA products domestically, including herb teas, cotton and fruit and vegetables. In other African countries, markets for uncertified, naturally grown products are reported to be growing (Parrott and Kalibwani, 2005). The Kenyan domestic market, for example, is growing fast, with 10 retail outlets in Nairobi and others in main Kenyan towns selling self-claimed organic products. Sales are also increasing in Uganda via the National Organic Agricultural Movement of Uganda (NOGAMU) shop, box delivery schemes, local supermarkets and contracts with local schools. Organic products in greatest demand there include fresh vegetables, fruit, spices, fruit juices and concentrates, eggs, vegetable oils and shea nut butter (Taylor et al., 2005). In Tunisia, the initial results of a new domestic market promotion initiative facilitating linkages between organic vegetable and fruit farmers and five supermarket chains are promising (see commentary by Maamer Belkhiria and Ben Kheder in this TER).

\section{Market access and entry requirements}

Although there has been some discussion ${ }^{24}$ on facilitating market access of developing-country exports of OA products, currently OA products face the same market-access conditions as their conventional counterparts in terms of tariffs and quotas. As mentioned above, there is no separate international HS code for organic products or separate national lines in customs classifications.

Like other agricultural products, organic products must meet all sanitary and phytosanitary requirements in the importing countries, which may include mandatory maximum residue levels (MRLs), hazard analysis of critical control points (HACCP) and traceability. In addition to government regulatory requirements, it may be necessary to meet private voluntary standards in order to gain market shares. EurepGAP is a prime example. For more information on these requirements, see chapter 1 in this TER by Hoffmann and Rotherham. It should be noted that organic products stand a better chance of meeting many of these requirements, for example those related to traceability and MRLs of synthetic agro-chemicals. 
For a product to be exported and sold as organic in another market, it must be certified by a third party as having met the organic production standards enshrined in that country's organic regulations. These third-party certifying bodies must in turn have been either approved (in the case of the EU) or accredited (e.g. in the case of the United States) by the relevant government authority. Some buyers may also require that the certifying body be IFOAM-accredited ${ }^{25}$ In addition, all relevant administrative and import procedures in the organic regulations must be followed. Moreover, in many markets, the concept of "organic" is strongly tied in consumers' minds to a particular label or mark. This mark is a sort of branding in the marketplace, and may ultimately play a stronger role in influencing market entry than any regulations. Many of these certification marks, particularly in Europe, are tied to private organic standards that meet the requirements in official organic regulations but also add additional requirements (as illustrated above in the case of the Bio Suisse mark). In order to sell products in a certain market, it is usually necessary to produce to the standard of and be certified by the particular certifying body or bodies whose labels have consumer confidence and recognition in that market. This branding effect seems to be stronger in many national European markets than in the United States, where more than 45 domestic certification bodies certify to a single USDA standard and the USDA organic logo is gaining increasing consumer recognition.

\section{Regulations governing imports of organic products in major markets: European Union, the United States, Japan and Switzerland ${ }^{26}$}

For the countries that import the bulk of developing-country OA products, facilitated market entry can be attained through governments or other channels. The following is an overview of the regulations governing organic imports in the EU, the United States, Japan and Switzerland. Canada, another major organic market, is currently in the process of developing national organic regulations. At present, two of its provinces - Quebec and British Colombia - have provincial regulations.

\section{European Union}

EEC Regulation No. 2092/91 governs imports of organic products into the EU from non-EU countries. There are three mechanisms for meeting the requirements of the regulation:

1. Getting on the third-country list (Article 11.1)

2. Member State authorization of products/importer derogation (Article 11.6)

3. Commission approval of inspection bodies in a third country (Article 11.7) ${ }^{27}$

Under Article 11.1, a country's government can request to be put on the EU's third-country list. ${ }^{28} \mathrm{EU}$ authorities will then carry out an evaluation to determine whether the country's organic standards and conformity assessment systems are equivalent to those of the EU. The evaluation involves physical visits by experts. Currently there are six countries on the list, only two of which are developing countries. ${ }^{29}$ Costa Rica is the only developing country to have recently been included in the list, although others such as the Dominican Republic, Guatemala, Honduras and India are in the process of applying. ${ }^{30}$

When the EU regulation was drafted, it was intended that Article 11.1 be the main avenue for entry of imported organic products. However, the evaluations to determine equivalency have proven to be rather time-consuming and complicated. Consequently, most organic products from non-EU countries enter the EU under Article 11.6, whereby member States can issue authorizations to importers wishing to import organic products from non-EU countries. The importer must submit documentation proving that the imported product was produced to organic standards equivalent to those of the EU regulation; was inspected and certified in a manner equivalent to the EU requirements; and was certified by an inspection body that operates in compliance with ISO 65 or the EU equivalent, EN45011. As 90 per cent of the organic imports to the EU are imported according to Article 11.6, organic producers or exporters in developing countries are highly dependent on es- 
tablished importers in the EU. Moreover, as Article 11.6 is applied differently in different member States, and is also due to expire, it has created uncertainty among developing-country producers/ exporters and their importing partners in the EU (Kommerskollegium, 2003).

In addition, Commission Regulation 1788/2001 (which entered into force in November 2002) tightened these rules by requiring that an original certificate of inspection for each consignment be submitted to and endorsed by the designated authority at the port of entry of the member State. This makes export to the EU of organic products, particularly perishables, more difficult.

The importer derogation, which was originally intended to be a temporary solution, has recently been extended until the end of 2006. At that time, it is expected to be replaced by a new permanent system. On 21 December 2005, the European Commission adopted a proposal for a new OA regulation aimed at clarifying and simplifying EU rules and regulations and enhancing flexibility to take account of regional differences in climate and conditions. Organic imports can come from countries whose production standards and conformity assessment systems are deemed equivalent to those of the EU or in accordance with Codex Alimentarius guidelines. Direct recognition of certification bodies in third countries is another new element. The proposal also aims to promote the use of the EU logo and reduce general claims by private bodies of having OA standards that are better or "more organic" than the EU rules. An initial analysis indicates that these changes should be quite favourable for developing-country producers and exporters of organic products. The proposal will now go through the normal consultative process, culminating in a EU Council decision, probably by the end of 2006. (Commission of the European Communities, 2005).

The United States

The United States National Organic Program (NOP) came into effect in October 2002. It establishes national standards for organic production and handling, a national accreditation programme run by the USDA's Agricultural Marketing Service, labelling requirements and organic imports. Imports labelled "organic" must be produced, certified and labelled in accordance with the NOP rules. Certifiers must be accredited or approved by the USDA. For foreign certifiers, there are three ways of achieving this:

- Direct accreditation by the USDA;

- Accreditation by a foreign government upon request of that government; and

- Equivalency agreement between the United States Government and a foreign government.

Most United States organic imports enter the market via the first option. Certifiers, both domestic and foreign, apply directly to the USDA for accreditation to enable them to certify to the NOP production standard. This accreditation covers the certifier's operations worldwide. All accredited certifiers are to be treated equally, regardless of whether they are based in the United States or abroad. USDA-accredited certifiers are required to accept the certification decisions made by all other USDA-accredited certifiers. ${ }^{31}$ As of 20 December 2005, there were 95 USDAaccredited certifying agents, of which 54 were based in the United States and 41 were foreignbased. Of these 41, 10 were based in developing countries, ${ }^{32}$ all in Latin America (USDA, 2005b). This option is advantageous for developing-country producers, since their domestic certifiers can be treated in the same manner as certifiers based in the United States. On the other hand, it requires producers everywhere to comply with United States organic production standards, which may or may not be suitable to the local climatic and socioeconomic conditions.

Under the second option, the USDA can accept the accreditation of a foreign certifying body by a foreign government upon request of that government. The foreign government would need to have a programme to accredit a certifying body to the NOP standard, and the USDA would need to determine that its conformity assessment system meets the requirements of the NOP. The certifying bodies would then be "approved", but not directly accredited, by the USDA. As of mid-2005, the USDA had recognized the conformity assessment systems of five foreign national or provin- 
cial governments: Denmark, New Zealand, the United Kingdom and the Canadian Provinces of British Colombia and Quebec (Bowen, 2005). These governments can thus accredit certification bodies in their territories to certify to the NOP standard.

Under the third option, a foreign government may negotiate an equivalency agreement with the United States Government. However, to date, no country or regional bloc has done this, although the EU and the United States are currently in the process of trying to negotiate one. Certifiers accredited by a foreign government with whom an equivalency agreement was in effect would also be "approved" - not "accredited" - by the USDA.

In the United States, all certified organic products, whether produced domestically or abroad, are eligible, although not required to bear the USDA organic label. Private certifiers may also fix their labels alongside the USDA label, as long as the USDA label is larger in size. Claims by private certifiers of having organic standards that are "higher" or more rigorous than those of the NOP are not allowed. Thus the NOP sets a ceiling as well as a floor on organic standards. This eliminates competition based on the "my standard is better than your standard" argument. This will tend to be advantageous to developing-country exporters, as meeting one production standard can get them access to the entire United States market.

\section{Japan}

In Japan, the term "organic" was given legal definition as part of the Law Concerning the Standardization and Proper Labelling of Agricultural and Forestry Products, which was adopted in 2000 and came into force in 2001. This law requires all foods (both domestically produced and imported) labelled as organic to carry the Japan Agricultural Standard (JAS) mark. Organic products must be certified by a certification/inspection organization that has been registered with the Japanese Ministry of Agriculture, Forestry and Fisheries (MAFF). These certification bodies may be based in Japan or in foreign countries whose standards and conformity assessment systems have been deemed by MAFF to be equivalent to those of Japan. Currently these include Australia, the 15 countries of the EU, Switzerland and the United States.

As of May 2005, there were 71 Japanese and 24 foreign certifying bodies registered with MAFF. The foreign certifiers may operate in third countries where they had been providing certification services at the time of their application to MAFF, but not in Japan. Registered certification organizations may delegate inspection to a certifying body in a third country with whom it has a "trust contract of providing inspection data", provided that the latter is recognized as a certifying body by that country's government or by a reliable international organization, such as ISO or IFOAM, and that it has considerable experience in certifying organic products.

A revision to the law was passed by the Japanese parliament in June 2005 and is expected to come into force in March 2006. Under the revised law, the country equivalency requirement for foreign certification bodies will be abolished; certification bodies in any country may apply for registration with MAFF. This improves developing-country export prospects. Another change under the revised law is that registered certification bodies must meet the criteria defined in ISO/IEC Guide 65 and not be under the control of the organic operators they certify. In addition to the above, organic food products certified in a country whose organic standards and conformity assessment system have been deemed to be equivalent to the JAS system can be exported with the relevant government certificate and be marketed as organic by a JAS-certified importer in Japan (Matsumoto, 2005, personal communication; MAFF, 2005; Commins and Kung Wai, 2003; JONA, 2005).

\section{Switzerland}

The Swiss Organic Farming Ordinance, which came into force in 1998, is modelled on the EU organic regulation; however it is stricter in some ways, including the requirement that the whole 
farm be under organic management, but less strict in others, such as requiring a two-year conversion period instead of the EU's requirement of three years. Switzerland and the EU have a bilateral agricultural agreement that recognizes their organic regulations as equivalent. Thus a product certified as organic in accordance with the EU regulation can be imported from the EU into Switzerland without additional certification. This applies also to products from third countries. However, it should be noted that the private labelling schemes in Switzerland, notably the market dominating Bio Suisse, impose additional requirements.

The Swiss system is analogous to that of the EU in that it maintains a country list of those countries whose governments impose conditions on organic products deemed equivalent to those in force in Switzerland. Currently this list includes all EU member States, Argentina, Australia, Costa Rica and New Zealand. For imports from countries not on this list, importers in Switzerland must apply for an individual authorization and provide an attestation of equivalence. An import certificate must accompany each shipment. While there are no import quotas for organic products per se, Switzerland has import quotas for fruit and vegetables that are set according to the seasonal availability of Swiss products (Kilcher et al., 2004).

\section{E. Challenges related to the production and export of developing-country OA products}

This section highlights a number of challenges that developing-country producers and exporters of organic agriculture must overcome in order to reap the benefits outlined above.

Developing country producers and exporters of OA products face many challenges in common with producers and exporters of conventional and traditional agricultural products. These include difficulties in getting the products to market due to production in remote locations with poor transport infrastructure; dependence on middlemen for marketing and access to retail outlets, with associated lower farm-gate prices; lack of access to credit, often necessitating resort to loan sharks and the payment of usurious interest rates; and lack of quality inputs and knowledge. Also, as described above, agricultural products must meet a range of market access and entry requirements (public and private) in the importing countries.

Another general problem for developing-country exporters of agricultural products that compete with domestically produced products in import markets is the sizeable agricultural support provided by many developed countries to domestic producers, which reduces the competitiveness of developing-country agricultural producers ${ }^{33}$. The secretariat of the Organisation for Economic Co-operation and Development (OECD) estimates that direct budgetary payments to producers accounted for 32 per cent of OECD gross farm receipts in 2003. Total agricultural support in OECD countries in that year amounted to $\$ 350$ billion - nearly $\$ 1$ billion a day (OECD, 2004). This amount is nearly 60 per cent more than the combined GDP of all 50 of the least developed countries (LDCs). ${ }^{34}$

In addition to the above, governments in many developed countries, particularly in Europe, have a variety of policies designed to increase the amount of land that is organically farmed. The rationale behind these policies in Europe is that organic farming provides a number of environmental benefits to society and that these are not taken into account in private production decisions. Organic farming is thus a public good. Providing government support to organic farming would bring farmers' private costs and benefits more in line with full social costs and benefits.

European programmes include green payments (i.e. subsidies), demand-side policies and national targets for land under organic management. Under the EU's agri-environment programme, farmers enter into a contract with their national government under which they commit for a period of time (usually five years) to specific environmentally preferable farming practices, such as organic agriculture, in return for payment. According to Häring et al.,

"In 2001, almost 500 million euros were spent on organic lands under the two measures 
(2078/92 and 1257/99), with organic farms averaging payments of 183-186 euros per hectare compared with 89 euros per hectare for conventional farms...The share of organic land supported by agri-environmental policies ranges from 33 and 37 per cent in France and Italy to almost 93 and 94 per cent in Finland and Denmark. ...Sweden's 113 percent has more policy-supported organic land than certified area, reflecting Sweden's policy of supporting uncertified organically managed lands." (Häring et al. (2004) cited in Dimitri and Oberholtzer, 2005).

EU governments set targets for land under organic management to demonstrate their commitment to the sector's growth. There is considerable variability across member States. Germany's goal of 20 per cent by 2010 may be difficult to reach, given that only just over 4 per cent of farmland was organic in the year 2003. Belgium, Denmark, Finland, France, Ireland, the Netherlands, Sweden and Wales (in the United Kingdom) have also set targets, ranging from 3 per cent by 2005 in France to 20 per cent by 2005 in Sweden. Austria, Greece, Italy, Luxembourg, Portugal, Spain and the United Kingdom, have not set national policy targets (Dimitri and Oberholtzer, 2005). The impact of the changes in the European Common Agricultural Policy - CAP Reform 2003 - which include, for example, a shift to single farm payments independent of the production level, is still unknown, but some believe that the changes will favour the expansion of organic farming (Häring et al., 2004, in Dimitri and Oberholtzer, 2005).

Another way in which developed-country governments support organic farming is through publicly funded research. In Europe, this amounts to some 70-80 million euros each year. Again, there is considerable variability across countries, with Denmark, the Netherlands and Switzerland providing over 60 per cent of all such spending in Europe (Niggli, 2005 in Dimitri and Oberholtzer, 2005). In the United States, publicly funded research accounts for the lion's share (at least two thirds) of the estimated $\$ 7$ million that the Government spends exclusively in support of organic agriculture (Dimitri and Oberholtzer, 2005).

The subsection below outlines a number of challenges that are particular to the production and export of developing country OA products.

\section{Challenges related to organic production}

In most developing countries, OA has generally developed outside the realm of public support. ${ }^{35}$ Many developing-country governments have been hesitant to embrace OA due to a lack of awareness of its potential benefits, concerns about organic agricultural productivity and food security, or perceptions that organic regulations and standards in developed-country markets may act as protectionist barriers to trade. Currently, many developing countries have government policies that are relatively disadvantageous for OA, though this is often an unintended side-effect: for example, the provision of heavily subsidized pesticides aims to support conventional agriculture but also makes OA relatively less competitive. Developing-country governments frequently pay little attention to the organic sector, and only a few have embarked on real OA policy development. This latter group includes, for example, Costa Rica, India and Tunisia. ${ }^{36}$

The conversion period (i.e. the first couple of years after switching to organic production) is often the most difficult for farmers, due to the many adjustments and changes to be made. Sometimes, agricultural yields may temporarily decrease if the farmer had been previously relying heavily on agro-chemicals. During the conversion period, farmers cannot benefit from the price premiums associated with certified OA products. Poor farmers do not have ample reserves to see them through a season or two of lower profitability.

A shift towards OA requires considerable investment in human capital in terms of knowledge and know-how of organic techniques that work well in that environment. Farmers need to be trained and informed, and this is perhaps one of the greatest impediments to growth of the OA 
sector. Training is labour-intensive, particularly when the target audience lives in remote places. On-farm demonstrations of OA techniques are especially needed in areas where illiteracy rates are high. Agricultural extension services in many developing countries are poorly funded, and staff seldom have training in organic production techniques. In many cases, most of the resource materials made available to them are provided by the agro-chemical industry. Extension workers are often trained to convey simple messages, such as what pesticide to use, and with little respect for traditional farming systems or knowledge about organic methods.

Public funds for agricultural research and development (R\&D) in developing countries have in general been falling for several decades, and $R \& D$ in $O A$ continues to receive a very small share of that already limited amount. Private sector agricultural R\&D helps fill the gap to a certain extent, although globally these funds are mainly directed towards conventional production in highincome countries. This lack of funds for R\&D in OA could potentially slow down relative productivity growth in the organic sector in general, and in developing countries in particular. In addition, in certain cases it may be difficult to find the needed organic inputs, such as sufficient organic composting materials, bio-pesticides, bio-fertilizers and high quality seeds.

While developing countries may have a natural comparative advantage in OA due to relatively abundant labour, an increasing number of cases have been observed where labour shortages have become a barrier to organic agriculture. Examples include female-headed and child-headed households. Furthermore, poorer segments of rural societies tend to gain much of their livelihood from off-farm employment, which occupies labour time and confronts farmers with new trade-offs (Hauser, 2005, personal communication).

Lack of secure land tenure has been cited as an obstacle to organic farming in a number of countries. Organic farming involves investing considerable effort to build up soil fertility. Farmers must feel secure that they will be able to reap the benefits of those efforts in the future. In some cases, women are doing much of the farming but are not allowed to own land. In other cases, for example in several countries in Africa, arable land may be owned at the community level and individual plots rotated among farmers on a regular schedule, which means that just when a farmer has built up his/her soil fertility it is time to change plots. This acts as a disincentive to "go organic" (Tesfai, 2005, personal communication).

\section{Challenges related to organic exports}

\section{Certification costs}

Third-party certification by a body accredited or approved by the government and recognized by the consumer in the target market is necessary for organic exports. This usually means that developing-country products are being certified by foreign certifiers that often have their headquarters in the target market. This can be quite costly for developing-country producers, particularly when the inspectors must fly in to carry out the annual inspection. In low-income countries, and particularly for smallholders, certification costs can entail a disproportionately high financial burden. The actual cost varies, as different certifying bodies use different pricing schemes. Some foreign certifiers employ local inspectors or make arrangements with local certifying bodies to carry out the actual inspections, which can lower costs. The certification decision itself, however, is usually still made by the foreign certifier.

Wynen (2005) gathered information on the cost in several countries of certification for export. In Mexico, for example, charges are approximately $\$ 320$ per day for initial administrative work and inspection by Certimex, a local certifying body, requiring around two days. These costs are 50 
to 60 per cent higher than the costs of certifying for the domestic market. In China, foreign certifiers charge approximately $\$ 500$ per day and a typical inspection takes 1-4 days. In South Africa, the foreign certifier, ECOCERT, charges farmers approximately $\$ 1,200$ per farm per year. Part II of this chapter by Vossenaar and Angel shows comparable rates in Central America.

In some cases, whole groups of smallholding farmers in the same area producing the same product can be certified as a group. Group certification generally relies on internal control systems (ICS) whereby the community self-manages and self-monitors, and the third-party certifier verifies that the ICS is functioning properly. Thus, as the inspections are done within the group itself, it is no longer necessary for the third-party certifier to conduct annual inspections of every small farm. This can greatly reduce the cost per farm.

According to Wynen (2005), in Uganda, for example, a farmers' group of 1,600 cocoa farmers was certified at a cost of $\$ 12,000$ per year $(\$ 7.50$ per farmer $)$ and a group of 2,000 coffee farmers paid $\$ 8,000$ ( $\$ 4$ per farmer). Wynen points out, however, that this can still represent a high cost for these farmers who may have small fields (less than an acre) with perhaps $80 \mathrm{kgs}$ of product per field. ${ }^{37}$ Indeed, certification in these cases was only possible because the exporter was able to provide the funds for the certification (Taylor, 2005, personal communication).

Certification costs rise significantly when multiple certifications are needed, as discussed further in the section on harmonization below.

\section{Marketing-related constraints}

Timely and accurate market information on organic markets is generally very hard to obtain, particularly in developing countries. Producers may not know which products are most in demand in which markets, and where imports from developing countries could fill demand-supply gaps. While demand for most, if not all, organic products is on the rise in major markets, occasionally situations of oversupply may occur for particular products. This happened recently with organic milk in Denmark, where growth of the mature market (more than one third of milk sales were organic) slowed down in 2002 giving rise to a short-term oversupply (Organic Monitor, 2002). Markets for individual organic products are also fairly small. This increases the probability of temporary market saturation. Some of these markets are fairly cartelized, leading to suboptimal solutions from the producers' point of view. Moreover, marketing chains are complicated and involve more paperwork than for conventional products. Serious delays in getting import permits for the EU have been reported. As a result of all of these factors, some certified organic products from developing countries might end up being sold as conventional, as recently happened for organic tea from India and sesame from Uganda.

\section{Logistics}

Certified OA products for export often have specific logistical requirements for handling and transport. For example, they must generally be stored and transported separately from conventional products, which entails higher logistical costs. Moreover, not all transport companies have such facilities. Processing facilities for organic products are generally limited in developing countries. This implies that the developing-country OA product range tends to be concentrated at the lower end of the value chain. Often they end up supplying inputs for processing in developed countries, thus forgoing more lucrative opportunities further up the value chain.

\section{Consumer preferences for locally produced food}

While consumer preferences are fuelling overall growth for organic products in major markets, prospects for developing-country products are somewhat dimmed by consumer preferences for 
locally produced organic food. This preference is driven by several factors, including the desire for very fresh food, the wish to support local farmers and a lack of trust in organic guarantee systems in faraway places. It is also tied into concerns about "food miles" (i.e. the number of miles food travels to reach the consumer's plate and the environmental damage caused by this transportation). The food miles campaign seems to be particularly strong in the United Kingdom, which has one of the highest shares of imported products (estimated at between 56 and 65 per cent) in its organic market.

Certain organic labels, particularly those in Europe, implicitly favour locally (including nationally and regionally) produced food. Kilcher et al. (2004) note, for example, that Bio Suisse, the main private organic label in Switzerland, will not put its label on any products that have been transported by air; the main French label, AB, owned by the Government, can only be used on OA products produced in the EU with the exception of certain listed exotic products that cannot be grown in the EU. Even the EU organic logo was originally allowed only on products produced in the EU, although a recent legal interpretation reversed that practice. ${ }^{38}$ It is difficult to sort out cause and effect regarding these preferences. Owners of such labels claim that their consumers want locally produced foods, but these consumers are often influenced by information provided by the local and national organic industry, which of course has an interest in promoting its own products. Retailers also play an important role: a few have adopted "buy local" policies for organic products as a marketing tool..$^{39}$ Whatever the ultimate cause, it is clear that such preferences and requirements will hinder developing-country exports.

Wynen and Vanzetti (2002) have examined the food miles argument from a quantitative perspective. They found that the pollution and other externalities (e.g. noise and accidents) caused by sea and rail transport are minimal. For road transport, these costs were much higher, but most of the costs are incurred in moving trucks in and out of cities, not between them, and thus would apply for locally produced products in the same measure as those produced further away. They also note that many organic products may be produced in a more efficient manner (i.e. using less energy and natural resources) in distant locations. They find that "total resource use for the production and transport of a good can be lower when transported internationally than produced and consumed locally". They conclude, "consumers should bear in mind that, where locally-produced goods use more resources to be produced, global environmental benefits may be foregone." Interestingly, some websites that strongly promote buying local food also advise consumers to buy fair trade products. ${ }^{40}$ Coupling organic agriculture with fair trade labels might be one way to overcome concerns about food miles.

\section{Lack of harmonization, equivalence and mutual recognition}

Discussions in a number of forums including UNCTAD, FAO and IFOAM, have indicated that the plethora of certification requirements and regulations is considered to be a major, if not the key, obstacle to a continuous and rapid development of the organic sector, especially for producers in developing countries. The organic market is confronted with hundreds of private sector standards and government regulations, two international standards for organic agriculture (of the Codex Alimentarius Commission and IFOAM) and a host of conformity assessment and accreditation systems. Mutual recognition and equivalency among these systems is extremely limited, with lack of cooperation and "harmony" being a central problem.

To service their clientele, certifying bodies must often obtain a number of costly accreditations. Producers interested in selling in more than one market (or sometimes even in two different stores on the same street!) have to bear the high costs of multiple certifications. In most markets, it is not enough to simply conform to government regulations; producers must also meet the specific requirements of the private organic standard whose associated label is used by a particular retailer or recognized by consumers in that market. For developing-country producers and exporters, this exercise is even more costly, as they are required to use foreign inspectors to carry out the certifi- 
cation. There are certainly many farmers around the world who would be interested in producing certified organic products, but are deterred by such complicated and costly certification procedures. $^{41}$

This confusing situation is likely to become increasingly complicated in coming years as more and more governments develop their own varieties of organic regulations. As of October 2003, 60 countries were at some stage of regulating the organic sector, of which 37 had fully implemented regulations. Table 10 provides a summary of organic regulations by region and status in 2003 . Among developing countries, those with fully implemented regulations included Argentina, Costa Rica, India, the Philippines, the Republic of Korea, Thailand and Tunisia. Those with finalized but not fully implemented regulations included Brazil, Chile, Guatemala, Egypt, Malaysia and Mexico. Those in the process of drafting regulations included China, Indonesia, Lebanon, Madagascar, Nicaragua, Peru, Saint Lucia, and South Africa (Commins, 2005). In the past two years, this situation has changed. For example China's organic regulation is now in place (see Xiao's commentary in this TER) and there have been developments in Central America (see part II of this chapter). However, an update of this table is not currently available.

The hundreds of different standards and regulations have much in common. But the devil is in the details; for example differences exist in specific conversion periods, packaging, storage and transport requirements, or lists of permitted substances for fertilization, disease control or food processing. To some extent these differences are necessary as they reflect underlying ecological and socioeconomic differences. However, many appear to be arbitrary.

The existence of so many different standards in the world will put pressure on export-oriented countries with emerging organic regulations to adopt the most restrictive elements of the standards and regulations in their targeted export markets. While this strategy could help gain market access and so boost organic exports, these standards may not be particularly well-suited to the local situation. When organic production in Europe and North America was in a similar early stage of development, their standards were less restrictive than they are now. Some question whether organic production would have expanded so rapidly there if farmers then had to meet today's standards.

Although consumer preferences are often cited as the reason for differing requirements, most consumers do not benefit from the current situation. First, it is they who ultimately bear the costs of multiple certifications. Second, inevitably they have less of a variety of organic products to choose from and consume. Third, there is considerable consumer confusion over the many different labels in the market. It is a reasonable assumption that the vast majority of consumers of organic products are not really aware of or particularly sensitive to the differences in the details of the various standards and regulations. Consumer surveys have indicated that they simply wish to

Table 10. Overview of status of OA regulations by region (as of October 2003)

\begin{tabular}{lccc} 
Region & Fully implemented & $\begin{array}{c}\text { Finalized but } \\
\text { not implemented }\end{array}$ & Drafting stage \\
\hline Europe & 26 & 2 & 4 \\
Asia and the Pacific & 7 & 1 & 3 \\
Americas and the Caribbean & 3 & 4 & 4 \\
Africa & 1 & 1 & 2 \\
Middle East & - & - & 2 \\
Total: 60 & 37 & 8 & 15
\end{tabular}

Source: Commins, 2005 
buy products that are free of harmful agro-chemicals, tastier, produced in a manner that is less harmful to the environment and that are not genetically modified. In short, besides hampering international trade, the lack of harmonization and equivalence of standards could also be stifling consumption of organic products, thus jeopardizing the high growth of recent years.

Table 11. Effects of harmonization of organic agriculture

Without harmonization

Exporting countries

Administration:

- Domestic market: set own standards

- Export: keeping up with a multitude

Setting and updating

national/regional standards

of standards

Certify according to a multitude

of standards

Extra training of inspectors/

officers

Many layers of accreditation

Production:

Use of foreign standards

Marketing:

Need for investments and operation of different storage facilities

Delay in marketing due to

required paperwork

Possibly high dependence on

importer (e.g. for many exporters

to EU)

Unequal treatment of exporters

(e.g. exporters on EU third-country

list compared with those not on list)

\section{Importing countries}

No need for consensus on

practicalities of equivalence

More paperwork on

import certificates

Some protection of local producers

Consumers: limited choice of products and relatively high price

With harmonization
Certify to one set of standards

Training of certification personnel

Some accreditation

Use of standards appropriate to local conditions

Need for investments and operation of one storage facility

Less delay in marketing

Less dependence on importer

Increased competition

Need for consensus on what is equivalence

Less paperwork on import certificates

Less protection of local producers

Increased trade, product diversity and lower product prices

Effect of harmonization

Lower costs due to less work, and fewer conflicts and administrative errors

Less paper work, travel, required skills

Less training of certification evaluation personnel

Less numbers of accreditation needed

No loss of production and fewer costs resulting from elimination of inappropriate standards

Less storage needed

Less delay in marketing, as less paperwork needed

More flexibility in choice of importer

More equal treat ment

More meetings

Less paperwork, lower costs of certification, lower consumer prices for organic products Increased free trade (WTO- consistent)

Consumers: increased trade, product diversity and even lower product prices

Source: Reproduced from Wynen, 2005. 
In a study prepared for the UNCTAD/FAO/IFOAM International Task Force on Harmonization and Equivalence in Organic Agriculture, Wynen (2005) analysed the impact of harmonization on factors related to administration, production, marketing and importing. An overview of this analysis is given in table 11. The table shows that a lack of harmonization (i.e. the current situation) generates additional costs in many areas. Harmonization would yield a wide range of benefits and cost savings. The main additional cost would be the time involved in reaching consensus on the practicalities of equivalence.

One point in table 11 that merits further elaboration is the general problem that organic standards in the importing countries may not be ecologically or socially appropriate for production in developing countries seeking to export to those markets. Environmental conditions in the tropics or the desert are quite different from those in the North. In addition, most of the rural population in developing countries comprises poor smallholding farmers, unlike in most developed countries.

Wynen (2005) provides a number of specific examples of the above. First, the EU requirement to use organic seeds is very difficult for many developing-country producers. The organic seed market in many countries is in its seminal stages; such seeds often either cannot be found or are only available at exorbitant prices. In South Africa, for example, it was reported that the cost of organic seeds for salad products was 35 times that of conventional seeds. Second, the use of peat, which is prohibited by a private European certifier based on environmental conditions in the United Kingdom, is not considered to be an environmental concern in South Africa. Third, the EU stipulation for a maximum use level of $170 \mathrm{~kg}$ of nitrogen per hectare per year for organic products was based on European conditions where pollution with nitrogen is a problem. But in many developing countries, soils lack nitrogen and cultivation under such a restriction would be impossible. This would be true, for example, for vegetable production in desert land in Egypt. Some foreign organic requirements would actually contravene national law. For example, complying with a foreign certifier's requirement not to use chlorinated water in packing houses would be considered an illegal action in South Africa where this is required under national regulations. This incompatibility makes it virtually impossible for South Africa to export fresh vegetables to the market concerned.

Wynen (2005) also notes the cumulative effects of these factors and fears that exporters may not be willing to get involved in organic trade as it could be perceived as too risky. This would leave producers in developing countries without buyers of their certified organic products, as domestic markets remain modest. She also notes that newcomers to organic production find it more difficult to comply with today's stricter requirements compared to those who entered this market 10 years ago. The stricter and many different requirements are also likely to deter the development of domestic certifying bodies.

The current situation leads to economically suboptimal outcomes. The multitude of regulations and private labelling schemes serve to increase market entry costs, particularly for foreign producers, and they segment markets. As a result, certain actors gain semi-monopolistic positions, and benefits are shifted away from consumers and export-oriented producers towards domestic producers producing only for the domestic market. Multiple layers of regulations and standards may therefore act as technical barriers to trade.

\section{3. $\mathrm{OA}$ and the least developed countries}

For LDCs, OA offers particular opportunities and challenges. Many of the poor in the LDCs live in rural areas, and are often smallholders carrying out subsistence farming of traditional food crops as opposed to the export of cash crops. For LDCs with a high population density, small plots tend to be ever more intensively cultivated. Food security, rural poverty and rural underemployment are often major issues. 
Many LDCs are located in sub-Saharan Africa (SSA) which is home to more than 60 million smallholder farmers. Food productivity growth in this region has been very low in the past few decades. According to the World Bank, among others, "it is increasingly recognised that declining soil fertility is at the root of stagnant agricultural productivity and increasing food insecurity and hunger in large parts of SSA" (Heerink, 2005). As a result of soil degradation in SSA, productivity levels of irrigated lands are around 7 per cent, rain-fed 14 per cent and rangelands 45 per cent below their potential (World Bank, 1998). Building up soil fertility is a main pillar of OA, and thus a direct response to the problem of soil degradation.

Many smallholder farmers in LDCs cannot afford to purchase external inputs such as agrochemicals. Some may already be de facto practicing OA, although most would be able to increase their productivity through greater application of organic techniques. The low level of agro-chemical use, combined with rich bodies of traditional agricultural knowledge, can be a source of comparative advantage for these countries. ${ }^{42}$

At least 20 LDCs produce and export certified OA products (Kortbech-Olesen, 2002, personal communication). However, most OA products in LDCs fall into the uncertified OA category. Certification poses a real challenge to many LDC OA producers. It is relatively costly and cumbersome, particularly for illiterate smallholders, and domestic markets for certified OA products in LDCs are virtually non-existent. Thus price premiums will only be obtained through export, which means that group certification is needed. Often, one or more NGOs or international agencies provide concerted assistance for export, including partially or wholly covering the costs of certification, at least initially. For example, the Export Promotion of Organic Products from Africa (EPOPA) programme, funded by the Swedish International Development Cooperation Agency, has enabled smallholders in Uganda and the United Republic of Tanzania to successfully export OA products. ${ }^{43}$

Access to good, up-to-date information on OA techniques and markets is also particularly difficult in LDCs, compounded by widespread illiteracy. ${ }^{44}$ Moreover, Internet access is limited. As mentioned above, OA is knowledge-intensive as opposed to external-input-intensive. In addition, the poor infrastructure in LDCs, such as inferior roads and other transport facilities, results in high transportation costs, thereby adversely affecting organic and other agricultural exports. Post-harvest losses are also quite high. Added to this is the lack of good facilities for standards, testing and quality control, which further hinders agricultural exports in general (Dao, 2004).

\section{F. Seeking solutions}

Sections C and D above highlighted the many different trade and sustainable development opportunities that OA production and export may offer developing-country agricultural producers and exporters. Section E outlined a number of challenges related to the production and export of OA products. This section recommends a number of actions at national and international levels that could help interested developing countries overcome these challenges and thus reap the potential benefits. It builds on recommendations made in the course of a number of UNCTAD activities over the past five years. ${ }^{45}$

\section{Recommendations at national level}

\section{Recommendations to governments}

There are a number of ways in which developing-country governments can promote the production of OA:

They can examine the current state of the national organic sector, with a view to identifying the main barriers and bottlenecks for the continued growth of OA production and export. This would 
include an assessment of the ways in which current government policies and programmes affect the OA sector relative to conventional agriculture. Relevant policy areas could include agriculture, trade and finance (including credit provision, taxation and land tenure). The emphasis could be on identifying those elements that are directly or indirectly hampering the development of the sector or favouring production by conventional means over organic production.

This national assessment exercise should be based upon dialogue with the various stakeholders, particularly the organic producers and exporters, at the national level, to identify what they perceive to be the main obstacles to further development of the sector (both production and export), as well as their aspirations and the specific ways in which they believe that the government could help.

The assessment should also examine issues such as the ways in which land tenure laws and community practices may affect prospects for OA. Without secure land tenure, farmers will have less of an incentive to make the investments needed to improve soil fertility or endure the two-year conversion period. As mentioned above, women can be particularly affected because in many countries they do the farming but are not entitled to own the land.

A national OA action plan could be designed that responds to the key needs identified in the assessment and multi-stakeholder dialogues. This might include an emphasis on development of OA production, domestic and overseas markets, extension services and research as a starting point. In situations where the organic sector is fairly well developed, it might be timely to put in place an organic regulation that is suited to local production conditions but also allows exports to key external markets. Such a standard should be based on or make reference to an accepted OA international standard. Another element of a regulation could be a programme for supervision of organic certification bodies operating within the country. However, governments should carefully consider if they have the capacity for providing this oversight at a level that could gain international recognition.

The national OA action plan could also include government actions to support research on OA production and to address bottlenecks in the supply of OA production inputs or in transport and storage of OA products.

Governments can support the organic sector through micro-credit and micro-enterprise programmes, particularly during the conversion period. Beneficiaries could include not only smallholding farmers interested in producing organically, but also self-help groups of landless agricultural families, particularly women, for organic seed preparation, organic compost, bio-pesticides and bio-fertilizers. ${ }^{46}$ Supporting the latter set of activities could also help alleviate any OA production input bottlenecks identified during the assessment.

Most of the investments in learning and transitional conversion/adjustment costs occur in the farmers' first two to three years of OA. This is the time when special government support programmes can play a vital role, such as covering certification costs, facilitating access to credit and organizing special training programmes. Certification and investment costs of OA during the first few years (or longer for smallholders) could be written off from taxes.

Governments can act to mainstream OA in the agricultural education system, in universities and agricultural extension worker training programmes.

Actions should also take into account the gender dimension and the potential of OA for helping female farmers. For example, in most developing countries women usually have responsibility for tending home vegetable gardens. Governments could train female agricultural extension workers to speak to the community's women about organic horticulture cultivation.

Governments "can facilitate the emergence of farmers' associations by publicly acknowledging their value and supporting their formation." (IFAD, 2005) 
Education and R\&D in OA should build upon farmers' knowledge of traditional agricultural practices and plant and animal varieties. It should further promote synergies and interactions between this traditional knowledge and practices and "modern" OA techniques. Participatory research programmes, in partnership with farmers, are particularly valuable in this context.

Governments can support the development of domestic markets, for example through activities aimed at raising consumer awareness of the benefits of $\mathrm{OA}$, by convening regular organic product markets and through public purchasing of organic products for institutions such as hospitals and schools.

Governments can support their organic sector's efforts to move up the value chain into processed and semi-processed organic products.

Governments should also promote exports of organic products from their countries. This could involve assistance in identifying market opportunities, facilitating access to market information and helping organic producers to make contact with foreign buyers through normal trade promotion channels such as embassies abroad and participation in international trade fairs.

In countries with more developed organic production, governments could consider setting up a conformity assessment system for organic agricultural products. Having such a system is generally a prerequisite for facilitated market entry to developed-country markets. The costs of setting up such a system need to be weighed carefully against the benefits.

Governments should explore areas for regional cooperation including development of regional or subregional organic standards as well as an appropriate infrastructure for conformity assessment, storage and transport. Such cooperation could bring benefits in terms of economies of scale and a more stable supply of OA products.

\section{Other actors and factors contributing to success}

Community and village organization involvement and enthusiasm greatly enhance the chances of success. Local exchange of information and seeds between communities of farmers can be beneficial. Communities can also join forces to solve transport and water problems (for example through shared irrigation). Micro-credit/savings programmes can raise the small amounts of funds needed to purchase necessary improvements, such as irrigation pipes or farm tools.

Group certification is a good opportunity for smallholder developing-country farmers to benefit from the opportunities offered in the main OA markets. ${ }^{47}$ For this, well-managed internal control systems (ICS) are needed (please see box 1). The initial investment in setting up ICS can provide benefits for many years, and it is preferable to base them on existing community organizational structures. Participatory conformity assessment schemes should also be explored.

It is important for OA exporters from developing countries to develop good long-term relationships with one or more importers in the main markets. These partners can provide valuable information on market trends and fluctuations, and help navigate the continuously changing maze of agriculture-related regulations and requirements.

\section{Recommendations at the international level}

The international community can facilitate the production and export of organic products from developing countries in a number of ways.

\section{Facilitating market access and entry of OA products from developing countries}

The World Summit on Social Development called on governments to "support voluntary WTOcompatible market-based initiatives for the creation and expansion of domestic and international 
markets for environmentally friendly goods and services, including organic products, which maximize environmental and developmental benefits through, inter alia, capacity-building and technical assistance to developing countries." (United Nations, 2002).

Developed-country governments and other stakeholders can take a range of measures to facilitate sales in their countries of OA products from developing countries. These include:

- Implement transparent and easily understandable rules and procedures governing OA imports;

- Pursue harmonization, mutual recognition and equivalence in the organic guarantee system (see below);

\section{Box 1. Smallholder group certification based on internal control systems (ICS)}

During the period 2001 to 2003, IFOAM commissioned a series of workshops on smallholder group certification that brought together the relevant certification bodies, competent authorities and producer groups. The goal was to agree on one global harmonized set of requirements for ICS for smallholder groups and how ICS should be evaluated.

This process defined an ICS as "a documented quality assurance system that allows the external certification body to delegate the annual inspection of individual group members to an identified body/unit within the certified operator. As a consequence, the main task of the certification body is to evaluate the proper working of the ICS." The operator in this case is "the actor who signs the contract with the certification body and which is responsible for maintaining the ICS. The operator should have a legal form and structure. Main types of operators are co-operatives, farmers' associations or exporters that contract smallholder farmers." (Van Elzakker and Rieks, 2003)

Elements of an ICS must include:

- A documented description of the ICS;

- A documented management structure;

- One person responsible;

- An internal regulation (production standard, conversion rules, sanctions, etc.);

- Conversion rules i.e. traditional farming/virgin land/known field history;

- A contract between the group and the certification body;

- Identified internal inspectors;

- Training of personnel, internal inspector;

- Some form of formal commitment of growers;

- Field records, maps;

- Annual inspection protocols;

- A farm inspection report/form, filled in per farm;

- An approval committee that decides to enter the producer on the Growers List;

- Use of internal sanctions;

- Regularly updated Growers List;

- Use of risk assessment to address risks, threats to integrity;

- Use of social control/community surveillance (depending on culture); and

- Documented post harvest procedures/product flow/quantities. (Van Elzakker and Rieks, 2003).

The workshops produced guidelines regarding definition of smallholders, non-compliance and sanctions, evaluation protocol, risk assessment and re-inspection (whereby the external certifier checks a number of producers to verify that the ICS is working properly. For more information, see Van Elzakker and Rieks, 2003). IFOAM has now also published an ICS guidance manual for producers and a training curriculum in ICS evaluation for inspectors and certification personnel. These are available at: www.ifoam.org. 
- Include OA products from developing countries in preferential trade arrangements;

- Enforce non-discriminatory use of labels (e.g. at the very least, government-owned organic labels should be open to foreign producers who meet the production and processing requirements);

- Recognize group certification in the importing country's regulations;

- Recognize and take into account the special conditions of developing countries (certifiers, traders and importing countries' governments);

- Promote consumption of organic products, including those from developing countries;

- Refrain from engaging in "buy local" organic food campaigns;

- Gather and provide up-to-date market information on organic products of export interest to developing countries;

- Encourage certifying bodies within their territories to accept the results of other qualified certifying bodies and to make their labels available to OA products produced in developing countries;

- Reduce agricultural subsidies for products competing with developing-country exports, particularly OA exports;

- Consider the possible implications for developing countries of programmes and subsidies to support domestic OA production; and

- Support technical assistance/capacity-building programmes that encourage developingcountry OA production and export, especially of high value products, including projects aimed at, for example, developing appropriate policy frameworks and improving market intelligence. ${ }^{48}$

\section{Harmonization, mutual recognition and equivalence}

A major avenue of action is harmonization, mutual recognition and equivalence in the organic guarantee system. This can take place at different levels:

- Standards level, including private standards;

- Government level, including OA regulations and equivalency agreements;

- Accreditation level; and

- Certification level (e.g. agreement among certifying bodies to accept each others' inspection reports and evaluations).

Thus the concerned actors include governments, supranational government entities such as the EU, accreditation bodies, certification bodies, retailers (including those with their own private label and standard) and consumers.

IFOAM, FAO and UNCTAD decided to join forces to find solutions in this area. In February 2003, they launched the International Task Force on Harmonization and Equivalence in Organic Agriculture (ITF), which has held five meetings to date, and adopted a stratergy on solutions (UNCTAD/FAO/IFOAM, 2006). It is recommended that all major stakeholders participate actively in this opportunity for multi-stakeholder dialogue and act upon the resulting recommendations for action. Governments, for example, should consider adopting a multilateral approach to establishing equivalency with other governmental systems. At the standards level, one possible way for this to work would be that if an organic standard meets a set of internationally agreed minimum criteria (for example, if it complies with Codex Alimentarius Commission guidelines or IFOAM Basic Standards or meets an agreed set of common regulatory objectives for OA), stakeholders should accept this standard as equivalent to their own, even if it is not identical. An international impartial expert body could do the evaluation of each standard against the international standard. ${ }^{49}$ 
Similarly, national systems of conformity assessment, such as inspection, certification and accreditation, could be evaluated against a set of internationally agreed minimum criteria in order to secure multilateral acceptance of conformity assessment results.

It is recommended that certifying bodies drop as many barriers as possible to accepting the results of each others' inspections and evaluations. Moreover, they should drop as many of their additional requirements as possible. In this context, efforts made under the multilateral agreement of IFOAM-accredited certifiers are important steps in the right direction, and further progress is called for. Certifying bodies should also consider allowing their label to be affixed to products that have been inspected by other certifying bodies that are party to the multilateral agreement, particularly where the certifying body enjoys a monopoly-like position in terms of consumer recognition in the national market.

At the accreditation level, for example, the International Accreditation Forum (IAF) is the world association of conformity assessment accreditation bodies. According to the IAF website, "its primary function is to develop a single worldwide program of conformity assessment which reduces risk for business and its customers by assuring them that accredited certificates may be relied upon." Its logo is "certified once, accepted everywhere." The IAF implements this objective through the Multilateral Recognition Arrangements (MLAs). IAF members who are signatories to the MLA are required to recognize the certificates issued by certification bodies that have been accredited by all other members of the MLA. For organic agriculture, it could considerably enhance organic trade if the International Organic Accreditation Service (IOAS), an independent, non-profit organization, were permitted to become a member of the IAF and signatory to IAF MLAs..$^{50}$ Development of an "organic MLA" should be explored.

Countries that have not yet developed organic regulations but are interested in doing so should consider making reference to an international standard. If their ecological and socioeconomic conditions are similar to those of neighbouring countries, these countries should actively consider developing a subregional or regional standard and, if possible, a common regulation. This could help prevent the creation of new trade barriers among the countries in the future, enlarge the size of the domestic market, and enhance bargaining power in possible future equivalence agreements.

\section{G. Conclusion}

Part I of this chapter has highlighted the multiple benefits that organic agriculture can offer developing countries in terms of export opportunities, improved livelihoods, food security, a better environment, community revitalization, improved livelihoods for women, respect for and preservation of traditional knowledge and traditional agricultural varieties, and better health and safety. While organic producers must face certain challenges in order to reap these benefits, evidence suggests that more and more of them are doing so successfully every year. The International Fund for Agricultural Development sums it up eloquently:

"For small and poor farmers, organics can be an effective risk management tool that reduces their input costs, diversifies their production and improves local food security. For rural communities it can provide improved incomes, better resource management and more labour opportunities. For agricultural competitiveness, it meets the increasing demands for improved food safety methods and traceability that are becoming the hallmark of high-value agricultural trade. For governments, organics reduce the possibility of environmental contamination, reduce the use of chemical inputs (often imported) and minimize the public health costs of pesticide poisoning. For nearly everyone involved in its production, processing and trade, organics quite simply earns more money." (IFAD, 2005).

Therefore, the answer to the central question of this paper, "Is organic agriculture a promising trade and sustainable development opportunity for developing countries?" is "yes". 


\section{Annex 1.}

\begin{tabular}{|c|c|c|c|c|c|}
\hline \multicolumn{6}{|c|}{ Estimates of land area (ha) under certified organic production by country, 2004} \\
\hline Land & Area & Land & Area & Land & Area \\
\hline Australia & 11300000 & Netherlands & 41865 & Croatia & 3530 \\
\hline Argentina & 2800000 & Estonia & 40890 & Philippines & 3500 \\
\hline Italy & 1052002 & Indonesia & 40000 & Azerbaijan & 2770 \\
\hline United States & 930810 & New Zealand & 40000 & Senegal & 2500 \\
\hline Brazil & 803180 & Norway & 38176 & Pakistan & 2009 \\
\hline Uruguay & 760000 & Kazakhstan & 36882 & Luxembourg & 3002 \\
\hline Germany & 734027 & Tunisia & 33500 & Belize & 1810 \\
\hline Spain & 725254 & Colombia & 33000 & Honduras & 1769 \\
\hline United Kingdom & 695619 & Japan & 29151 & Algeria & 1400 \\
\hline Chile & 646150 & Ireland & 28514 & Jamaica & 1332 \\
\hline France & 550000 & Belgium & 24163 & Bosnia and Herzegovina & 1113 \\
\hline Canada & 516111 & Lithuania & 23289 & Liechtenstein & 984 \\
\hline Mexico & 400000 & Slovenia & 23280 & Lebanon & 758 \\
\hline Bolivia & 364100 & Dominican Rep. & 22151 & Malaysia & 600 \\
\hline Austria & 328803 & Morocco & 20040 & Bulgaria & 437 \\
\hline China & 298990 & Zambia & 20000 & Sudan & 430 \\
\hline Czech Rep. & 254995 & Ghana & 19460 & Malawi & 325 \\
\hline Greece & 244455 & Rep. of Korea & 18936 & Syria & 260 \\
\hline Ukraine & 240000 & Egypt & 17000 & Suriname & 250 \\
\hline Sweden & 207488 & Venezuela & 16000 & Iran & 200 \\
\hline Bangladesh & 177700 & Sri Lanka & 15215 & Fiji & 200 \\
\hline Denmark & 165148 & Serbia and Montenegro & 15200 & Benin & 197 \\
\hline Poland & 159987 & Guatemala & 14746 & Albania & 192 \\
\hline Peru & 150000 & Costa Rica & 13967 & Mauritius & 175 \\
\hline Uganda & 122000 & Thailand & 13900 & Cyprus & 166 \\
\hline Portugal & 120729 & Nicaragua & 10750 & Madagascar & 130 \\
\hline Hungary & 113816 & Cuba & 10445 & Guyana & 109 \\
\hline Switzerland & 110000 & Cameroon & 7000 & Togo & 90 \\
\hline Turkey & 103190 & Russian Federation & 6900 & Nepal & 45 \\
\hline Paraguay & 91414 & Viet Nam & 6475 & Zimbabwe & 40 \\
\hline Kenya & 90000 & Iceland & 6000 & Lao People's Dem. Rep. & 35 \\
\hline India & 76326 & Israel & 5640 & Malta & 14 \\
\hline Romania & 75500 & Panama & 5111 & Bhutan & 13 \\
\hline Latvia & 48000 & El Salvador & 4900 & Jordan & 7 \\
\hline South Africa & 45000 & Papua New Guinea & 4265 & Total & 158270 \\
\hline
\end{tabular}


AnNeX 2.

Farm-gate prices of selected organic and conventional products in the United States (April 2005)

\begin{tabular}{|c|c|c|c|c|c|}
\hline Product & State & Unit & $\begin{array}{c}\text { Organic } \\
(\text { price in \$) }\end{array}$ & $\begin{array}{c}\text { Conventional } \\
\text { (price in \$) }\end{array}$ & $\begin{array}{c}\text { Premium } \\
(\%)\end{array}$ \\
\hline \multicolumn{6}{|l|}{ Grain } \\
\hline Barley (feed) & $\mathrm{M}$ & Bushel & 2.75 & 1.70 & 62 \\
\hline Barley (malting) & M & Bushel & 3.75 & 2.45 & 53 \\
\hline Corn (\#2 yellow) & $\mathrm{S}, \mathrm{F}, \mathrm{M}, \mathrm{Dt}, \mathrm{D}, \mathrm{O}, \mathrm{SF}$ & Bushel & 6.11 & 2.31 & 165 \\
\hline Soy (feed stock) & M, D, O & Bushel & 14.25 & 5.99 & 138 \\
\hline \multicolumn{6}{|l|}{ Fruit } \\
\hline Apples (Fuji, Waf) & S, P, SF & $72 \mathrm{Ct}$ & 28.98 & 21.50 & 35 \\
\hline Apples (Gala) & $\mathrm{B}, \mathrm{S}, \mathrm{P}, \mathrm{SF}$ & $88 \mathrm{Ct}$ & 39.36 & 18.75 & 110 \\
\hline Apples (Golden delicious) & $\mathrm{B}, \mathrm{P}, \mathrm{SF}$ & $100 \mathrm{Ct}$ & 23.17 & 17.50 & 32 \\
\hline Apples (Granny Smith) & $\mathrm{B}, \mathrm{P}$ & $100 \mathrm{Ct}$ & 43.25 & 22.25 & 94 \\
\hline Apples (Red delicious) & & $100 \mathrm{Ct}$ & 27.75 & 16.00 & 73 \\
\hline Blueberries & $\mathrm{B}, \mathrm{S}, \mathrm{P}, \mathrm{SF}$ & $124.4-$ oz cups & 44.61 & 31.88 & 40 \\
\hline Grapefruit (Ruby) & S, SF & $48 \mathrm{Ct}$ & 27.98 & 17.00 & 65 \\
\hline Lemons & $\mathrm{B}, \mathrm{P}, \mathrm{SF}$ & $140 \mathrm{Ct}$ & 29.00 & 24.50 & 18 \\
\hline Pears (Bartlett) & SF,S & $90 \mathrm{Ct}$ & 40.98 & 35.00 & 17 \\
\hline Pears (Danjou) & $\mathrm{B}, \mathrm{S}, \mathrm{P}, \mathrm{SF}$ & $80 \mathrm{Ct}$ & 39.63 & 26.88 & 47 \\
\hline Raspberries & B, S, P & $126-$ oz cups & 51.82 & 26.67 & 94 \\
\hline Strawberries & $\mathrm{S}$ & 8/1\# & 28.50 & 12.00 & 138 \\
\hline \multicolumn{6}{|l|}{ Herbs } \\
\hline Basil & $\mathrm{S}$ & 1 Doz & 13.25 & 8.60 & 54 \\
\hline Chives & $\mathrm{SF}$ & 1 Doz & 11.50 & 5.00 & 130 \\
\hline Marjoram & SF, S & $1 \mathrm{Doz}$ & 11.25 & 10.45 & 8 \\
\hline Oregano & SF, S & $1 \mathrm{Doz}$ & 12 & 9.53 & 26 \\
\hline Rosemary & SF, S & $1 \mathrm{Doz}$ & 11 & 7.1 & 55 \\
\hline Sage & $\mathrm{SF}, \mathrm{S}$ & 1 Doz & 11.25 & 9 & 25 \\
\hline Sorrel & $\mathrm{S}$ & $1 \mathrm{Doz}$ & 12.50 & 13.55 & -8 \\
\hline Tarragon & SF, S & $1 \mathrm{Doz}$ & 13.13 & 12.27 & 7 \\
\hline \multirow{2}{*}{\multicolumn{6}{|c|}{ Vegetables }} \\
\hline & & & & & \\
\hline Asparagus & $\mathrm{B}, \mathrm{S}, \mathrm{P}, \mathrm{SF}$ & 11\# & 49.86 & 24.63 & 102 \\
\hline Avacados (Hass) & $\mathrm{B}, \mathrm{P}, \mathrm{SF}$ & $48 \mathrm{Ct}$ & 59.5 & 33.33 & 79 \\
\hline Broccoli & $\mathrm{S}$ & $14 \mathrm{Ct}$ & 39.75 & 17.00 & 134 \\
\hline Cabbage (green) & SF, S & $40 \#$ & 25.38 & 12.50 & 103 \\
\hline Carrots & $\mathrm{B}, \mathrm{S}, \mathrm{P}$ & $24 \times 2 \#$ & 29.42 & 14.67 & 101 \\
\hline Cauliflower (Cello) & $\mathrm{SF}, \mathrm{S}$ & $12 \mathrm{Ct}$ & 35.38 & 27 & 31 \\
\hline Celery & SF, S & $24 \mathrm{Ct}$ & 49.23 & 25.5 & 93 \\
\hline Garlic (Super Col) & $\mathrm{SF}, \mathrm{S}$ & $30 \#$ & 77.13 & 42.75 & 80 \\
\hline Green beans & $\mathrm{S}$ & $25 \#$ & 59.95 & 41.00 & 46 \\
\hline Lettuce (Green leaf) & SF, S & $24 \mathrm{Ct}$ & 38.23 & 26.5 & 44 \\
\hline Lettuce (Red leaf) & SF, S & $24 \mathrm{Ct}$ & 38.23 & 26.5 & 44 \\
\hline Lettuce (Romaine) & SF, S & $24 \mathrm{Ct}$ & 43.88 & 27.25 & 61 \\
\hline Mushrooms (Portabella) & $\mathrm{B}, \mathrm{S}, \mathrm{P}, \mathrm{SF}$ & $5 \#$ & 22.06 & 12.88 & 71 \\
\hline Mushrooms (Shiitake) & B, P & $3 \#$ & 20.25 & 13.00 & 56 \\
\hline Onions (Green) & S, P & $48 \mathrm{Ct}$ & 48.88 & 24.50 & 99 \\
\hline Onions (Yellow medium) & $\mathrm{B}, \mathrm{S}, \mathrm{P}$, & $40 \#$ & 28.98 & 11.75 & 147 \\
\hline Snow peas & SF & $10 \#$ & 26.00 & 13.00 & 100 \\
\hline Peppers (bell, green med) & $\mathrm{B}, \mathrm{S}, \mathrm{P}, \mathrm{SF}$ & $25 \#$ & 56.03 & 19.13 & 193 \\
\hline Peppers (bell, yellow) & B, SF & $11 \#$ & 52.75 & 26 & 103 \\
\hline Peppers (Jalapeno) & B, S, P, SF & $10 \#$ & 26.06 & 11.63 & 124 \\
\hline Potatoes $(\operatorname{Red} \mathrm{A})$ & B, S, P & $50 \#$ & 33.48 & 13.33 & 151 \\
\hline Potatoes (Yukon, gold baker) & $\mathrm{B}, \mathrm{S}, \mathrm{P}, \mathrm{SF}$ & $50 \#$ & 47.69 & 19.13 & 149 \\
\hline Potatoes (Russett) & $\mathrm{B}, \mathrm{P}$ & $70 \mathrm{Ct}$ & 27.5 & 11.25 & 144 \\
\hline Radish & $\mathrm{B}, \mathrm{P}$ & $24 \mathrm{Ct}$ & 33.25 & 11 & 202 \\
\hline Spinach & $\mathrm{S}, \mathrm{P}$ & $24 \mathrm{Ct}$ & 38.75 & 26.5 & 46 \\
\hline Squash (winter, acorn) & $\mathrm{S}, \mathrm{SF}$ & $35 \#$ & 47.48 & 20.75 & 129 \\
\hline Squash (winter, butternut) & SF & $35 \#$ & 48.00 & 22.50 & 113 \\
\hline Squash (winter, spaghetti) & $\mathrm{B}, \mathrm{S}$ & $35 \#$ & 41.38 & 21.5 & 92 \\
\hline Tomatoes & $\mathrm{B}, \mathrm{SF}$ & 2 layers $4 \times 5$ & 49.63 & 17.5 & 184 \\
\hline Zucchini & & $20 \#$ & 30.81 & 18.71 & \\
\hline
\end{tabular}

Source: New Farm (2005).

B: Boston; SF: San Francisco; \#: pounds; D: Dallas; S: Seattle; Ct: count; Dt: Detroit; O: Omaha; doz: dozen; F: Fargo; P: Philadelphia. 


\section{Notes}

1 These activities include a component on organic agriculture in the UNCTAD intergovernmental Expert Meeting on Ways to Enhance the Production and Export Capacities of Developing Countries of Agriculture and Food Products, including Niche Products, such as Environmentally Preferable Products, held in Geneva in July 2001; the UNEPUNCTAD CBTF Policy Dialogue on Promoting Production and Trading Opportunities for Organic Agricultural Products in Brussels February 2002; the ongoing CBTF project on Promoting Production and Trade of Organic Agricultural Products in East Africa; a Regional Workshop on Market Access, Environmental Requirements and Organic Agriculture in Costa Rica, March 2005; the studies and first five meetings of the FAO/IFOAM/UNCTAD International Task Force on Harmonization and Equivalence in Organic Agriculture (ITF) in 2003-2005, as well as the initial conference on the subject in February 2002. For information on these and other relevant UNCTAD activities, see the website of UNCTAD's Trade, Environment and Development Branch, at: www.unctad.org/trade_env.

2 The European Information System for Organic Markets (EISFOM) project aims to build a framework for reporting credible European organic production and marketing statistics (for more information, see their website at: www.eisform.org).

3 The survey was carried out by Stiftung Ökologie \& Landbau (SÖL, or Foundation Ecology \& Agriculture, Germany) between October and December 2004.

4 Mexico and Peru are the two largest producers of organic coffee in the world and account for more than half of the total world organic coffee production. The coffee is produced mainly by indigenous smallholders. Several Central American countries are also important producers of organic coffee (see part II of this chapter by Vossenaar and Angel).

In Argentina and Uruguay, about 99 per cent of certified OA land is devoted to livestock production.

See commentary on this chapter by Maamer Belkhiria and Ben Khedher in this TER.

Many of these were certified as farmers' associations using internal control systems.

The last two factors may apply to certified or uncertified OA.

In the context of OA, the price premium is the difference between the organic price and the price of its conventionally produced equivalent, expressed as a percentage of the latter. For example, if the price of a kilogram of organically produced carrots is 3 euros, and regular carrots is 2 euros, the price premium is $(3-2) / 2=0.50$, or 50 per cent. One also needs to distinguish between the price premium received by farmers and the retail price premium paid by consumers.

10 The expected price premium equals the observable price premium multiplied by the probability of getting that premium. For example, the observable price premium may be 50 per cent; but a particular farmer may know that in recent years in the neighbourhood, only 80 per cent of the certified OA products were sold as organic and the remaining 20 per cent as conventional. The expected price premium is therefore $(0.8) \times(0.5)=0.4$, or 40 per cent.

11 According to a recent report published by the United States Department of Agriculture (USDA), "U.S. farmers do not experience a similar [to Europe] post-transition yield reduction, although yields for major crops may be lower over time because of organic crop rotation. Organic EU farmers, on the other hand, often continue to have yields below conventional producers after the 3 -year conversion period.... One possible explanation for this difference is that, for conventional production systems, land is farmed more intensively in Europe than in the U.S." (Dimitri and Oberholtzer, 2005; see also Liebhardt, 2001 for further information.).

12 See also Pesticide Action Network North America website at: www.panna.org.

13 The relative profitability of organic versus conventional agriculture can be mathematically expressed as:

$$
\frac{\Pi_{\mathrm{O}}}{\Pi_{\mathrm{C}}}=\frac{\left(\mathrm{P}_{\mathrm{O}}+\mathrm{S}_{\mathrm{O}}\right) * \mathrm{Q}_{\mathrm{O}}-\mathrm{TC}_{\mathrm{O}}}{\left(\mathrm{P}_{\mathrm{C}}+\mathrm{S}_{\mathrm{C}}\right) * \mathrm{Q}_{\mathrm{C}}-\mathrm{TC}_{\mathrm{C}}}
$$

where $\mathrm{Ð}$ is net profits, $\mathrm{P}$ is price per unit, $\mathrm{Q}$ is quantity and $\mathrm{S}$ is subsidy per unit, and $\mathrm{TC}$ is total costs (cost per unit * quantity).

14 Note, however, that OA is not included in the category of EPPs currently being discussed in the WTO negotiations under paragraph 31 (iii) of the Doha Ministerial Declaration, as the term organic refers to a production and process method.

15 Please see Chapter 1 in this TER for more information.

16 Although there can be some contamination from nearby conventionally farmed fields or groundwater, which are factors beyond the control of the organic farmer.

17 In 1997, United States organic food sales amounted to $\$ 3.6$ billion out of total food sales of $\$ 443.7$ billion. In 2003, these figures were $\$ 10.4$ billion and $\$ 554.8$ billion respectively (Nutrition Business Journal, 2004).

18 Some experts believe these figures to be somewhat overestimated.

19 There is currently an initiative to create a database of imports and exports that traders declare to be "USDA organic" as part of the Automated Commercial Environment, International Trade Data System, which is a multi-agency effort (USDA, 2005a).

20 Moreover, a number of tropical products are not produced in the EU and must therefore be imported.

21 Zentrale Markt- und Preisberichtstelle für Erzeugnisse der Land-, Forst- und Ernährungswirtschaft GmbH.

22 Estimates of the size of the Japanese organic market vary according to the source. The ITC estimates in table 3 above (\$350-\$450 million in 2003) tally with those of Sahota (2005) in table 4 (\$0.48 billion for Asia in 2003), but differ from IFOAM Japan's estimates of 114 billion yen in 2002 (which, using the average exchange rate for 2002 of $\$ 1=$ 125 yen, amounts to $\$ 0.91$ billion) (IFOAM Japan, 2004). 
23 For more information on the development of the organic sector in China, see commentary on this chapter by Xiao in this TER.

24 OA products have occasionally been mentioned in the context of the WTO negotiations on "the reduction or, as appropriate, elimination of tariff and non-tariff barriers to environmental goods and services" (EGS). Some developing countries have been disinclined to include OA products in these negotiations, as the definition of such products is based upon non-product-related production and process methods. These countries generally feel that the WTO regime should be based on product characteristics only, and not on how these products are produced. For more information on EGS negotiations, see UNCTAD, $2004 \mathrm{~b}$.

25 This is the case, for example, for own-label organic products sold by the supermarket chain, Sainsbury's, in the United Kingdom (Duxbury, 2003).

26 Information on the EU and United States regulations was largely drawn from Commins and Kung Wai, 2003, and Bowen, 2005.

27 This option has not been used.

28 EEC Regulation No 94/92 of 1992 includes more detailed rules.

29 The six countries are Argentina, Australia, Costa Rica, Israel, New Zealand and Switzerland. The Czech Republic and Hungary used to be on the list, but have now joined the EU.

30 See part II of this chapter by Vossenaar and Angel for information on these first three countries.

31 This is in contrast to the situation in the EU, where private certifiers may have additional requirements and not accept each other's certification decisions.

32 These comprise four in Argentina and one each in Bolivia, Brazil, Chile, Colombia, Costa Rica and Guatemala.

33 Domestic support for agriculture is currently a key area of WTO negotiations.

34 In 2003, the combined GDP of 49 LDCs (excluding Tuvalu) was \$221.7 billion (World Bank, 2005).

35 Even in developed countries, it is only in the last decade or two that governments have started getting actively involved in promoting the organic sector.

36 See part II of this chapter by Vossenaar and Angel, and the subsequent commentary by Maamer Belkhiria and Ben Khedher for information on government policies and initiatives that promote development of the organic sector in Costa Rica and Tunisia respectively.

37 For example, with the export price of organic robusta coffee in May 2005 at $\$ 1.35 / \mathrm{kg}$ (The Standard, 2005), revenues for $80 \mathrm{kgs}$ would be $\$ 108$. Thus, for this example, certification costs account for nearly 4 per cent of the export revenue generated. As farm-gate prices are lower than export prices, certification costs constitute an even higher share of the revenue received by the farmer.

38 At any rate, the EU logo is not well recognized by consumers.

39 See for example Duxbury, 2003.

40 See for example www.farmerslink.org.uk/wtbsf.htm; www.wwf.org.uk/core/about/scotland/sc_0000001318.asp; http:/ /homepages.poptel.org.uk/nfn/links-ethicaltrade.html; www.organicconsumers.org/starbucks/buyloca1021605.cfm.

${ }^{41}$ This is an important issue even in developed countries. For example, it was reported that in the Canadian province of Alberta, one third of organic farmers stopped being certified organic as the administrative procedures were considered too complicated to be worthwhile. These certification "drop-outs" were largely smaller farming operations (The Organic Standard, 2003).

42 Cambodia and Uganda provide illustrative examples of this; see, for example, Dao, 2004.

43 Gunnar Rundgren's commentary on this chapter provides more information, as does the EPOPA website at: www.grolink.se/epopa.

44 In LDCs, the average literacy rate for males aged 15 years and older was 67.6 per cent and for females 44.4 per cent in 2002. In rural areas, these percentages would be even lower than the national averages (World Bank, 2005).

45 Listed in endnote 1.

46 Recommendation from CBTF workshop in Brussels, 2002.

47 The resulting group certification also needs to be recognized in those markets. Today, group certification is, de facto, accepted in most major markets, although generally it is not written into the regulations.

48 One example is the UNEP/UNCTAD CBTF project on Promoting Production and Trade of Organic Agricultural Products in East Africa, supported by the European Commission and the Swedish International Agency for Development. This project will assess the current situation regarding OA at the national level in Kenya, Uganda and the United Republic of Tanzania, and will draw up a national action plan to support the development of the sector. It is also a practical case study of harmonization in practice, as it will explore the possible development of a subregional organic standard. More information on this project is available in chapter 4 of this TER.

49 Under the WTO TBT Agreement, national governments are required to notify the WTO of deviations from international standards.

50 Until now, the IAF has rejected this request, since the IOAS only deals with one sector and is not a national government body. 


\section{REFERENCES}

ACNielsen (2005). What's Hot Around the Globe: Insights on Growth in Food and Beverages 2004; available at: http://www2.acnielsen.com/reports/documents/2002_whatshot.pdf

Bowen D (2005). Current mechanisms that enable international trade in organic products. In: UNCTAD/FAO/ IFOAM, Harmonization and Equivalence in Organic Agriculture, Vol. 1, Background papers of the International Task Force on Harmonization and Equivalence in Organic Agriculture (revision March 2005). Bonn, UNCTAD, FAO, IFOAM.

CBI (2004). EU Market Survey 2004: Organic Food Products. Compiled for CBI by ProFound Advisors in Development in collaboration with Joost Pierrot. Rotterdam, the Netherlands.

Chamberlain D, Fuller R and Brooks D (1996). The effects of organic farming on birds. EFRC Bulletin 21, Jan 1996, Berkshire, United Kingdom, Elm Farm Research Centre.

FAO/WHO Codex Alimentarius Commission (2001). Codex Guidelines for the Production, Processing, Labelling and Marketing of Organically Produced Foods. GL 32 - 1999, Rev.1 - 2001. Rome, FAO,WHO.

Commins K (2005). Overview of current status of standards and conformity assessment systems. In: UNCTAD/ FAO/IFOAM, Harmonization and Equivalence in Organic Agriculture, Vol. 1, Background papers of the International Task Force on Harmonization and Equivalence in Organic Agriculture (revision March 2005). Bonn, UNCTAD, FAO, IFOAM.

Commins K and Kung Wai O (2003). Regulation of imports into major markets. In: IFOAM/FAO/UNCTAD (2003). The Organic Guarantee System: The Need and Strategy for Harmonization and Equivalence. Westermayer C and Geier B, eds. Tholey-Theley, Germany. IFOAM, FAO, UNCTAD.

Commission of the European Communities (2005). Proposal for a Council Regulation on organic production and labeling of organic products. COM(2005)671, Brussels, 21 December; Available at: europa.eu.int/comm/ agriculture/qual/organic/com2005_671_en.pdf

Commission of the European Communities (2004). Communication from the Commission to the Council and the European Parliament: European Action Plan for Organic Food and Farming. COM(2004)415, Brussels, 10 June; available at: www.europa.eu.int/comm/agriculture/qual/organic/plan/index_en.htm.

Dabbert S, Häring AM and Zanoli R (2004). Organic Farming: Policies and Prospects. London. Zed Books.

Dao C (2004). Country case study on environmental requirements, market access/entry and export competitiveness for horticultural products from Cambodia. Study prepared for the UNCTAD Sub-Regional Workshop on Environmental Requirements, Market Access/Entry and Export Competitiveness in the Horticultural Sector, Bangkok, 29 September-1 October 2004; available at: http://r0.unctad.org/trade_env/test1/meetings/ bangkok6page.htm.

Dimitri C and Oberholtzer L (2005). Market-led versus government-facilitated growth: Development of the U.S. and EU organic agricultural sectors. Electronic Outlook Report for the Economic Research Service, United States Department of Agriculture (USDA). Washington, DC, August 2005; available at: www.ers.usda.gov/ publications/WRS0505/.

Duxbury R (2003). A retailer's experience with the organic market. In: IFOAM/FAO/UNCTAD (2003). The Organic Guarantee System: The Need and Strategy for Harmonization and Equivalence. Westermayer C and Geier B, eds. Tholey-Theley, Germany. IFOAM, FAO, UNCTAD.

ESCAP (2003). Organic agriculture and rural poverty alleviation: Potential and best practices in Asia; available at: www.unescap.org/rural/doc/oa/oa-bgrd.htm.

FAO (2002). Organic Agriculture, Environment and Food Security. Scialabba N and Hattam C, eds. Rome.

FAO (1996). Report on the State of the World's Plant Genetic Resources for Food and Agriculture. Rome.

Fliessbach A et al (2001). DOK long-term farming systems trial: microbial biomass, activity and diversity affect the decomposition of plant residues. In: Rees R et al., eds. Sustainable Management of Organic Matter: 363 to 369. CABI, London.

Gómez Tovar L and Gómez Cruz MÁ (2004). Mexico. In: Willer H and Yussefi M, eds. The World of Organic Agriculture: Statistics and Emerging Trends 2004. Bonn, IFOAM.

Global Resource Action Center for the Environment (GRACE) (2005). Introduction to sustainability: sustainable dictionary; available at: www.sustainabletable.org/intro/dictionary/\#s.

Haas G and Köpke U (1994). Vergleich der Klimarelevanz ökologischer und konventioneller Landbewirtschaftung. Studie (H) im Auftrag der Enquetekomission des Deutschen Bundestages Schutz der Erdatmospäre. Economica Verlag, Karlsruhe.

Häring AM et al. (2004). Organic Farming and Measures of European Agricultural Policy. Organic Farming in Europe: Economics and Policy, Vol. 11. Universität Hohenheim, Germany. 
Hartman Group (2004). Organic Food and Beverage Trends 2004: Lifestyles, Language and Category Adoption. Washington, DC, The Hartman Group Inc.

Heerink N (2005). Soil fertility decline and economic policy reform in Sub-Saharan Africa. Land Use Policy, 22: 67-74.

Holt-Giménez E. (2002). Measuring farmers' agroecological resistance after Hurricane Mitch in Nicaragua: a case study in participatory, sustainable land management impact monitoring. Agriculture, Ecosystems and Environment 93. Elsevier.

IFAD (2003). The adoption of organic agriculture among small farmers in Latin America and the Caribbean. Thematic evaluation, report no. 1337. April.

IFAD (2005). Organic agriculture and poverty reduction in Asia: China and India focus. Thematic evaluation, report no. 1664, July; Giovannucci D, lead author. available at: www.ifad.org/evaluation/public_html/eksyst/ doc/thematic/organic/asia.pdf

IFOAM (2004). Organic Agriculture Worldwide: IFOAM Directory of the Member Organizations and Associates 2005. Neunkirchen, Germany, IFOAM.

IFOAM/FAO/UNCTAD (2003). The Organic Guarantee System: The Need and Strategy for Harmonization and Equivalence. Westermayer C and Geier B, eds. Tholey-Theley, Germany. IFOAM, FAO, UNCTAD. Available at: www.unctad.org/trade_env.

IFOAM Japan (2004). The Japanese market for environmentally and socially certified agricultural products from Central America. Tokyo; available at: www.fao.org/es/esc/en/20953/22218/highlight_102516en.html

Intermediate Technology Development Group (ITDG) (2002). Agricultural biodiversity: Farmers sustaining the web of life. Farmers' World network briefing. Rugby, United Kingdom.

Japan Organic and Natural Foods Association (JONA) (2005). Outlines of JONA; available at www.jona-japan.org/ English.html.

Kilcher L et al. (2004). The Organic Market in Switzerland and the European Union: Overview and Market Access Information for Producers and International Trading Companies. Zurich/Frick, Switzerland, FiBLSIPPO.

Kommerskollegium (Swedish National Board of Trade) (2003). Market access for organic agriculture products from developing countries: analysis of the EC Regulation (2092/91). Stockholm.

Kortbech-Olesen, R (2004). The Canadian market for organic food and beverages. International Trade Centre of UNCTAD and the WTO (ITC). Geneva; available at: www.intracen.org/mds/sectors/organic/welcome.htm.

Kung Wai O (2004). Asia. In: Willer H and Yussefi M, eds. The World of Organic Agriculture: Statistics and Emerging Trends 2004. Bonn, IFOAM.

Lang S (2005). Organic farming produces same corn and soybean yields as conventional farms, but consumes less energy and no pesticides, study finds. Cornell University News Service. 13 July; available at: www.news.cornell.edu/stories/July05/organic.farm.vs.other.ssl.html

Lernoud P (2005). Latin America. In: Willer H and Yussefi M, eds. The World of Organic Agriculture: Statistics and Emerging Trends 2005. Bonn, IFOAM.

Lernoud P and Piovano M (2004). Latin America: Country Reports. In: Willer H and Yussefi M, eds. The World of Organic Agriculture: Statistics and Emerging Trends 2004. Bonn, IFOAM.

Liebhardt W (2001). Get the facts straight: organic agriculture yields are good. Information Bulletin 10 (Summer). Santa Cruz, California, Organic Farming Research Foundation.

Lotter DW, Seidel R and Liebhardt W (2003). The performance of organic and conventional cropping systems in an extreme climate year. American Journal of Alternative Agriculture, 18 (3): 146 to 154.

Ministry of Agriculture, Forestry and Fisheries of Japan (2005). Revision of JAS Law. MAFF Update, No. 584, 9 May. Tokyo; available at: www.maff.go.jp/mud/584.html.

Musiime E and Naluwairo R (2004). Report of the Proceedings of the Workshop on Organic Agriculture, Food Security and Poverty Eradication: Policy Options for Increasing the Role of Organic Agriculture in Ensuring Sustainable Food Security and Poverty Alleviation in Sub-Saharan Africa, Kampala, Uganda, 30 to 31 March 2004. ACODE Policy Research Series No. 4, Kampala, Uganda.

Musiime E, Keizire B and Muwanga M (2005). Organic agriculture in Uganda: the Need for a Coherent Policy Framework. ACODE Policy Research Series, No. 11. Kampala, Uganda, ACODE.

Myers D (2000). Cotton tales. New Internationalist 323, May; available at: www.newint.org/issue323/tales.htm.

National Safety Council (2005). Environmental glossary; available at: www.nsc.org/ehc/glossar2.htm.

New Farm (2005). Organic price index, 15 April; available at: http://newfarm.org/opx/

Niggli, U (2005). Organic Farming Research - Definitely Out of the Niche. In: Organic Farming in Europe 2005: Market, Production, Policy \& Research, Lampkin N, ed.. Available at www.fibl.org

Nutrition Business Journal (2004). NBJ's Organic Foods Report 2004. 
OECD (2004). OECD Agricultural Policies 2004 at a Glance. Paris, OECD.

Offermann F and Nieberg H (1999). Economic performance of organic farms in Europe. Organic Farming in Europe: Economics and Policy 5. Stuttgart-Hohenheim, Auflage.

Organic Agriculture Centre of Canada (2004). Prices for organic and conventional food in Canada: Market Report, January 10; available at: www.organicagcentre.ca/MarketReports/Jan10-04.html.

Organic Monitor (2002). The European market for organic dairy products. London.

Organic Monitor (2003). Japan: food scares spur organic food sales, 24 January; available at: www.organicmonitor.com.

Organic Trade Association (2004). What's news in organic, 28 (Summer). Greenfield, MA, United States of America; available at: www.ota.com/pics/documents/WhatsNews28.pdf.

Panyakul V and Kung Wai O (2005). Asia. In: Willer H and Yusseffi M, eds. The World of Organic Agriculture: Statistics and Emerging Trends 2005. Bonn, IFOAM.

Parrott N and Kalibwani F (2004). Africa. In: Willer H and Yussefi M, eds. The World of Organic Agriculture: Statistics and Emerging Trends 2004. Bonn, IFOAM.

Parrott N and Kalibwani F (2005). Africa. In: Willer H and Yussefi M, eds. The World of Organic Agriculture: Statistics and Emerging Trends 2005. Bonn, IFOAM.

Pfiffner L and Mäder P (1997). Effects of biodynamic, organic and conventional production systems on earthworm populations. Entomological research in organic agriculture. Biological Agriculture and Horticulture, 15:3-10.

Pimental D (2005). Organic farming offers real advantages for such crops as corn and soybeans. Bioscience, 55: 7, July.

Pinton R and Zanoli R (2004). Organic farming in Italy 2004. Frick, Switzerland. Research Institute of Organic Farming (FiBL); available at: www.organic-europe.net/country_reports/italy/default.asp\#market.

Richter T and Padel S (2005). The European market for organic foods. In: Willer H and Yusseffi M, eds. The World of Organic Agriculture: Statistics and Emerging Trends 2005. Bonn, IFOAM.

Republic of Tunisia, Ministry of Agriculture and Hydraulic Resources (2005). Organic agriculture in Tunisia. Paper presented at the fourth meeting of the International Task Force on Harmonization and Equivalency in Organic Agriculture, Nuremberg, Germany, 28 February 2005.

Sahota A (2005). Overview of the global market for organic food and drink. In: Willer H and Yussefi M, eds. The World of Organic Agriculture: Statistics and Emerging Trends 2005. Bonn, IFOAM.

Stolze M et al (2000). The environmental impacts of organic farming in Europe. Organic farming in Europe, 6. University of Stuttgart-Hohenheim, Stuttgart.

Taylor A et al. (2006). Overview of the current state of organic agriculture in Kenya, Uganda and the Republic of Tanzania and opportunities for regional harmonization. Study commissioned by the UNEP-UNCTAD Capacity Building Task Force on Trade, Environment and Development (CBTF), Geneva. Advance copy available at www.unep-unctad.org/cbtf. United Nations (forthcoming).

The Organic Standard (2003). Organic farmers shunning certification in Canada. Grolink, Sweden, July.

The Standard (2005). Uganda coffee exports up 95 pc. 14 June; available at: www.eastandard.net/hm_news/ news.php?articleid $=22797$.

UNCTAD (2003). Organic fruit and vegetables from the tropics: market, certification and production information for producers and international trading companies. UNCTAD/DITC/COM/2003/2, Geneva. Available at www.unctad.org/en/docs/ditccom20032_en.pdf

UNCTAD (2004a). Protecting and Promoting Traditional Knowledge: National Systems and International Dimensions (Twarog S and Kapoor P, eds.). UNCTAD/DITC/TED/10, Geneva. Available at: www.unctad.org/en/docs/ditcted10_en.pdf

UNCTAD (2004b). Trade and Environment Review 2003. UNCTAD/DITC/TED/2003/4, Geneva. Available at: www.unctad.org/en/docs/ditcted20034_en.pdf

UNCTAD/FAO/IFOAM (2005). Harmonization and Equivalence in Organic Agriculture, Vol. 1, Background papers of the International Task Force on Harmonization and Equivalence in Organic Agriculture (revision March 2005). Bonn, UNCTAD, FAO, IFOAM.

UNCTAD/FAO/IFOAM (2006). Strategy on Solutions for Harmonizing International Regulation of Organic Agriculture. Harmonization and Equivalence in Organic Agriculture, Vol.2, Background papers of the International Task Force on Harmonization and Equivalence in Organic Agriculture. Geneva, UNCTAD, FAO, IFOAM (forthcoming).

United Nations (2002). Report of the World Summit on Sustainable Development held in Johannesburg, South Africa 26 August to 4 September 2002. A/CONF.199/20, New York. 
United States Department of Agriculture (USDA) (2005a). U.S. market profile for organic food products. 22 February; available at: www.fas.usda.gov/agx/organics/USMarketProfileOrganicFoodFeb2005.pdf

United States Department of Agriculture (USDA) (2005b). Accredited certifying agents. 20 December; available at: www.ams.usda.gov/nop/CertifyingAgents/Accredited.html.

Van Elzakker B and Rieks G (2003). Smallholder group certification: compilation of results. Proceedings of three workshops (Feb. 2001, Feb. 2002, Feb. 2003). Bonn, IFOAM.

Vossenaar R, Jha V. and Wynen E (2004). Trading opportunities for organic food products from developing countries. In: Vossenaar R, Jha V. and Wynen E eds. (2004). Trading Opportunities for Organic Food Products from Developing Countries. UNCTAD/DITC/TED/11. Geneva, UNCTAD.

Waniala N (2004). Uganda. In: Vossenaar R, Jha V. and Wynen E eds. (2004). Trading Opportunities for Organic Food Products from Developing Countries. UNCTAD/DITC/TED/11. Geneva, UNCTAD.

Willer H and Yusseffi M eds. (2004). The World of Organic Agriculture: Statistics and Emerging Trends 2004. Bonn, IFOAM.

Willer H and Yusseffi M eds. (2005). The World of Organic Agriculture: Statistics and Emerging Trends 2005. Bonn, IFOAM.

World Bank (1998). Improving soil fertility management in sub-Saharan Africa. African Region Findings No. 121, October; available at: www.worldbank.org/afr/findings/english/find121.htm.

World Bank (2005). Word Development Indicators, online data, at: www.worldbank.org/data/countrydata/ countrydata.html.

Wynen E (2005). Impact of organic guarantee systems on production and trade in organic products. In: UNCTAD/ FAO/IFOAM, Harmonization and Equivalence in Organic Agriculture, Vol. 1, Background papers of the International Task Force on Harmonization and Equivalence in Organic Agriculture (revision March 2005). Bonn.

Wynen E and Vanzetti D (2002). Does it make sense to buy locally produced organic products? In: Hall D and Moffitt J, eds. (2002) Economics of Pesticides, Sustainable Food Production and Organic Food Markets. Amsterdam, Elsevier.

Yunhua C (2005). Presentation made at the fifth meeting of the International Task Force on Harmonization and Equivalence in Organic Agriculture (5-7 December 2005). Hammamet, Tunisia.

Yussefi M, Willer H and Lünzer I (2004). Öko-Landbau in Deutschland. Stiftung Ökologie \& Landbau, available at: www.soel.de.

Zarea A, Koocheki A and Nasiri M (2000). Energy efficiency of conventional and ecological cropping systems in different rotations. In: Alföldi T, Lockeretz W and Niggli U, eds. IFOAM 2000 - The World Grows Organic: Proceedings $13^{\text {th }}$ International IFOAM Scientific Conference. Vdf Hochschulverlag, Zürich.

Zentrale Markt- und Preisberichtstelle für Erzeugnisse der Land-, Forst- und Ernährungswirtschaft GmbH (ZMP) (2005). Märkte Online; available at: www.zmp.de.

Zanoli R et al. (2004). Organic Marketing Initiatives and Rural Development: Vol 4 The European Consumer and Organic Food. Aberystwth, University of Wales. 


\title{
Commentaries
}

\author{
Moses K. Muwanga \\ Coordinator, National Organic Agricultural Movement of Uganda (NOGAMU)
}

Part I of this chapter by Sophia Twarog brings to light important realities about the potential of organic agriculture to help developing countries attain sustainable national development. In devising appropriate development strategies, it is important to understand the unique but often disregarded socio-cultural dimensions that characterize developing countries. While producers in developed countries are sophisticated, literate and have access to inputs, support and markets, their counterparts in developing countries are largely small, in many cases illiterate, and have relied on traditional farming practices to sustain their production and livelihood. Thus, a shift to sustainable agricultural practices such as organic farming is not only appropriate for these resource-poor farmers, it is also already bringing enormous economic, socio-cultural and environmental benefits to communities in these countries.

Consider the case of Uganda, a least developed country (LDC) in East Africa. The adoption of organic farming in this country has resulted in improved incomes to many small, resource-poor farmers. Organic farmers participating in certified export projects have been able to obtain farmgate prices for their products that are 40-200 per cent higher than farmers who use conventional methods. They have also been able to enjoy stable and more direct relationships with exporters and importers, unlike the conventional farmers. Small organic producers are registering increased gross income earnings in the range of $25-150$ per cent from the same size of fields as their conventional counterparts. For the small producers involved in these projects, organic markets have created an opportunity to come together and market their products as a group, and this is facilitated by the establishment of internal quality management systems. An example is a group of 12,000 small organic cotton growers in northern Uganda, who have been able to export their products to Europe uninterrupted for the last 11years. For these small farmers, organic farming is a source of livelihood in addition to the other benefits obtained such as an improved environment.

The notion that conversion to organic agriculture results in reduced yields is not valid for a number of situations in many developing countries. As Twarog points out, this depends very much on the state of the farm prior to conversion. In the case of Uganda, and indeed in many developing countries, conversion to organic farming has always resulted in increased rather than decreased yields. For example, organic farmers in Uganda obtain higher yields for their pineapple and banana crops than their conventional counterparts. This is probably why there are very few pineapple and banana farmers there who use synthetic inputs; it does not make economic sense in their situation, unlike in many developed countries where a long tradition of use of synthetic inputs results in initially reduced yields on conversion to organic agriculture. In many developing countries, on the other hand, little or no use of synthetic inputs in the past means that the soils respond well to organic farming practices. Thus converting to organic agriculture makes good economic sense for smallholder producers in a country like Uganda, where the use of synthetic inputs is among the lowest, at less than 2 per cent, compared to the sub-Saharan average of 9 per cent or compared to some of the developed countries where synthetic input use may even be above 40 per cent.

The increasingly stringent food quality and safety requirements in developed-country markets position organic farming as an ideal solution for the smallholder farmers because of its holistic approach to the production and marketing process. With the new legal and private sector market requirements in Europe and other developed markets, such as regulation EC178/2002 and EurepGap respectively, the gap between the market requirements and the social and economic realities of small producers in developing countries is becoming wider. Fortunately, organic farming, with its 
holistic approach, overcomes these constraints. For example, the non-use of synthetic pesticides in organic farming gives the small producers an advantage to easily meet the legal requirements on the use and management of pesticides and compliance with maximum residue limits (MRLs) acceptable to the European and other developed markets for fresh produce, which would otherwise be a challenge in the smallholder farming set-up.

A random informal survey carried out in October 2004 in Uganda shortly before the coming into force of the mandatory traceability requirements for the EU market (EC178/2002, effective 1 January 2005), indicated that all certified organic projects would meet the requirement by the stipulated date, and that farmers were accustomed to issues of traceability because it is part of the transparency and trust enshrined in the organic farming system. In addition, the projects would meet over 70 per cent of the EurepGAP requirements as a result of not using pesticides. On the other hand, the requirements as a whole presented a completely new obstacle to the conventional smallholder farmers, so that quite a number of them were left out when the regulation came into force. The holistic approach used in organic farming and the incorporation of social and environmental issues in the production systems therefore make this type of farming an ideal solution for meeting increasingly stringent market requirements.

In conclusion therefore, organic farming provides a viable strategic development option for developing countries for improving the economic situations of smallholder producers, who constitute the majority of the population, while meeting the increasingly dynamic social and environmental challenges in their localities. In addition, the previously low use of synthetic inputs in the agricultural systems of many developing countries gives organic production a comparative advantage, and therefore an opportunity, to increase the competitiveness of products from developing countries in the global market. 


\section{Daniele Giovannucci \\ Consultant, World Bank}

Organic agriculture and trade is a fast evolving field with potentially important implications for the work of development agencies and governments. Parts I and II of the chapter on organic agriculture by Twarog and Vossenaar, respectively, are useful contributions to the emerging, often considerably heated, debate on whether this sector indeed offers real opportunities for developing countries.

With the increasing adoption and importance of organics, which has become a global $\$ 30$ billion industry, it is useful to analyse the trade and sustainable development implications for organic producers and traders in developing countries. A range of potential benefits and also challenges currently exist in the areas of production, markets and policy that require careful analysis and thoughtful recommendations for action.

It is important to first make a distinction - as Twarog's paper does - between organic agriculture, which can be defined by generally accepted standards, and traditional forms of agriculture that may not use synthetic agrochemicals but do not necessarily abide by the systemic principles of organic agriculture. Traditional forms of production which are generally characterized by limited productivity and low levels of agricultural income are often - erroneously - considered to be synonymous with organics. While it is true that organic agriculture relies partly on traditional or local understanding of natural cycles and tends to make use of local resources for fertilization and pest management, it also relies on a sophisticated use of biological products and processes. Wellmanaged organic farms can be considerably productive and extremely efficient in terms of risk management, but achieving this can be challenging.

Premium prices for organic products have in recent years become the main impetus for the adoption of organic agriculture, providing much needed income for producers in developing countries. However, the inherent volatility of what is a relatively small and somewhat fragmented market has also led to difficulties, especially for producers who invest in organic certification. Today, the premiums for certified products vary enormously by product and origin. For products that have been marketed for a number of years, such as coffee and cacao, the premiums are experiencing a downward trend as the markets mature, with more producers participating and bringing supply and demand into balance. For most products, it seems unlikely that today's premiums - as high as 50-200 per cent for some products - will continue for very long, and this has considerable implications for farmers and development schemes. Initiatives based on current and historic premiums may not meet expectations as premiums adjust downwards. Nevertheless, there are a number of other reasons, besides premiums, for developing-country producers to embark on organic initiatives. A number of studies (Uphoff, 1999; Pretty, 1995; Burton et al., 1998; Yamauchi, 1995) ${ }^{1}$ note some intrinsic advantages, which include:

- Improved ability to meet emerging trade standards such as traceability;

- Crop diversification and reduced input costs, that together minimize financial risk;

- Increased use and value of rural labour;

- Better natural resource management and biodiversity conservation;

- Improved crop resilience to climatic shocks such as drought and floods; and

- Fewer health risks due to potential mishandling of agrochemicals.

Many analysts believe that organics typically offer a "higher income"; while this appears often to be true, there is certainly more evidence for the other assertion that these markets offer higher prices. For some farmers, particularly those engaged in large and intensive conventional operations, these higher prices may not necessarily translate into higher total income due to often reduced yields and an increase in other cost factors - particularly during what could be a lengthy conversion process. 
Accurately estimating farm income for organic agriculture can be difficult, as Twarog notes, because organic producers do not simply cultivate a monocrop for easy comparison. Multiple crops that are rotated annually, and that may not all be destined for the market, make it somewhat more difficult to calculate the overall value of farm production. Productivity is of course a vital element, and organic agriculture is often believed to deliver less than conventional approaches. There is in fact credible and rigorously estimated evidence for both sides of this argument. However, it seems clear that for smaller producers in developing countries, particularly poor or rural ones, there can be distinct advantages in terms of higher productivity, resulting primarily from better management practices and improved soil quality as a result of organic methods. ${ }^{2}$

Furthermore, the intangible benefits often credited to organics, such as improved soil fertility, absorption capacity, tilth and stability, are difficult to accurately evaluate, though any farmer would assert that they are considerable assets. It is equally difficult to place a value on local biodiversity that is promoted by organic systems, though recent efforts, including those by scientists of Stanford University and the conservation organization, World Wildlife Fund, have credibly estimated the monetary value of the pollination services provided by a local natural habitat rich in biodiversity in which many beneficial species are able to thrive.

A new effort initiated by three institutions - the International Institute for Sustainable Development (IISD), Centre de coopération internationale en recherche agronomique pour le développement (CIRAD) and the Sustainable Markets Intelligence Centre (CIMS) ${ }^{3}$ - seeks to use the most up-todate techniques for estimating the actual costs and benefits at the environmental, social and economic levels, of not only organics but also five other standards that purport to foster sustainability. This effort will result in a scientific measurement tool for farmers or policy-makers to use for determining the realistic viability of adopting certified methods that conform to organic, fair trade or Eurep-GAP standards.

It is often asserted that organic markets tend to offer "more stable farm-gate prices and stable markets", yet in reality this is difficult to demonstrate. It is clear that, historically, organic producers have had long-term relationships with their buyers, and this appears to continue in most markets today. There is, however, little evidence that farm-gate prices are indeed more stable for organic products; in fact indications from various markets, both developed and less developed, seem to point to significant volatility due primarily to the relatively small volumes being traded through comparatively less established supply chains. The notion that organic markets are more stable is also largely untested. In many cases, organic distribution channels are limited or involve very little competition among exporters, traders, processors, importers, or distributors, and could thereby create an oligopsony. Organic markets were probably more stable in their early phases, when they were more local and supported primarily by a core group of ideological supporters (Giovannucci, 2003) ${ }^{4}$. However, as such markets develop, more producers become involved and new and aggressive market channels are opened. As a result, the market tends to move in the direction of a more conventional business model, characterized by increased competitiveness and change.

Twarog clearly notes that organic producers in developing countries face nearly all the challenges of conventional producers, plus some additional challenges of their own. Field experiences in Asia and Latin America indicate that the major challenges to organics include:

Inadequate institutional support, especially at the rural level;

- Lack of adequate technical advice on production technology. Extension services in many developing countries are poorly funded, and the staff have little, if any, training in organic production techniques;

- Limited access to certification, the ability to pay for it, and to the learning that it involves;

- Increased demands of marketing to a niche export market and often the lack of both a domestic outlet and good market information; and

- Financing for the transition period. 
Conversely, organic farming systems embody elements of sustainability that can make them useful as poverty reduction tools. These elements include:

- Processes that are knowledge-intensive rather than capital- and resource-intensive;

- Adaptation of traditional knowledge to modern methods such as bio-controls and efficient nutrient management;

- A long-term commitment to soil fertility, and elimination of soil degradation and erosion;

- The reduction of water use and external energy consumption; and

- An effective risk management tool - especially for small and poor farmers - to reduce input costs, diversify production and improve local food security.

Bilateral and multilateral agencies have been involved in considerable research and policy analysis on this subject in recent years. However, with rare exceptions, they have not yet taken the often positive conclusions of their analytical work and translated them into official policies or other credible forms of development assistance (i.e. significant project investments). In most cases, organic agricultural practices have evolved - at least in the initial stages - under conditions of more or less benign neglect from governments and large public bodies. As governments in Europe, Japan and the United States increasingly recognize the significant "public good" aspect of organic agriculture and invest in it, the groundwork and example is set for other governments and public institutions to foster it through supportive policies and targeted investment in applied research, technology training, and strategic market knowledge.

Private companies increasingly use certification systems to ensure that food safety, labour and environmental criteria are being met by their suppliers in order to reduce risks to their reputation or legal risks. As Twarog notes, systems such as organic certification can also help provide traceability, improve farm management, and alert both firms and farmers to potential problems in the field or along the supply chain. Clearly, there is a pressing need to prepare farmers for such requirements so that they can be competitive in a globalized trade climate that increasingly demands such standards. This will require more than obtaining simple organic certification. To enable the effective integration and participation of smallholders, especially poor farmers, greater attention should be given to strengthening the organizational and managerial capacities of their local institutions, such as trade associations, NGOs and cooperatives, so that these can more effectively serve farmers' needs and better interact with their supply chain partners. 


\section{Xingji Xiao \\ Director, Organic Food Development Center, State Environmental Protection Administration, China}

The development of organic agriculture (OA) can significantly help to guarantee the quality and safety of agricultural produce. It is therefore extremely important that China develop its organic food industry, in order to capture benefits such as protection and improvement of the rural ecoenvironment, securing a harmonious relationship between man and nature, and the promotion of sustainable agricultural development.

Part I of this chapter by Twarog is a comprehensive and useful information source for stakeholders of the organic sector in developing countries like China, especially governmental officials, organic producers and consumers.

\section{Organic Agriculture: a good choice for long-term sustainable development}

This chapter lists many benefits of OA to developing countries. Development of this form of agriculture in China is fast becoming an integral part of the country's socio-economic development and environmental protection. In the last century, "chemical agriculture" or "petro-agriculture" helped people meet their basic needs such as for food and clothing, but it also led to a series of environmental and food safety problems. This prompted the question as to how the agricultural economy could be developed in a way that would supports environmental protection and human health. Hence, ecological farming or integrated farming (Sheng-Tai-Nong-Ye) made its debut and resulted in the establishment of ecological demonstration zones in almost every corner of the country. Today, these ecological farming bases and demonstration zones play a role in assisting the development of organic food production. In China, "organic food" has come to be associated with such issues environmental and health and safety concerns. More and more people have begun to consider organic food as safer, more nutritious and more environment-friendly than any other kinds of agricultural produce.

\section{OA and environmental protection}

In China, it was environmentalists who spearheaded the OA movement in an effort to find alternative ways to reduce rural environmental pollution and soil erosion, and improve agricultural ecosystems and biodiversity. Thus, the Nanjing Institute of Environmental Sciences (NIES) under the National Environmental Protection Agency (NEPA) has long been engaged in conducting research on and establishing eco-farming experimental sites and ecological demonstration zones. In 1994, NEPA authorized the NIES to set up an organic food development centre (renamed the Organic Food Development Center (OFDC) of the State Environmental Protection Administration (SEPA) in 1998). Since then, the OFDC has pursued a path of vigorous growth along with the development of the organic food sector.

\section{$O A$ as an export opportunity for developing countries}

External demand from developed countries was the initial driving force behind organic production in China. About 12 years ago, the concept of organic food was completely new to the Chinese people. It only became understood in the late 1980s when the NIES joined IFOAM. Although we took the lead in introducing the concept of organic food to the country, we knew very little aboutit. It was not until April 1990, when a Canadian organic certification inspector, working for an organic certifying agency in the Netherlands, came to inspect tea production with NIES researchers that Chinese researchers began to get involved in organic food and organic certification. As a result of that inspection, China gained its first organically certified tea in 1990. From then, the phrase "organic food" became more widely understoodand so began the development of what is known in Chinese asYou Ji Shi Pin. 
Chinese exports of organic produce have increased significantly, amounting to $\$ 150$ million in 2003 (though this represents less than 1 per cent of the world's organic food market). The main export products are soybeans, tea, vegetable, and cereals, and their major markets arethe EU, Japan and the United States. In 1996, the first OFDC-certified organic producer from China took part in the BioFach international organic trade fair, and in 2004 more than 30 Chinese companies participated.

\section{Market access, entry requirements and certification of $\mathrm{OA}$}

China has been making the necessary preparations to support its request for inclusion in the EU's third-country list, and has recently submitted an application to that effect. The preparation process has involved the formulation of organic standards and regulations in China and their implementation.

In 1995, the OFDC developed the first organic food rules -Regulations for management of organic (natural) food labels (provisional) and Technical criteria for production and processing of organic (natural) food -in an effort to incorporate both the experiences of western countries in developing their organic sectors and specific conditions in China. These rules were ratified by SEPA, and represented both the technical criteria for production of organic food and guidelines for the management of organic certification. With the technical support of GTZ (Germany), the OFDC compiled the first edition of OFDC Standard for Organic Certification in 2001, which was comparable to international standards. The success of these regulations provided the basis for the Technical Criteria for Organic Food (HJ/T80-2001) and Approaches to Management of Organic Food Certification (HJ/T80-2001), which formally promulgated by SEPA in 2001; HJ/T80-2001 has since, become the first trade standard for organic certification in China.

In 2002, the State Council of China gave the Certification and Accreditation Administration of China (CNCA) responsibility for the administration of all certifiers - including organic ones - in China. Since then, regulation of the Chinese organic sector has become more stringent.. On 19 January 2005, the China National Organic Product Standard (CNOPS) (GB/T19630-2005) was officially issued by the State General Administration of Quality Supervision, Inspection and Quarantine (SAQSIQ), and Standardization Administration of China, and took effect as of1 April 2005. Organic Product Certification Management Rule (OPCMR) was promulgated after approval by the Bureau Affairs meeting of the State General Administration of Quality Supervision, Inspection and Quarantine on 27 September 272004 as decree No. 67 and took effect as of 1 April 2005. On 1 June 2005, the CNCA issued The Rule on Implementation of Organic Products Certification, which became effective the same day. It stipulates the implementation of organic certification in detail. Within CNOPS, there are separate national certification labels for "organic" and "organicin-conversion" products (i.e. products from farms that utilize organic methods but which have not yet attained organic status). The OPCMR requires that the Chinese national organic or organic-inconversion certification label be indicated on the product or the smallest package of the product along with the label or name of the certification body.

Before 2003, accreditation of organic food certifying agencies was carried out under the authority of the National Organic Food Certification and Accreditation Committee, which is affiliated to SEPA. As stipulated by the Regulations for Certification and Accreditation of the People's Republic of China, promulgated on November 1, 2003, the committee handed over this authority to the Certification and Accreditation Administration of China (CNCA). Any institution that intends to carry out organic certification must first apply to the CNCA for approval.

On assuming this responsibility, the CNCA began to adopt strict supervision, and conducted an overall investigation and evaluation of organic certifying agencies, organic production and processing enterprises and organic product distributors operating throughout the country. This laid a solid foundation for the centralized management of accreditation of organic certification. The China 
National Accreditation Board (CNAB) has started to evaluate and accredit all institutions involved in organic certification within the country. Organic certification in China is therefore well advanced.

\section{The potential for organic markets in developing countries}

Although only a very small proportion of certified OA products are consumed in developing countries, there is enormous potential for the expansion of organic markets along with economic growth in developing countries.

In China, most organic food is produced in the eastern and northeastern parts of the country, due to their strong economic development. So far, China has developed a list of 250-300 types of organic products grouped into 19 categories, including vegetables, fruit, tea, cereal, oil crops, cotton, bee products, Chinese medicinal herbs, products collected from the wild, aquaculture, poultry and animal husbandry.

According to available statistics (albeit incomplete), about 300,000 ha of farms and 300,000 ha of wild harvesting areas were certified as organic in 2003. These produced about 2.5 billion yuan $\left(\$ 309\right.$ million $^{5}$ ) worth of organic products, of which 1.2 billion yuan (\$150 million) worth was exported, and 200 million yuan (\$25 million) worth was sold in the domestic market as certified organic produce. This indicates that a considerable portion of organic products were sold as other types of safe food or conventional food rather than organic products.

Before 1999, essentially no certified organic food was sold in the domestic market. Since then, the domestic organic food market has been developing so rapidly that customers can purchase organic vegetables at supermarkets in Beijing and Shanghai. Today, a variety of organic food products are available, including fresh vegetables, tea, rice, fruits and honey, which are all certified by the OFDC-China and other domestic certifiers.

In developed countries, organic food has progressed to such an extent that organic food markets no longer have "organic-in-conversion" products, but only "organic" products. According to international requirements, all farms must undergo at least a 12-month conversion period, and in most cases a 24-36 month period, before they are eligible to be certified as organic. Thus, after one to two years of organic management, a farm can only produce products termed "organic-inconversion", and in developed countries, such products can only be sold as conventional goods. In China, however, as the organic sector is still in its initial stage of development, a number of farms are still in their conversion period and are unable to supply the market immediately with "organic" products, as these can only be produced after they have completed the conversion of their farming and management systems. Nonetheless, owing to the pressing demand for safe food, consumers are ready to accept "organic-in-conversion" products, because they know that even though the products originate from farmland under conversion, they have never been treated with any chemical fertilizers or pesticides. Therefore, they are ready to pay price premiums even for these products.

According to a survey of the organic food markets in Beijing, Shanghai and Nanjing, the price of OFDC-certified organic-in-conversion vegetables in Nanjing is 1.5-2 times that of conventional ones, while that of organic vegetables is $3-5$ times, and even 7 times, that of conventional ones in the supermarkets in Beijing and Shanghai. What is more, sales are good. Of course, this may be due to the scarcity of organic produce, which influences its pricing in the most developed cities of the country at this initial stage of the development of organic food. With the further development of organic farming, prices are likely to gradually fall, and with development of the market the supply of organic products will increase, providing more choices for customers and relatively lower prices. By then, consumers of organic food will significantly increase and so also will its market share. Assuming that currently food consumption amounts to 1,200 yuan $(\$ 150)$ 
per capita per year, sales of organic food account for only 0.015 per cent of total food sales: over 100 times less than the 2 per cent average for developed countries. With the development of organic farming and the organic food market, if the market share of organic food in China were to reach 1 per cent, expenditure on consumption of organic food could amount to 16 billion yuan ( $\$ 2$ billion).

\section{Challenges related to organic production and market development}

The chapter by Twarog gives a good description of the challenges facing organic production and market development, most of which also apply to China, such as conversion periods, training, research and development, and organic inputs, as well as consumer education and information exchange.

In China, sharp differences exist between regions in terms of geography, history, economy, culture and various social conditions. This leads to the uneven development of organic production and poses several challenges to organic farming, especially in the context of inefficient agriculture, poorly informed rural areas and unorganized farmers.

In order to feed the huge Chinese population, the agricultural policy of "Grains is the Key Link" had been adopted since 1964. This policy aimed at maximizing China's grain production through intensive farming. However, over the years it has led to the abuse of chemical fertilizer and pesticides, especially in the more developed regions of China, and this in turn has resulted in problems such as a decrease in agro-biodiversity, compacted soil, destruction of bio-systems, deforestation and reclamation of grassland for grain production, and overexploitation of natural resources. The resulting rise in agricultural production costs and decline in product quality is not easily remedied. Organic farming has the potential to contribute to solving these problems, but significant challenges remain.

The organic food market at present lacks adequate mechanisms such as information exchange, the ability to correct the balance between surplus and deficiency, improvement of organic food production through exchange and competition, and optimization of resource allocation. The international organic market remains dominated by trade in simple, unprocessed products and there is insufficient exchange of techniques, culture and knowledge of organic farming, organic food production and processing, and management of organic production.

\section{Recommendations at the national level}

This chapter's comprehensive set of recommendations for action at the national level is equally applicable to China's situation. Traditional agricultural practices are widely adopted in organic agriculture in China. Smallholder group certification in the country is done via farmer organizations as well as private organizations. Government support in promoting organic agriculture is one of the most important ways of developing the organic industry.

In recent years, all levels of government in China have begun to take an interest in the organic food sector. In late 2004, a total of 11 ministries and commissions, such as the Ministry of Commerce, Ministry of Science and Technology, Ministry of Finance, SEPA, and CNCA, jointly issued a document aimed at promoting the rapid development of the organic food sector in China. Some provinces have integrated development of the organic food industry with efforts to tackle wider problems related to farmers' livelihoods and the rural environment. This has resulted in a series of incentives such as the provision of subsidies which aim to compensate for the costs of certification and agricultural materials, especially in the initial period of conversion to organic. As a result, organic food producers have become increasingly enthusiastic, and an era of rapid growth of organic food production can be expected. 


\title{
Diane Bowen \\ Organic Guarentee System Manager, International Federation of Organic Agriculture Movements (IFOAM)
}

\author{
"When we try to pick out anything by itself, we find it hitched to everything else in the \\ universe." - John Muir.
}

American's greatest conservationist, writing in 1911, defined the essence of Nature in the simple statement above. Modern jargon describes this concept as "holism," a term often used when referring to organic agriculture (OA). Forsaking the jargon, we can also distinguish OA as respecting the fact that everything in the farming system is linked to everything else in the environment. Best practices in farming are tuned to nature's rhythms, including nutrient recycling, biological competition and cooperation, and, in general, ecological balance. Respecting this balance extends to the relationships of farmers and other humans to the farming system, and therefore OA also incorporates the concepts of social and economic balance.

\section{Defining organic agriculture}

Part I of chapter 3 on organic agriculture by Sophia Twarog presents attempts by several organizations to define and explain the concept, including historical explanations of OA by the IFOAM. Recently, IFOAM has been working to enhance its explanation of "what is organic agriculture" through the elaboration of four basic principles. The first of these, the Principle of Health, states, "Organic Agriculture should sustain and enhance the health of the soil, plant, animal and human as one and indivisible." Health is further described as the wholeness and integrity of living systems. The role of organic agriculture is to sustain and enhance the health of ecosystems and organisms from the smallest in the soil to human beings. In particular, organic agriculture is intended to produce high quality food that is nutritious and has a function in preventive health care.

Another organic principle, the Principle of Ecology, states, "Organic Agriculture should be based on living ecological systems and cycles, work with them, emulate them, and help sustain them." This means that organic management must be adapted to local conditions, ecology, culture and scale. A third Principle is that of fairness, which states, "Organic Agriculture should build on relationships that ensure fairness with regard to the common environment and life opportunities." Natural and environmental resources that are used for production and consumption should be managed in a way that is socially and ecologically just, and should be held in trust for future generations. Fairness requires systems of production, distribution and trade that are open and equitable and which take into account the real environmental costs. Finally, the Principle of Care states, "Organic Agriculture should be managed in a precautionary and responsible manner to protect the health and well-being of current and future generations and the environment." Precaution and responsibility are the key concerns in management, development and technology choices in organic agriculture. These choices should be informed both by scientific and traditional knowledge, and by practical experience.

\section{What is sustainable agriculture?}

Agriculture that is consistently practiced in steadfast adherence to these Principles will be sustainable. However, the Organic Principles describe the aspirations of OA practitioners and other advocates and not necessarily what it always achieves. As with any quality system, the practice of OA represents various degrees of achieving the aspiration. Any single practice of OA is influenced by the ecology, economics, culture, and politics of the site, the region, and indeed, the globe. However the practice of OA, along with the Principles, aspires for agriculture to be sustainable. Accordingly, IFOAM's goal is "the worldwide adoption of ecologically, socially and economically sound systems that are based on the Principles of Organic Agriculture. "

"Sustainable agriculture" is often a broad-brush term used to describe anything that is even a small step away from the chemical industrial model of producing sustenance. Twarog portrays 
organic agriculture as a subset of sustainable agriculture, which includes an array of agricultural models. Individually, these models are "trying to be sustainable agriculture," and differ greatly in their potential to really achieve it. OA is at the very high end of that potential, whereas some practices of so-called sustainable agriculture, including many of the practices of "integrated pest management", are at the low end. Integrated pest management, as the term implies, is about pests, which is a fraction of the large picture of sustainability in agriculture. Some of the "brands" in the marketplace of agricultural models may be better described as "trying to appear as sustainable agriculture." The organic movement is dismayed that global agribusiness and some powerful governments are now trying to sell genetically engineered agriculture as sustainable, when its practical implementation has so far failed to fulfil virtually every long-term measure of sustainability.

\section{Potential contribution of organic agriculture to national sustainable development}

Twarog outlines a lengthy list of benefits of OA to developing countries, grouped into four categories: economic, environmental, food security, and social and cultural. In each of these categories the following themes are addressed:

- Economic: Price, quantity, profitability;

- Food security: Diversified production, nutrition;

- Environmental: Less pollution, improved soil, less erosion, more biodiversity, mitigated climate change, landscape values; and

- Social and cultural: Women's empowerment, traditional knowledge, rural-urban migration, health and safety.

As Twarog correctly points out, food security is related to economic factors. However, the interrelationships are more profound than that, and provide further illustration of the interrelationship of all things, including the issues which NGOs, governments and intergovernmental bodies all try to address. One could consider just one way to scramble the terms (and there are others):

- Economic: Improved soil, less erosion, landscape values (agro-tourism, for example)

- Food Security: Profitability, improved soil, less erosion, women's empowerment, mitigated climate change, rural-urban migration, traditional knowledge

- Environment: Women's empowerment, rural-urban migration, diversified production

- Social and cultural: Nutrition, more biodiversity, landscape values

Thus, "When we try to pick out anything by itself, we find it hitched to everything else."

\section{Organic agriculture as a trade opportunity}

Part I of chapter 3 in this TER offers a useful primer on the rules for exporting products to the major organic markets in the United States and the EU. It consolidates recent organic market information in a way that is valuable not only to developing countries but to anyone who is interested in obtaining a broad perspective of worldwide markets for organic products. It dwells considerably on the premiums for organic products.

Will price premiums be sustained in organic markets? Surely this question is on the minds of many. The answer lies in why these premiums exist in the first place. Price premiums include a reflection of the "value added" by the organic nature of the production of the product. But let us turn this idea on its head. When considering the relationships of values and costs in the global economy, one could come to the conclusion, as have many progressive economists, that our current economic paradigm externalizes many "costs" from the system that it is quantifying. This means, for example, that the true costs of food and fibre to the consumer should, but does not, include the costs of the environmental and human health "clean-up" resulting from the current chemical-industrial agricultural system. The "cheap" price of food externalizes these costs. Instead, consumers in developed countries pay these costs in government taxes and health insurance, which provide the "clean-up" for the cheap industrial food system. In terms of personal 
health, "paying externally for clean-up" means paying later, and probably a lot more. Many consumers in developed countries recognize this, and it is reflected in the results of numerous studies on the reasons why they choose to purchase organic products despite the higher retail prices. They consider them to be healthier for themselves and their families. They seek the immediate health benefits and avoidance of health risk. They do not process this idea in terms of economic modeling. Rather, they adopt it by instinct. They are thus employing the precautionary principle mentioned earlier in this paper.

It is a safe bet that until we change the food system, there will be organic price premiums.

\section{Recommendations to governments}

Twarog offers a comprehensive set of recommendations to governments on how to support the development of organic agriculture within their countries. Hopefully, these will be well received, because earlier sections of the paper seek to convince governments to adopt a policy supportive of organic agriculture.

The recommendations to governments are sound and comprehensive. To this, IFOAM can add some information about what it is doing to support governments with emerging organic sectors. Under a programme called "I-GO", funded by the Dutch development organization, HIVOS, IFOAM is embarking on a programme of assistance to both governments and the private "movement" in countries with emerging organic sectors. IFOAM intends to develop a curriculum for training the governments and private "movement", equipping them with what they need in order to develop their organic agricultural sector. For governments, this includes information on standards-setting, supervision of organic certification bodies, requirements for export to the EU and the United States, and advice on establishing organic extension training and other agronomic assistance to producers. The International Organic Accreditation Service (IAOS), which implements IFOAM accreditation, offers training courses for governments in the area of certification body supervision. For the private "movement", training materials will include information on how to organize and interact with governments to establish favourable policies and programmes to support organic agriculture. Governments should be mindful that organic agriculture has arisen from the movement at the grassroots level, and that partnership with this movement in their countries will yield the best and most satisfying results.

\section{International challenges}

The challenge to developing countries to have their domestic organic standards and programmes recognized internationally cannot be overemphasized. As the chapter states, since implementing its organic regulations in 1996, the European Commission has recognized only eight countries as having equivalent organic regulations - Argentina, Australia, the Czech Republic, Costa Rica, Hungary Israel, New Zealand and Switzerland. ${ }^{7}$ Nine countries have made requests to be added to the list and are at various stages of consideration (Chile, Colombia, the Dominican Republic, Guatemala, India, Japan, Tunisia, Turkey and the United States). Some of these countries have been waiting for many years. The United States National Organic Program (NOP), which was implemented in 2002, has not forged any equivalence agreements, although it has approved five governments to supervise their certification bodies to conduct certification of compliance with the NOP standards. These are two provincial governments in Canada (British Colombia and Quebec), and Denmark, New Zealand and the United Kingdom.

As the chapter also states, the International Task Force (ITF) is hard at work to find ways to lower the trade barriers created by the importing countries' regulatory requirements. IFOAM is also revising its Organic Guarantee System to afford certifiers and producers, especially those from developing countries, much easier access to it. By joining the IFOAM system, certification bodies gain a measure of increased recognition and market access, particularly into EU markets. 
Funding from the Dutch development agency, NOVIB, enables IFOAM to organize an International Certification Body Forum and to support certification bodies from developing countries to participate in it. The objective of the Forum is to build the capacity of the certifiers, mutually solve problems and strengthen the system. It is hoped that the Forum will lead to greater recognition of and cooperation among certifiers, and therefore increase access of developing countries to the importing markets via actions in the private sector.

Until international recognition improves, developing countries with emerging organic sectors will have to find creative ways of exporting their organic produce. This will include choosing wisely those export products that need to be developed and promoted, and building stable and positive relationships with both importers and certification bodies in the target markets. 


\section{David Crucefix, Assistant Executive Director, and Ken Commins, Executive Director \\ International Organic Accreditation Service (IOAS)}

Sophia Twarog poses the question: Is organic agriculture a promising trade and sustainable development opportunity? She concludes with a resounding "yes". In arriving at this conclusion she raises a number of obstacles and challenges. We agree on the conclusion, and that obstacles remain in the way of OA fulfilling its potential.

In this commentary we would like to provide our perspective, both as individuals contributing to the work of the FAO/IFOAM/UNCTAD International Task Force on Harmonization in Organic Agriculture (ITF) and as an international accreditation body, the International Organic Accreditation Service (IOAS), which works solely in the field of organic agriculture. This perspective focuses mainly on national and international issues and solutions rather than the issues raised by the UNCTAD report at the farm level.

The so-called ITF "Solutions" paper (UNCTAD/FAO/IFOAM, 2006) ${ }^{8}$ sets out an objective and work plan to achieve harmonization by:

- The use and adaptation of existing structures and mechanisms of regulation, by both private and public sector;

- Creating production standards equivalent to a single international standard; ${ }^{9}$

- Having one international requirement for conformity assessment; $;^{10}$

- Laying down common international procedures for approval or accreditation of conformity assessment bodies, which would reduce duplication of work and enhance access to markets, including by countries in which regulatory infrastructure is absent or less well developed.

Without doubt, the IOAS sees itself as part of this future.

The initial draft of the "Solutions" paper proposed the establishment of some sort of supranational body to push the process along, but this was rejected in favour of using existing structures. Although nobody wants to add more bureaucratic layers, the worry is that there will be no agency to bully the process along. As has been said more than once before, "everybody wants to harmonize, but generally it's assumed that you harmonize to me and not the other way round". This is as true of government authorities as it is of the private sector. The move in June 2005 by Japanese authorities to allow only direct accreditation of conformity assessment bodies, performed by themselves and no other country or body is one more step in this direction. One solution, proposed in the work plan by the ITF, and the subject of recent work by the IOAS, can best be phrased as "one assessment, multiple markets" ${ }^{11}$ This should work at the farm certification level and can operate in a number of ways.

The worst way for this to happen (which is where we are now) is that the farm works to the various standards required by its markets and the conformity assessment body (CAB) conducts multiple standard checks to ensure compliance. Although having said this is the worst option, it is at least an improvement on the still common option of inspection by more than one conformity assessment body. Accreditation or approval of the conformity assessment body is currently done by every "market" to which the farm (the client of the $\mathrm{CAB}$ ) wishes to sell. An improvement on this would be for one accreditor to assess against all requirements. This is beginning to happen through IOAS collaboration with a number of accreditors and national authorities. The result is lower accreditation costs for CABs, which in turn means lower certification costs for farms and traders, which in turn means lower cost organic products for consumers. IOAS is currently working on developing monitoring systems that can handle multiple standards and conformity assessment requirements that will deliver the "one assessment, multiple markets" goal. It is hoped that authorities in the EU, Japan and 
the United States will increasingly utilize the services of an expert body like IOAS, at least to perform oversight of "foreign" CABs if not those operating domestically.

A better option is for the farm to work to one standard, appropriate to its environment and stage of development, that is recognized as equivalent to an international organic standard such as that proposed by the ITF. This would avoid confusion for the farmer in complying with standards, would bring more farmers into OA because the standards are developed for their situation, and would result in a better quality of inspection and certification because the inspector would not have to think about two or three norms at one time. Accreditation of the conformity assessment body would also be simplified, and should of course provide access to all markets. This is common sense, but we have some way to go before this can prevail, because it requires both a change of mindset towards equivalence and the further development and implementation of the practice of judging equivalence: something which, though much talked about, is not yet in play.

The IOAS has expended and continues to expend much energy on being a key organization in the field of harmonization. For a small, non-profit organization we believe we have achieved excellence and substantial respect in this field; for example, in August 2004 our competence was recognized by the United States Department of Commerce's National Institute of Standards \& Technology. Nevertheless, the IOAS remains in a "no-mans land" of formal acceptance by government authorities. As a result, our work is respected and used, but not acknowledged. This is not only frustrating for us in the IOAS but also confusing for our clients, and their clients in turn. Twarog's paper calls upon the International Accreditation Forum (IAF) to approve IOAS' membership application, which has been before them for over two-and-a-half years.

The IOAS does not see itself as the solution, just part of it. Government authorities should seek to work more closely with bodies such as the IOAS in order that public and private sector expertise can jointly achieve an orderly and considered expansion of organic agriculture, and so exploit the trade and sustainable development opportunity discussed by Twarog. 


\section{Florentine Meinshausen \\ Institute for Marketecology (IMO)}

In order to be marketed as "organic" in the major export markets, agricultural products must be certified by accredited certification bodies. This requirement, which is not well known even to consumers in Europe, often comes as an unpleasant surprise to producers and traders in developing countries. In addition to detailed production rules (which include much more than just non-use of chemicals) and tedious documentation requirements, certification implies an annual inspection of all production steps and chemical analysis of the final product. Yet this is the only way such producers can sell their "naturally grown" products as "organic" in the major markets, which fetches them a premium price.

Nowadays, organic certification is widely accepted as a necessary quality assurance step. It provides consumers in an anonymous global market with a guarantee that the product for which they pay a price premium has in fact been produced according to agreed rules. But what are those agreed rules?

Since the EU took the lead more than 15 years ago in formally regulating the use of the term "organic", all the major markets for organic products (Japan, Switzerland and the United States) have followed with their own regulations. A large number of producer countries worldwide are also in the process of establishing regulations and standards. In addition, there are many private organic standards which often predate government regulations and today serve as marketing tools through labels indicating to the consumer that the product is organic (e.g. Naturland, Demeter, Bio Suisse).

From rather simple and short documents that indicate the main principles of organic production (which a well-informed consumer might also associate with organic farming) and include a few additional requirements to enable inspection, organic standards have developed into regulatory texts of more than 100 pages. Many farmers and traders, let alone consumers, are barely able to read and understand such complex, specialized requirements. Some requirements have become very formal, entailing increasing bureaucratic processes, and are extremely difficult to implement. In addition, the standards are written for the agricultural, economic and ecological conditions existing in consuming countries/regions (mostly Europe and the United States), and hence are, in some instances, almost impossible to implement in developing countries where the conditions are very different.

Taken together with steadily increasing requirements from the food industry regarding food safety and traceability, the result of such requirements is that organic certification is becoming more and more burdensome for producers and manufacturers worldwide. Moreover, producers in developing countries receive the lowest overall prices for their (mainly unprocessed) products, not to mention the enormous difficulties in the practical implementation of certification requirements. Therefore, it is the developing-country producers that suffer the most from the burden of certification.

Certification bodies find themselves in a similar position, squeezed between the difficulties for the farmers on the one hand and market expectations in importing countries on the other. The proliferation of standards for different markets has led to the absurd situation that many producers need to be certified according to many different organic standards, as well as related schemes such as EurepGAP. To offer these multiple certifications, the certifier must have many different accreditations. Even large international certification bodies like the IMO find it almost impossible to afford the many different, often very costly accreditations and ever-growing formal requirements. The result of having to undertake so many bureaucratic procedures and expensive accreditations is that the costs of certification remain relatively high, even when only local inspection personnel are used. 
The IMO, an organic certification body that is active in more than 60 countries worldwide, has chosen a unique new way to address this challenging situation. The local IMO inspection offices develop full expertise and know-how in organic inspection and certification in years of interaction with the head office. Finally, they become ISO-accredited certification offices within the IMO group. All of IMO's local inspection and certification staff work according to the same basic quality manual. The IMO's organizational structure guarantees the clients of any IMO office access to the many different standards and services offered by the overall group, and the organization's high reputation in consuming countries can secure its clients market access to the major organic markets. At the same time, it offers clients strong support as well as a reduction in certification costs. By contrast, local, small certification bodies that lack major, continuous external support are often unable to meet all of the challenges described above, in particular multiple accreditations and market recognition in consumer countries.

A concept that has considerably helped reduce certification costs in developing countries is smallholder group certification. For more than a decade, IMO and the private certifier Naturland have together developed and promoted a system whereby a small or large group of small farmers (instead of individual farmers) in the same region are certified as a group. As a group they run an internal control system (ICS), which ensures both the implementation of some formal quality assurance requirements (e.g. documentation of activities) and compliance by each farmer with the actual production rules. The organic inspection then focuses on the proper functioning of the ICS through a close examination of the quality system as well as re-inspection of a certain number of farmers.

The group structure is also of considerable importance in improving farmers' knowledge of organic production methods through continuous training. Further, it can be instrumental in improving overall product quality, and can result in farmers taking more initiative to organize themselves and the wider development of their communities. While some certifiers continue to emphasize the inspection of all or a large percentage of farmers, and do not require a fully functional ICS, IMO stresses the promotion of group certification as the best structure for certification in developing countries.

Although smallholder group certification is well known and well accepted, it has sometimes been argued that ICSs are too complicated for farmer groups to implement on their own. IMO presently certifies more than 350 smallholder groups, most of which have set up their internal control systems without too much external input; assistance is often provided through some rather basic guidance documents and by learning from other groups in the region. However, this is mainly the case in Latin America, where many well-organized cooperatives exist. While these organizations can incorporate the organic ICS into their already existing procedures and structures, in Africa and Asia there is the additional challenge of organizing farmers into a marketing group. This is often achieved only by traders or NGOs that "contract" farmers for organic production and set up the ICS.

In IMO's experience, ICS in relatively small genuine farmers' groups (e.g. 50-100 farmers) is fairly easy and straightforward to set up if the groups receive good initial training. Often the group needs a good leader and some dedicated individuals within it to run the basic ICS. For example, an IMO expert trained four farmer groups (50-150 farmers per group) in Indonesia on ICS for one week, using the new IFOAM ICS training curriculum for producer groups; the first inspection six months later showed that all groups that had implemented the ICS by themselves had managed to fulfil the certification requirements. The only group that had problems was the one receiving support from a local NGO that was supposed to act as the ICS provider.

On the other hand, often the major difficulties for such small, "genuine" farmers' groups concern product quality management and the handling of marketing and exports, as well as the high certification costs per farmer. Since minimum re-inspection rates relate to the total number of 
farmers, and since the effort required for certification of a group does not increase proportionally to the size of the group, certification costs per farmer normally decrease considerably with any increase in size of the group. Big groups, however, face different challenges. Implementing an ICS at the same time as handling production quality and purchases may require highly educated and skilled personnel, and expert input may therefore be needed over long periods of time.

In conclusion, IMO's experience suggests that small groups need comprehensive training at the start, and some continuous support in the first year. Most of all, however, such groups require major funding support in order to bear the cost of certifications until they are able to sell their products at premium prices. Normally, small groups also need a trading partner with the capacity to improve the marketing of their products, as they often have relatively poor capabilities in this area; otherwise they will require support in setting up marketing links and acquiring sufficient product quality expertise. Larger groups also tend to need funding for the costs of setting up an ICS with professional staff, for covering the conversion period (larger groups tend to include more farmers who may need further time to qualify as organic) and for expert consultant support over the first period of activity. Although marketing support is also needed for some products, the general marketing capacity of larger groups is generally better than that of small groups.

Group certification is one of the few aspects of international certification in which some improvement has been achieved for producers in developing countries. IFOAM played a major role in securing formal acceptance of group certification in the EU and other markets. Unfortunately, the situation with regard to other aspects is far less positive. The number of standards which are a "must" for international trade continues to increase each year, both with regard to organic regulations and other standards emerging in areas such as food safety. Although standards such as HACCP and EurepGAP are voluntary in a formal sense, in reality they are often imposed on producers in developing countries by their buyers, who will only accept certified produce. The Utz Kapeh coffee certification scheme attempts to provide more benefits for developing-country producers, including a simplified certification process, but it is also bound by benchmarking to EurepGAP, and hence is not very flexible.

Although certifiers have taken up this issue by developing one-stop solutions to certification (i.e. offering multiple certifications as a package, carried out by the same inspector), the present system remains very complicated and expensive, both for certifiers and consumers. All standards require laborious and expensive accreditations and entail specific formal requirements regarding inspection staff, how to evaluate compliance and so on. In spite of much talk about harmonization, every scheme still has its own "rules of the game". So far, it has been up to certifiers and producers to find ways to bring the schemes together in order to facilitate implementation and control. This task is often far too complex for farm managers, ICS staff and inspectors in developing countries, even if they are well trained. Better solutions must be found, both to combine schemes at the top level and to adapt them to the specific situations of developing countries.

Finally, it seems important to mention that certification and its costs are definitely not the only obstacles preventing small farmers in developing countries from accessing the organic world market. In many developing countries, it is said that if only certification costs were low or even nonexistent, small farmers could immediately sell their products at organic premium rates on the world market. However, this is clearly not the case. In most cases lack of group management, quality control and marketing skills is a much bigger bottleneck. Product quality nowadays is a much more important issue than it used to be. Organic products must meet the same high requirements as premium-quality conventional products. In addition, supposing that certification and quality challenges could be overcome, demand for organic produce would still be a limiting factor. At current prices, global demand is nowhere near sufficient to provide a market for the total production of all small farmers were they to convert to organic methods.

When discussing certification costs, it is also important to bear in mind that certification is also a marketing tool. It is only worth going to the trouble of obtaining organic certification if the 
premium price obtained for the certified product exceeds any extra certification, production and management costs incurred. If this is not the case, it may make more sense to adhere to organic principles - which bring the other benefits of organic production described in this chapter - while at the same time avoiding the administrative burdens and costs of organic certification by simply selling the produce on the conventional market, possibly as a premium-quality product. 


\section{Gunnar Rundgren}

Chief Executive Officer, Grolink AB

\section{Exports of organic products improve livelihoods of thousands of farmers}

Chapter 3, part I by Sophia Twarog covers a lot of ground and demonstrates most of the potential of organic farming. Producers in developing countries that seek benefits from the organic market fall into two quite different categories. On the one hand, there are advanced producers who have close contact with the markets, often supermarkets in the importing countries. They see that organic products are in demand and that general requirements for production in the food sector are moving in a similar direction as that of organic products (i.e. the need for well defined production standards, traceability, certification, record-keeping and transparency). They therefore believe they might as well opt for organic production. On the other hand, there are smallholders, who some consider as having been "left behind" in the move to modernization. They have no contacts with distant markets, most of them have never heard the word organic, but their production systems are in many - but not all - cases quite similar to organic. Therefore, with just minor changes to their production systems, and given an operating trading structure, they can reap the benefits of the growing organic markets.

The Export Promotion of Organic Products from Africa (EPOPA) programme was established by the Swedish International Development Cooperation Agency in 1997. It was based on a fairly simple line of thought: since many African smallholders cannot afford to buy the inputs that currently form the basis for conventional farming (i.e. chemical pesticides and artificial fertilizers), why not turn this into an advantage, and let them access the organic market which gives them higher prices? In addition, it was recognized that the smallholder farmers themselves are not able to cope with export requirements or finance the export operation, and therefore a qualified exporter is needed to liaise between the farmers and the markets. Due to its success, the programme was extended first in 2002, and recently, has again been extended to 2008 .

The EPOPA programme develops exports of organic products from Africa. It helps participating countries to increase and diversify their exports. At the same time, the agricultural sector is taught innovative and environmentally sound farming techniques. Prices paid for certified organic products are higher than for conventional products. On average this results in a premium of 15-40 per cent on the prices paid to the farmers. In most cases, farmers respond with higher productivity and more attention to their crops. At present, 20 export projects are being implemented, most of them in Uganda and the United Republic of Tanzania, and one in Zambia, the latest country to be included in the programme. Products range from typical export commodities, such as coffee, to processed products such as lemon grass oil or bark cloth.

\section{Box 1. EPOPA support to farmers and exporters}

EPOPA support to farmers and exporters includes:

- Management assistance;

- Staff training;

- Field officer training;

- Advice on organic agriculture; field extension services and setting up of demonstration gardens;

- Development and revision of an internal control system;

- Farmer mobilization techniques and inputs;

- Provision of seed money for farmers' inputs;

- Setting up of tree/crop seedling nurseries;

- Technical consultancy and agricultural improvements;

- Product quality management and quality improvement measures; and

- Development of new crops and products. 


\section{Market surveys and buyer contacts}

The four main areas of EPOPA activities are:

- Quality and production development;

- Market links;

- Organic production; and

- Certification.

As the organic market grows, so does competition. To assume market success just because a product is organic is naïve. However, it is not too difficult to find markets for quality organic products. Quality improvements in production, post-harvest and processing are an important focus of EPOPA. The programme provides marketing assistance to the participants, ranging from matchmaking between the exporter and the markets for its commodities, to the development of pre-packed retail products. EPOPA provides market information and initiates market contacts, for example at organic trade shows. Once a business relationship is established, it is up to the exporter to maintain the contact, although EPOPA continues to provide backstopping and follow-up support with buyers, where necessary, to ensure reliable and stable trade relations.

In many parts of Africa where government extension services are virtually non-existent, EPOPA has shown that it is possible for exporters, through field staff, to provide and finance such services instead. Apart from assuring the organic aspect, the exporters have discovered that taking on such a role is necessary to ensure high quality produce. EPOPA's experience has shown that the exporters need assistance to get accustomed to this new role, especially in the first years, and that they require additional sets of skills apart from mere trading.

Organic production is characterized by strict inspection and certification. There are far too many farmers in most EPOPA projects (the largest ones comprising more than 10,000 farmers) to allow a system where each farmer is annually inspected by an external inspector as is common in the North. In addition, even with higher prices, the total income for many farmers is just $\$ 100$ $\$ 500$, which cannot pay for individual external inspections. Already in the first EPOPA projects the system of group certification was introduced, and EPOPA, together with the Swedish certification body KRAV and the Swiss-based Institute for Marketecology (IMO), developed internal control systems (ICS), which allow for smallholder group certification (discussed in more detail in chapter 3, part I of this TER).

While EPOPA works with exporters, its real target is the smallholder farmer. The programme managed to improve the livelihoods of over 27,000 small farmers in 2004. They gained from securing 15-40 per cent higher prices for their cash crops. Higher prices result not only from the organic nature of the products but also from their better quality. In some cases the higher prices result from more direct trading structures. After a few years of farming organically, the farmers have also reported a significant increase in productivity due to better and more intensive crop management. Earlier, EPOPA had supported another 30,000 farmers involved in export projects, and today they no longer require the programme's support, which is probably the best indicator that it is sustainable.

Given the increased value of the exports, the majority of EPOPA interventions are paid back in four to five years from the start of the support. Most exporters would not be willing to take the risk because of their lack of knowledge about the organic market and its development. Assistance by EPOPA allows them to enter this market and set an example to other exporters.

\section{Institutional development and capacity building}

The first seven years have shown that the Programme's premise, development through organic trade, has true potential. At the same time, the organic export sectors of countries should not be 


\section{Box 2. What happens to food production when farms are converted to organic agriculture?}

In reality this varies considerably, depending on the conditions before conversion. In "traditional" smallholder agriculture in rain-fed areas, organic agriculture normally leads to increased yields. This increase in productivity is due to several reasons:

- Greater crop diversity, which has the added benefit of more varied diets, and lowers the risk of harvest failure for the farmers;

- Improved organic matter management through the use of green manure crops, resulting also in better water retention;

- Improved on-farm recycling of nutrients and better use of organic materials from the surrounding ecosystem;

- More attention to soil and nature conservation, and therefore less soil erosion and no deforestation; and

- It is a system that is understood by and accessible to the smallholder farmers.

islands of development. EPOPA encourages the development of local and regional markets and the development of local organic certification bodies. It provides training programmes for the sector at large and supports the local organic movements in the programme countries. In addition, it engages in policy dialogue with the governments and other stakeholders.

\section{Developing national certification}

UgoCert and TanCert are the first national certification bodies for organic agriculture in Uganda and the United Republic of Tanzania respectively. Developing certification, standards, certification procedures and training of inspectors is crucial to ensure sustainable local and international trade in organic products. UgoCert and TanCert are both stakeholder-based organizations that engage in local and international certification. To date they are not internationally recognized, but they operate in close cooperation with a European certifier. However, they both intend to apply for IFOAM accreditation soon.

Locally based certification bodies often initially play a prominent role in the local development of the sector and for the formulation of locally adapted standards. A branch of a foreign body is rarely engaged in local development in the same way, and as the service it offers is generally uniquely for the export market, it has little interest in developing the local market. For producers wanting to access the home market, the only certification available is therefore from a foreign agency and at a cost more adapted to the export sector. Therefore there are some developmentrelated arguments for supporting local bodies. In some regards, a local body can also exercise more efficient controls; only an organization with a local presence can follow the market on a dayto-day basis and react quickly to important developments - such as pest outbreaks or government pesticide distribution programmes - that can affect certification.

\section{Conclusions}

EPOPA has shown that it is possible to organize farmers to undertake organic farming, to set up a group certification system and to initiate export businesses that are rewarding for all parties. However, it should be recognized that all economic activities naturally go through cycles of good and bad times. To develop sustainable agriculture, more time is needed, and solid trade relations only develop over time. There is potential for more EPOPA-type projects, also in other countries. At present, the programme benefits only a few selected exporters.

More policy support is needed from international agencies and national governments to make organic agriculture a major component of their development strategies, for reasons ranging from 
poverty eradication via food security to sustainable resource management. This would mean not only considering special programmes and incentives for organic producers, but also seeing how overall agricultural policies affect organic producers. For example, a number of developing countries still have subsidies for agro-chemicals, or other special programmes to promote their use. This clearly puts organic producers at a disadvantage. Unfortunately, often the initial government reaction to an emerging organic sector is to regulate it (i.e. introduce market regulations such as the ones in the EU or the United States). There is no evidence that this is the best policy response; on the contrary, a premature regulation may stifle the development of the sector. Other actions as outlined by Twarog should also be given priority.

Standards and certification requirements are currently posing the greatest challenge for the sector, especially for those dependent on many export markets, such as the producers in the EPOPA programme. The lack of operational equivalence, both in the private sector and among governments, is creating an inefficient market and keeping a number of potential producers out of the sector. Standards and certification requirements developed in the main markets are not readily applicable all over the world. One could imagine a system that uses locally adapted standards, based on an international baseline (IFOAM or Codex Alimentarius), where organic certification bodies work in mutual recognition of agreed requirements. The government's role would mainly involve oversight to ensure honest marketing (labelling) claims and focusing on deterring fraudulent and deceptive practices.

In addition, it is somewhat absurd that the producers who are not using dangerous technologies, such as pesticides or genetically modified organisms, should need certification and pay for the costs, while those adopting risky practices are considered as being "normal". In the longer term it seems to be a more logical development if organic is seen as "normal" and the other products have to undergo all the additional procedures and associated costs. The road towards this goal is surely not by constantly increasing certification requirements for organic producers. 


\section{Felicia Echeverría Hermoso \\ Special Adviser on Organic Agriculture to the Minister of Agriculture and Livestock, former Manager of the National Organic Agriculture Programme, Costa Rica}

\section{Introduction and background}

First of all, from the perspective of someone who during the past seven years has worked directly with small farmers, national institutions, NGOs and other stakeholders in a joint effort to support organic agricultural development in Costa Rica, I would like to point out that part I of the chapter on organic agriculture by Sophia Twarog does an excellent job of highlighting (and updating) the main issues to provide a better understanding of the dynamics of the "organic agriculture world". This commentary first briefly describes the organic situation in Costa Rica in order to provide the context for my comments on the issues most relevant to that situation.

Costa Rica has a territory of 51,100 sq. $\mathrm{km}$. and a population of nearly 4 million people; ${ }^{12} 25.6$ per cent of its land constitutes environmentally protected areas, while farming is done on 56 per cent $(2,845,000$ ha.). In 2004 there were 10,682 ha. of farmland certified as organic at the official registry of the Gerencia Técnica de Acreditación y Registro de Agricultura Orgánica del Ministerio de Agricultura y Ganadería (GTRAO, or Organic Agriculture Accreditation and Registry Office of the Ministry of Agriculture and Livestock). This area represented 2.1 per cent of total cropland for that year. The main organic products currently being exported include: bananas (mashed for baby food and dried), cacao, coffee, blackberries, raw sugar, mango, pineapple (fresh and dried), orange juice and concentrate, and passion fruit. The domestic market for organic products is still very small but has been slowly growing over the past five or six years. As well as the items listed above, domestic sales of organic produce comprise almost everything that the regular consumer needs, including animal products, although output is not sufficient to satisfy current demand. Organic products are sold mainly at local community markets, weekly farmers' markets and supermarkets.

The national organic movement, now organized as Movimiento de Agricultura Orgánica Costarricense (MAOCO), has been growing for the past 10 to 15 years. As in many other countries around the world, small farmers and NGOs were the first to get involved, a number of them supported by projects undertaken by academic groups or NGOs, as well as by a few intermediaries (mainly for the export markets). During the past seven years, more active involvement from the public sector and a greater openness to developing alliances among the different actors involved has resulted in a considerably stronger organic movement in which the Government operates along with the other stakeholders. MAOCO has also developed a long-term action plan, the National Strategy for Organic Agriculture Promotion, based on wide-ranging consultation.

As mentioned in part II of the chapter, by René Vossenaar and Amy Angel, at the governmental level there are currently two offices in charge of organic agriculture-related issues. These are the Programa Nacional de Agricultura Orgánica del Ministerio de Agricultura y Ganadería (PNAO, National Organic Agriculture Programme) and the GTARAO. Both offices are under the Direction of Phytosanitary Protection in the Ministry of Agriculture and Livestock (MAG), although they have quite different mandates. PNAO's main objective is to promote production, transformation, international trade and local marketing of organic products. It helps to identify national organic farmers' needs, and coordinates with public and private institutions in charge of supporting agriculture, as well as with national and international financial and technical cooperation organizations. PNAO works to ensure that these organizations cater for the needs of organic farmers in the same way as they do for conventional farmers.

The national organic guarantee system is managed by GTARAO through the following activities:

- Accreditation of certification bodies;

- Maintenance of a registry of certification bodies, inspectors, certified farmers, processors and others; and 
- Supervision and auditing of the entire organic guarantee system, based on the following national laws and regulations:

- Environmental Law No. 7554 of 1995;

- Phytosanitary Protection Law No. 7664 of 1997 and the Organic Agriculture Regulation Decree No. 29782 of $2001 .^{13}$

Costa Rica was included in the EU's "third-country list" (section 1, article 11 of the CEE Regulation No. 2092/91) on March 2003, which means that the EU recognizes Costa Rican regulations and its conformity assessment system as equivalent to its own. Costa Rica is also on Switzerland's third-country list, and the processes for equivalency recognition from the United States and Japan are under way.

There are currently two national certification agencies (EcoLogica and AIMCOPOP) and four international ones (BCS Oko Garantie, OCIA, Ecocert and SKAL) accredited by GTARAO. A national seal to back up the official certification system has been developed by the Ministry of Agriculture and Livestock, and it may be used at no charge by those who are certified by any of the accredited bodies.

\section{To what extent have we been able to take advantage of organic agricultural production as a new trade opportunity for Costa Rica?}

Unfortunately, studies that would be necessary to measure the impact of trade in organic products on, for example, export opportunities for small farmers or sustainable development indicators during the past 15 years are not available. However, to address the above-mentioned question, some concrete examples provide evidence for what could be considered more a perception than a scientific conclusion.

Grasping the new trade opportunities afforded by OA is not easy. As Twarog points out, some of the challenges related to organic exports - especially those concerning the lack of harmonization - have an adverse impact on the possibilities for production growth. This means that once a country has certified and is exporting a certain "natural base" of easily accessible organic products, the sector can face certain constraints that make it difficult to increase production levels for new export products in order to take advantage of new trade opportunities.

Without wanting to sound too confident, it seems that the hard work of many actors from both the private and public sectors have put Costa Rica in the lead in addressing certification issues that are considered crucial to facilitate trade in organic products. Costa Rica's achievements in this area include: the development of a national organic guarantee system (which includes the less expensive option of group certification); recognition of equivalence with one of the main markets (the EU); and an internationally recognized national certification body. In fact, according to a recent study by Els Wynen $(2005)^{14}$ for the FAO/IFOAM/UNCTAD International Task Force on Harmonization and Equivalence in Organic Agriculture (ITF), farmers in Costa Rica currently enjoy one of the lowest certification costs in the region.

In order to achieve this, much coordination, hard work and investment in studies and capacitybuilding activities for both government officials and local certification bodies was required. Other sectors of the organic movement were also involved in the process: in 2000, organic regulations were reviewed by a national committee comprising participants representing all sectors (e.g. farmers, NGOs and the academic sector). The challenge was to adapt the national regulation that already existed in order to suit local conditions better and still comply with EU requirements. The discussions were intense and, in order to be "eligible" for the third-country list, some compromises had to be made to the detriment of local farmers' needs and of local development of organic production and marketing. For example, an important limitation on local organic production and marketing is the fact that organic certification has to be mandatory, even if the farmers' operations 
are very small and their produce is sold at nearby markets where most consumers know them. In such cases, certification is still too costly for small farmers, as local consumers usually are not prepared to pay a price premium for certified products.

According to local certification bodies, the main advantage of having the Costa Rican guarantee system recognized as equivalent by the EU is that it simplifies the process of exporting organic products to the EU. In addition, some producers participating in BioFach in 2003 and 2004 report greater confidence in Costa Rican organic products. As a result of this simplified process, and growing confidence, producers are receiving higher levels of interest from importers in buying Costa Rican organic produce.

However, formal recognition does not necessarily translate into marketing reality. Local Costa Rican certification bodies are not necessarily recognized in EU markets, and many farmers are still asked to certify under different European certification bodies to meet clients' preferences (as pointed out by Vossenaar and Angel with reference to organic bananas). This continues to raise certification costs for local farmers, sometimes by as much as 100 per cent. We believe this need for multiple certifications does not originate so much in the public sector, but rather is the result of a lack of transparency and sometimes even alliances between importers and private European certification bodies.

In promoting new trade opportunities for organic products from developing countries, it is vital that this problem be addressed. Even if harmonization efforts were to be successful, with equivalency agreements between governments of all countries and fully implemented legislation, unless there is a concerted effort to support certification bodies from developing countries, organic farmers will continue to face unfairly high certification costs when they attempt to export.

In addition to these multiple certification problems, lack of international harmonization has the further consequence that farmers who wish to export to several countries often have to comply simultaneously with several sets of different regulations (which may even be contradictory). The result is that our farmers end up having to comply with the most restrictive aspects of the different sets of regulations. This only considers what happens with government regulations; in addition, if a buyer in one of the importing countries asks for a specific certification body, this private body may have its own standards of certification. Thus the farmer has to comply with multiple layers of standards, each additional requirement restricting more and more the techniques and technologies that the farmer can use.

For most small farmers in Costa Rica, other negative aspects associated with the present organic guarantee system are: the indirect costs of the system (farmer training, time dedicated to record-keeping and administrative costs of the internal control system for groups); farmers becoming discouraged because of "too much complication and not enough compensation" especially during the transition period (complicated regulations required to be learned and followed, too much detail in record-keeping, a long transition period with no price premium); and lack of appropriate technical assistance (certification bodies tend to tell farmers what they are not allowed to do but offer no help for improving techniques, while most local technicians find it hard to follow up on the immense variety of regulations and standards).

\section{Organic agriculture and sustainable development in the field}

Twarog's comprehensive summation of the potential of organic agriculture to generate the economic, environmental, social and cultural benefits that are expected to accrue from national sustainable development is an important contribution to an understanding both of the breadth of this activity and of the importance of adequate policy development to support it. 
In examining the benefits described, it becomes easier to establish a clear relationship between these benefits and certain technological and cultural practices implicit in the kind of "model" utilized by small farmers in developing countries. Key features of the kind of organic agriculture described include: the highly efficient use of farm resources, including family labour, with little or no external input utilization; diversified cropping (providing a good source of food for the farm family, as well as favouring an ecological balance of species) and the high priority accorded to soil and water conservation practices, the protection of natural resources, the development of local market initiatives and family and community involvement (often resulting in the development of farmer-consumer alliances). This is indeed an alternative rural development model in itself, in line with what many in Latin America now call the agro-ecological approach.

These small and unspecialized production units are much more profitable for small farmers than the high-input, high-yield monoculture model. Furthermore, there exist hundreds of examples in the field to show that this model, spontaneously developed by the farmers themselves, does work in a sustainable fashion. It is common to hear about farmers who, when working a conventional monoculture farm, cannot earn enough money to live solely from their land. After converting to an organic, diversified and integrated model, however, and once past the difficult transition period, such farmers can not only live completely from the farm, but often are also able to increase their income and quality of life.

It is, however, important to note that not all organic agriculture being practiced and even certified in developing countries fits with the "model" just described. Indeed, very often, and especially when a specific organic product is highly oriented to an export market that demands high volumes (e.g. organic orange juice from Costa Rica), the organic production is carried out under an "input substitution" model, with little crop diversification or agro-ecological balance and high dependence on expensive organic external inputs. This type of organic agriculture is being implemented mainly by large holdings, and is dependent on high premiums for profitability. By contrast, agro-ecological initiatives are not dependent on high premiums, at least in Latin America (where in any case the domestic market does not provide them). Profits are mainly derived, instead, from cost reductions and increased farm yields.

There are important sustainability issues involved in these different approaches, and more economic and technical research needs to be done to arrive at figures and facts that can guide us when trying to draft the best policies to promote the most sustainable forms of organic agriculture in developing countries.

\section{Importance of promoting public and private sector alliances for policy and strategy development and implementation}

Although a consensus exists on the sustainable nature of organic practices, most policy- makers and government officials working in the agriculture sector have only very basic knowledge about organic agriculture. In particular they have little knowledge about the wider agro-ecological interrelations that play an important role in ensuring that the benefits of OA effectively accrue to small farmers in developing countries. For example, when government officials, extension workers and researchers first get involved in organic agriculture, they often perceive it primarily as an activity aimed at avoiding contamination from synthetic pesticides. As a result, their main concerns when trying to put in place conditions for the development of OA are related to the availability of input substitutes, subsidies for inputs and/or infrastructure, and certification.

Though these are important issues, they do not cover the wider challenges faced by organic farmers. For the design of effective policies, a more thorough understanding of the holistic nature of sustainable organic agriculture (including a number of factors not necessarily related to inputs) is needed, particularly an awareness of the fact that, as Twarog notes, it is "knowledge-intensive as opposed to external-input-intensive". If government initiatives fail to take into account the wider 
social, ecological and economic relations in which organic practices are rooted, efforts to ensure the necessary conditions for small farmers to access national and international markets, as well as to enjoy the collateral, and, most importantly, the benefits of OA will fail. This is especially true for approaches on research and technology transfer, credit lines and incentives, among others.

One crucial way of ensuring that policies, legislation and strategies address the real needs of small organic farmers is the promotion of strong and open alliances between the public sector and local organic movements (including small farmers, NGOs, certification bodies and universities). By involving a range of stakeholders in the policy-making process, particularly those with experience and expertise at the farm level, governments can benefit from a pool of knowledge that can be used to broaden their understanding of OA. As a result, initiatives aimed at supporting the development of OA are more likely to target the most important obstacles faced by the sector, and thus will be more effective.

This is especially important now that governments in developing countries are increasingly being approached by international institutions, organizations and cooperation agencies with proposals for legislation and policy development aimed at supporting organic agriculture and taking advantage of related trade opportunities.

National organic movements, whether organized or not, can play an indispensable role in giving policy- and decision-makers the correct policy orientation with regard to the long- term strategies and legislation needed to benefit the majority of those working in the productive organic sector in developing countries: small farmer families. The Costa Rican experience with national policy development through MAOCO's Regional Organic Agriculture Strategies and, more recently, the drafting and negotiations for the submission of a Law for the Promotion of Organic Agriculture to the national congress, are examples of the potential positive outcomes of such alliances. 


\section{Mohamed Ben Kheder}

Director, Technical Center of Organic Agriculture, Tunisia

Samia Maamer Belkheria

Department of Agricultural Production, Ministry of Agriculture, Tunisia

\section{Organic agriculture in Tunisia - a success story}

\section{Introduction}

Organic agriculture is relatively new in Tunisia. The development of OA began in the mid-1980s through private initiatives, and the sector continued to evolve slowly until 1997. Recent years have seen a large increase in the area farmed and in the number of farmers using organic techniques, as well as greater crop diversification and better organization of the organic sector. These important developments have been the result of policies aimed at supporting the sector and underlined in a national strategy based on the following aspects.

\section{National regulation}

Tunisian legislation makes reference to organic standards such as the IFOAM Basic Standards, EU regulations on organic production and Codex Alimentarius Organic Guidelines ${ }^{15}$. National regulations were implemented during the period 1999-2004, and are being extended to cover aspects of processing and labelling. The main regulations are: the law related to organic agriculture, a decree related to certification, Order of the Minister of Agriculture related to Organic Plant Production, Order of the Minister of Agriculture related to Organic Animal Production, Order of the Minister of Agriculture related to Processing and Labelling (in preparation)

Tunisia presented the EU with dossiers of information related to its organic regulations and practices in March 2000 and January 2003 in order to apply for inclusion on the EU's thirdcountry list referred to by Twarog.

The competent authority is the National Commission for Organic Agriculture, which is composed of representatives of government ministries, farmers, industry, consumers and certification bodies. Its main tasks are to: prepare proposals for organic agricultural promotion and support; study all files and documents related to organic agriculture; and approve or withdraw certification bodies.

\section{Inspection and certification bodies}

Four inspection and certification bodies are operating in Tunisia following approval from the Ministry of Agriculture, Environment and Natural Resources. They are ECOCERT SA, Instituto Mediterraneo di Certificazione (IMC), LACON Ltd. and BCS Öko-Garantie GmbH. They seek to ensure compliance with IFOAM standards, EU regulations and Tunisian legislation, and each has a representative bureau in Tunisia.

\section{Incentives and subsidies}

\section{Tax breaks}

Like other agricultural investments, those in organic farming benefit from the following tax reductions:

- Tax deductions for all investment income and benefits during the first 10 years;

- Tax deductions on incomes and benefits reinvested as part of the initial capital investment in an OA company or as an increase in such investment, including invested benefits in the company; 
- Exemption from customs duties and suspension of value added tax (VAT) for imported equipment that does not have a locally manufactured equivalent, and suspension of VAT for locally produced equipment; ${ }^{16}$ and

- Reimbursement of contract fees incurred as a result of investing in agricultural land. The purchaser must submit a request for reimbursement no later than one year after the declaration of the investment.

Moreover, organic agriculture projects that are entirely export-oriented also receive the following benefits:

- Exemption from customs duties and suspension of VAT for the acquisition of equipment and supplies necessary for production;

- Possibility of assistance for local marketing at the rate of 30 per cent of the production value. This is authorized by the national regulation for the Tunisian exporting societies; and

- Recruiting of four foreign supervisors without prior agreement.

\section{Financial benefits}

- Subsidies related to project study fees equivalent to 1 per cent of the invested amount and up to a maximum of 1,500 Tunisian dinars for B category investments and 5,000 Tunisian dinars for C category investments;

- Investment subsidies fixed at 30 per cent of the value of equipment and tools specific to organic projects; and

- Annual subsidies over a five-year period to cover inspection and certification fees, equivalent to 70 per cent of the cost, provided that the overall value of the subsidies does not exceed 5,000 Tunisian dinars. ${ }^{17}$

\section{Research}

\section{Adaptation of research results}

Many results of national and international research applicable to organic agriculture are being adapted at experimental stations and in organic farm trials (e.g. relating to fertilization and plant protection).

\section{Research projects}

Universities and research institutions are conducting new research projects that focus on organic agriculture, including variety testing (vegetables), compost quality, use of various organic matter (farm by-products and manure), plant cultivation techniques (e.g. grafting), disease and pest control (e.g. relating to olives, date palms and vegetables), and organic animal farming techniques.

\section{Training}

\section{Academic training}

Some modules in organic agriculture are being offered to students (agricultural technicians and engineers) in different agronomic institutes, and there are plans to introduce specialization in OA for engineers. Two Master of Science level programmes are being offered in sustainable agriculture and organic agriculture.

\section{Professional training}

Many training days, short sessions and short courses in various OA topics have been offered to technicians, engineers and farmers. This training has led to the setting up of regional networks. 


\begin{tabular}{|c|c|c|c|c|c|c|c|c|}
\hline \multicolumn{9}{|c|}{ Table 1: Growth in organic area and number of operators } \\
\hline & 1997 & 1998 & 1999 & 2000 & 2001 & 2002 & 2003 & 2004 \\
\hline Area (ha) & 300 & 7201 & 15036 & 15036 & 16533 & 18638 & 33500 & 100000 \\
\hline $\begin{array}{l}\text { Number of } \\
\text { operators }\end{array}$ & 10 & 63 & 141 & 141 & 294 & 481 & 580 & 660 \\
\hline
\end{tabular}

Each region has:

- Three technicians/engineers representing the regional agricultural service, the regional agricultural training centre and the regional union of agricultural farmers. These technicians are in charge of information extension and training;

- Professionals involved in OA, including production, processing and marketing.

\section{Structures and organizations}

There are various structures and organizations involved directly in OA. At the administrative level these are the National Commission of Organic Agriculture, the National Bureau of Organic Agriculture, the Technical Center of Organic Agriculture, technical regional networks in organic agriculture, organic units in inter-professional organizations, as well as other organizations and institutions involved indirectly or partially in organic agriculture. At the professional level, are the National Federation of Organic Agriculture and many organic farmers' associations

\section{Organic agricultural sector}

Tables 1, 2 and 3 show respectively the increase in area farmed organically and the number of farmers, the crop area and production levels. Organic farms vary in size, from 1 ha to over 28,000 ha. Most of the organic date farms are smallholdings (1-2 ha), while organic olive farms are much larger. With organic livestock farming still in its infancy, the number of animals reared organically is low.

As for geographic distribution, this is mostly in the centre and the south, with only a little found in the north of the country.

Table 2: Area under organic crops (2004)

\begin{tabular}{lrr} 
Crops & Area (ha)* & \multicolumn{1}{c}{$\%$} \\
\hline Olives & 83791 & 83.79 \\
Almonds & 1251 & 1.25 \\
Date palms & 1035 & 1.03 \\
Other fruit trees & 3030 & 3.03 \\
Aromatic plants/jojoba & 6563 & 6.56 \\
Vegetables & 80 & 0.54 \\
Cereals & 1110 & 1.11 \\
Forage & 74 & 0.07 \\
Cactii & 304 & 0.30 \\
Other crops & 2762 & 2.76 \\
Total & 100000 & 100.00
\end{tabular}

\footnotetext{
* About 71 per cent certified and 29 per cent in conversion
} 
Table 3: Organic plant production (2003)

\begin{tabular}{lrr} 
Crops & Production (tons)* & \multicolumn{1}{c}{$\%$} \\
\hline Olives & 33170 & 87.25 \\
Dates & 3300 & 8.67 \\
Vegetables & 480 & 1.26 \\
Aromatic plants / jojoba & 303 & 0.79 \\
Cereals & 578 & 1.52 \\
Other crops & 194 & 0.05 \\
Total & 38025 & 100.00
\end{tabular}

* There are about 20 processing units, located mostly in the centre and the south and a few in the north of the country.

No organic farms are owned by foreign companies, though partnerships between Tunisians and foreigners exist in a few farms (of about $400 \mathrm{ha}$ ).

\section{Soil fertility}

In Tunisia the soil quality is generally poor (low organic matter content, low biological activity and poor structure). The main problems of soil fertility are being addressed by the introduction of green manure in rotation programmes, training farmers in compost management, and the supply of authorized organic and mineral fertilizers (in sufficient quantity) in the country.

The low level of organic matter in most soils, the need for farmers to harvest two to three vegetable crops per year from the same plot, and the frequent intercropping of fruit trees and annual crops with palm date trees means that organic agriculture requires a high amount of nutrients. The application of compost and extensive manure has increased the olive yield of different organic olive farms from 14 to 40 per cent after the conventional period.

\section{Pest and weed control}

The control of some pests and diseases is not efficient, because many authorized products cannot be found in the country and those that exist are not yet registered. In this connection, a list of registered products is being prepared. Farmers do not always adopt crop rotation for weed control. Working towards biological equilibrium and restoring biodiversity should be considered integral to the organic approach to agriculture.

Table 4: Organic plant production (2004)

\begin{tabular}{lrr} 
Crops & Production (tons) & \% \\
\hline Olives & 23000 & 63.88 \\
Dates & 4600 & 12.77 \\
Vegetables & 130 & 0.36 \\
Aromatic plants / jojoba & 6950 & 26.80 \\
Cereals & 620 & 1.72 \\
Other crops & 700 & 1.05 \\
Total & 36000 & 100.00
\end{tabular}




\section{Inputs for $O A$}

There are some constraints to the import of important inputs: the list of recorded inputs authorized in organic agriculture is short and incomplete, and farmers are not familiar with the equipment and techniques used in organic agriculture (i.e. compost and weed management).

The main authorized materials for soil fertilization, protection and processing are:

- local organic matter;

- natural minerals allowed by EC regulations;

- sulfur products;

- copper products;

- mineral oils;

- Bacillus thuringiensis;

- pheromones in traps;

- methaldehyde in traps;

- local natural predators and enemies (i.e. beneficial insects); and

- additives and processing aids allowed by EC regulations.

A complete list of authorized material has already been prepared.

Seeds, seedlings and other propagating material used in organic agriculture are both local and foreign, and are either organically certified or just not chemically treated. Olive and date production relies on plants that were planted in the past.

Local firms are beginning to produce materials for organic production, but as yet such enterprises exist only on a very small scale. Some farmers' associations have begun to produce compost and local predators. Other projects are being prepared.

\section{Market aspects}

Tunisian organic products are produced under sustainable agro-ecosystems and thus are of good quality.

Most of the production is directed to the export market and is sold as being typically Tunisian. The main products are olive oil and dates (table 4). Organic olive farmers receive a price premium ranging from 10 to 20 per cent. Production of other crops is still low and is aimed mainly at the local market. However, there is not yet a real local market for organic products. A strategy is being prepared to encourage local marketing and consumption of organic products. Moreover, a new initiative relating to domestic market promotion involving vegetable and fruit farmers and five supermarket chains has been launched, and the initial results are promising.

The main foreign markets for the major Tunisian organic exports (listed in order of importance) are:

- Olive oil: The United States, Italy, Spain, France;

- Dates: Germany, the United Kingdom, the Netherlands, France, Switzerland;

- Vegetables: France and the United Kingdom;

- Jojoba: Switzerland; and

- Aromatic plants: Italy and France.

Recently, some companies have started to export organic products from Tunisia, including CHO, Med Gold, Borges, Sfax huile, Agro CRC and CCF. In addition, some farmers' associations such as Zayatine Sfax and Beni Ghrib continue to export their products. At the same time, some farmers both produce and export organic products, while other farmers are under contract with exporting companies. 
The marketing of Tunisian organic products has been improving gradually since 1999. The main export constraints are related to the lack of market assessment and marketing planning (i.e. evaluation of opportunities, estimating future demand and prices of organic products), as well as the lack of efficient regional and national marketing networks in organic products.

Most of the organic olive oil farmers sell their organic olive oil at an acceptable price premium to exporters who have experience in marketing conventional olive oil. However, the exporters still experience some difficulties in exporting their entire supply of certified oil, probably because of their lack of experience and knowledge in exporting organic products. Organic products are also promoted through participation at national and international fairs. A strategy is currently being prepared to promote the marketing of organic products abroad.

\section{International cooperation}

The Tunisian OA sector has established relationships with the following organizations with regard to expertise, training and information exchange: Mediterranean Agronomic Institute of Bari (Italy), Technical Institute of Organic Agriculture (France), Research Institute of Organic Agriculture (Switzerland), FAO, IFOAM, and International Society of Organic Agriculture Research (ISOFAR)

\section{Conclusion}

Many crops and regions in Tunisia can be converted easily to OA owing to favourable conditions: climatic conditions that are conducive to pest and disease control, combined with favourable levels of biodiversity and traditional cultural practices. The national strategy covers all aspects of OA and aims at promoting coordination and cooperation among all partners.

The major needs for the development of OA in Tunisia are: training of technicians and farmers; supply of organic fertilizers and authorized products for use in plant and animal production; establishment of farmers' associations; promotion of marketing at national and international levels; and registration of Tunisia on the EU third-country list.

Table 5: Production and export of the main organic products: olive oil and dates

\begin{tabular}{lrrr} 
& Year & Olive oil & Dates \\
\hline Production (tons) & 2001 & 1700 & 1750 \\
& 2002 & 3450 & 2200 \\
& 2003 & 33000 & 3300 \\
Export (tons) & 2004 & 23000 & 4000 \\
& 2001 & 340 & 740 \\
& 2002 & 370 & 760 \\
& 2003 & 180 & 789 \\
& 2004 & 2200 & 1393
\end{tabular}




\section{Notes to Commentaries}

1 Uphoff, Norman (1999). Agroecological implications of the System of Rice Intensification in Madagascar. Environment, Development and Sustainability, 1(3-4): 297-313;

Pretty JN (1995). Regenerating Agriculture: Policies and Practice for Sustainability and Self-Reliance. Earthscan Publications: London;

Burton, M., D. Rigby, T. Young, and H. de Souza Filho.1998. The Adoption of Sustainable Agricultural Technologies in Parana, Brazil. Revista de Economia e Sociologia Rural: Brazil, 36(4);

Yamauchi, M. (1995) Country Report: Japan. In: Appropriate Use of Fertilizers in Asia and the Pacific. Asian Productivity Organization and the Food and Fertilizer Technology Center, Tokyo.

2 Giovannucci, Daniele. 2005. Organic Agriculture and Poverty Reduction in Asia. IFAD: Rome.

3 These are the lead agencies in a consortium-based global effort to measure the actual costs and benefits of adopting sustainability standards in agriculture, beginning with coffee (see www.iisd.org/trade/commodities/ sci_coffee.asp.org).

4 Giovannucci Daniele (2003). Emerging Issues in the Marketing and Trade of Organic Products. (Monograph). Report on the proceedings of the OECD Workshop on Organic Agriculture, September 2002. Paris, OECD.

5 At the September 2005 exchange rate of $\$ 1=8.1$ yuan.

6 Muir's original entry in the journal that became the basis for his book, My Summer in the Sierra, is wordier, but additionally illuminating: "When we try to pick out anything by itself we find that it is bound fast by a thousand invisible cords that cannot be broken, to everything else in the universe."

7 Hungary and the Czech Republic were removed from the list after their accession to the EU.

8 UNCTAD-FAO-IFOAM (2006) Strategy on Solutions for Harmonizing International Regulation of Organic Agriculture, Volume 2, Background papers of the International Task Force on Harmonization and Equivalence in Organic Agriculture (forthcoming).

9 This envisages regional or national standards that relate to, and are equivalent to, a single international standard.

10 The requirement for conformity assessment refers to the guidelines established for how conformity assessment bodies should be structured and how they should perform their work of inspection and certification.

11 This has the same aim as the IAF "certified once, accepted everywhere" slogan, and could, in theory, be achieved under such a system if agreement could be reached on standards and conformity assessment. However as Twarog's chapter points out, it is impossible to have one organic production standard for the whole world; other, more sensitive mechanisms are required.

$123,906,700$ ha according to the last national survey in 2001.

13 This Decree modifies No. 25834 of 1997 and 29067 of 2000.

14 Wynen E (2005). Impact of organic guarantee systems on production and trade in organic products. In: UNCTAD/FAO/IFOAM, Harmonization and Equivalence in Organic Agriculture, Vol. 1, Background papers of the International Task Force on Harmonization and Equivalence in Organic Agriculture (revision March 2005). Bonn.

15 FAO/WHO Codex Alimentarius Commission Guidelines for production, processing, labelling and marketing of organically produced foods, 2001, available at www.fao.org/organicag/doc/glorganicfinal.doc

16 Decree number 1030 of May 2, 1994 and amending decrees.

$17 \$ 1=1.35$ Tunisian dinars 